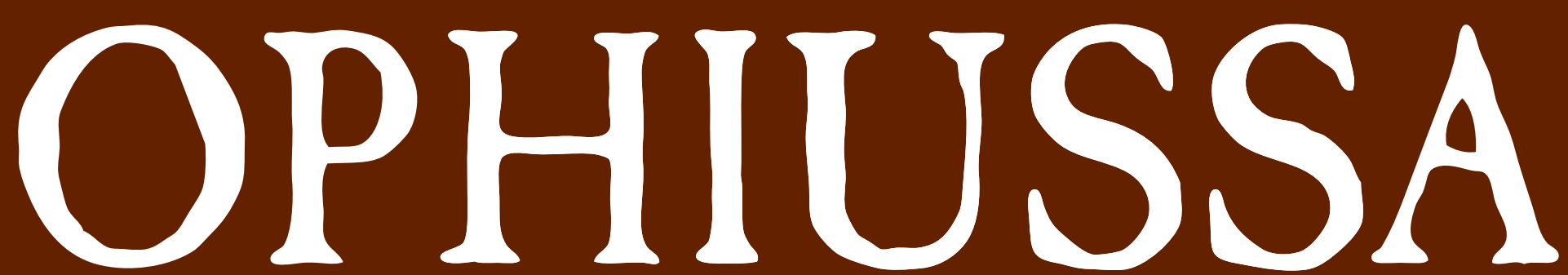
REVISTA DO CENTRO DE ARQUEOLOGIA DA UNIVERSIDADE DE LISBOA

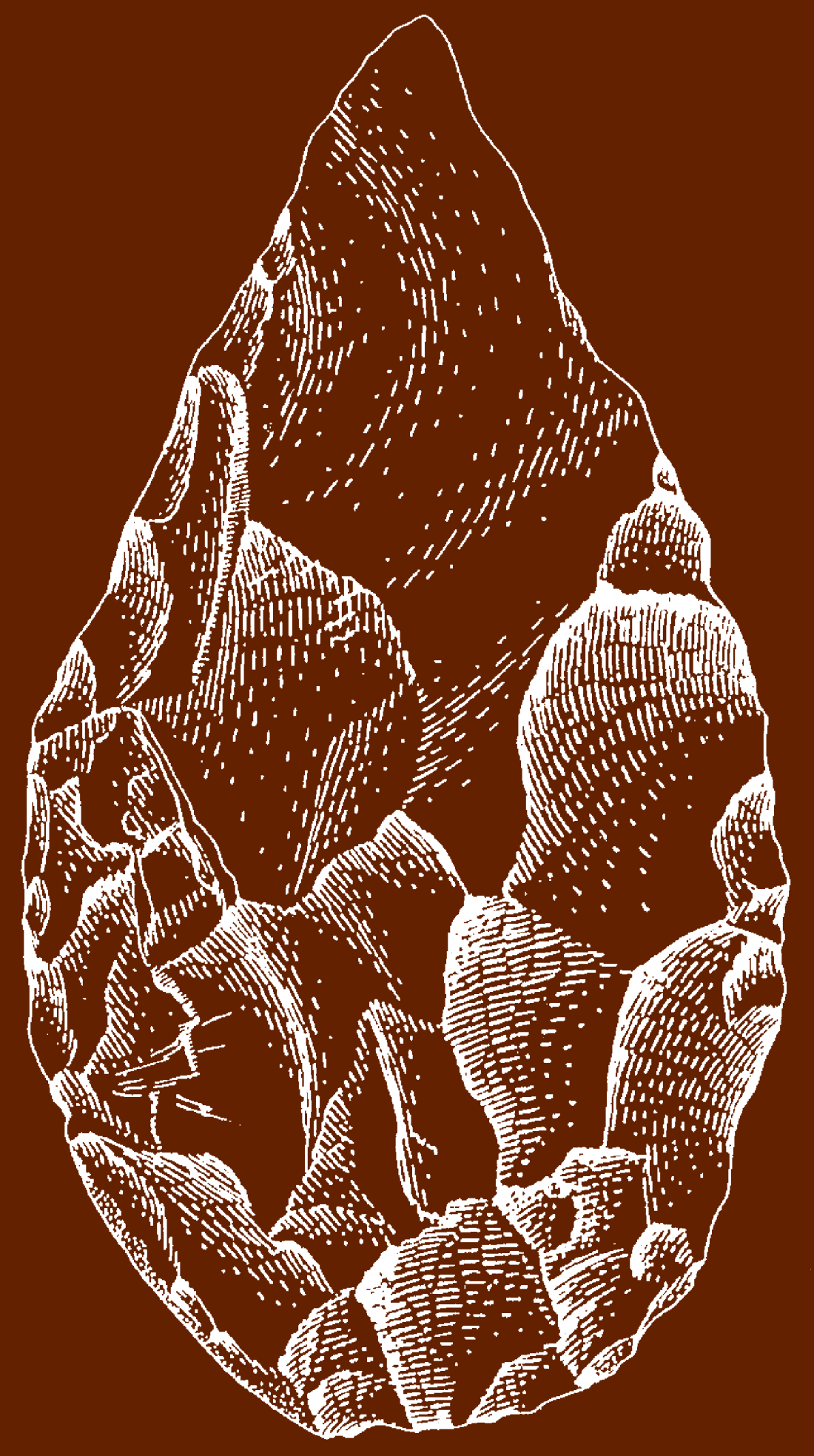

CENTRO DE ARQUEOLOGIA

DA UNIVERSIDADE

DE LISBOA 


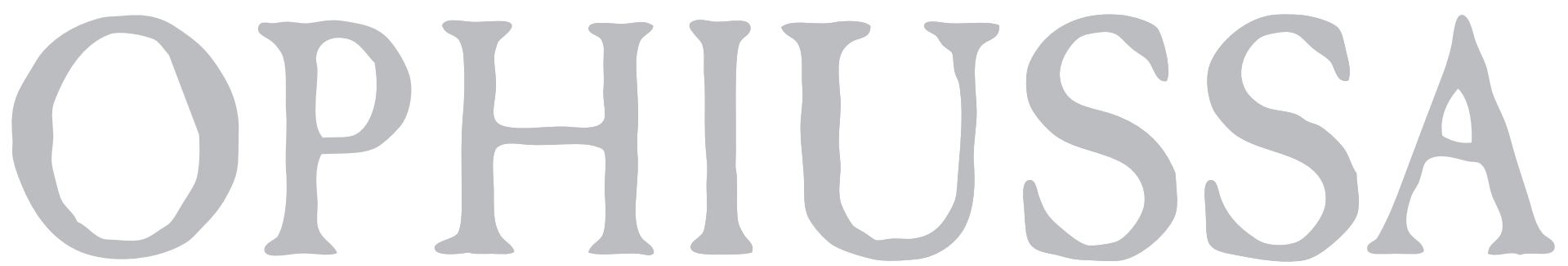

REVISTA DO CENTRO DE ARQUEOLOGIA DA UNIVERSIDADE DE LISBOA

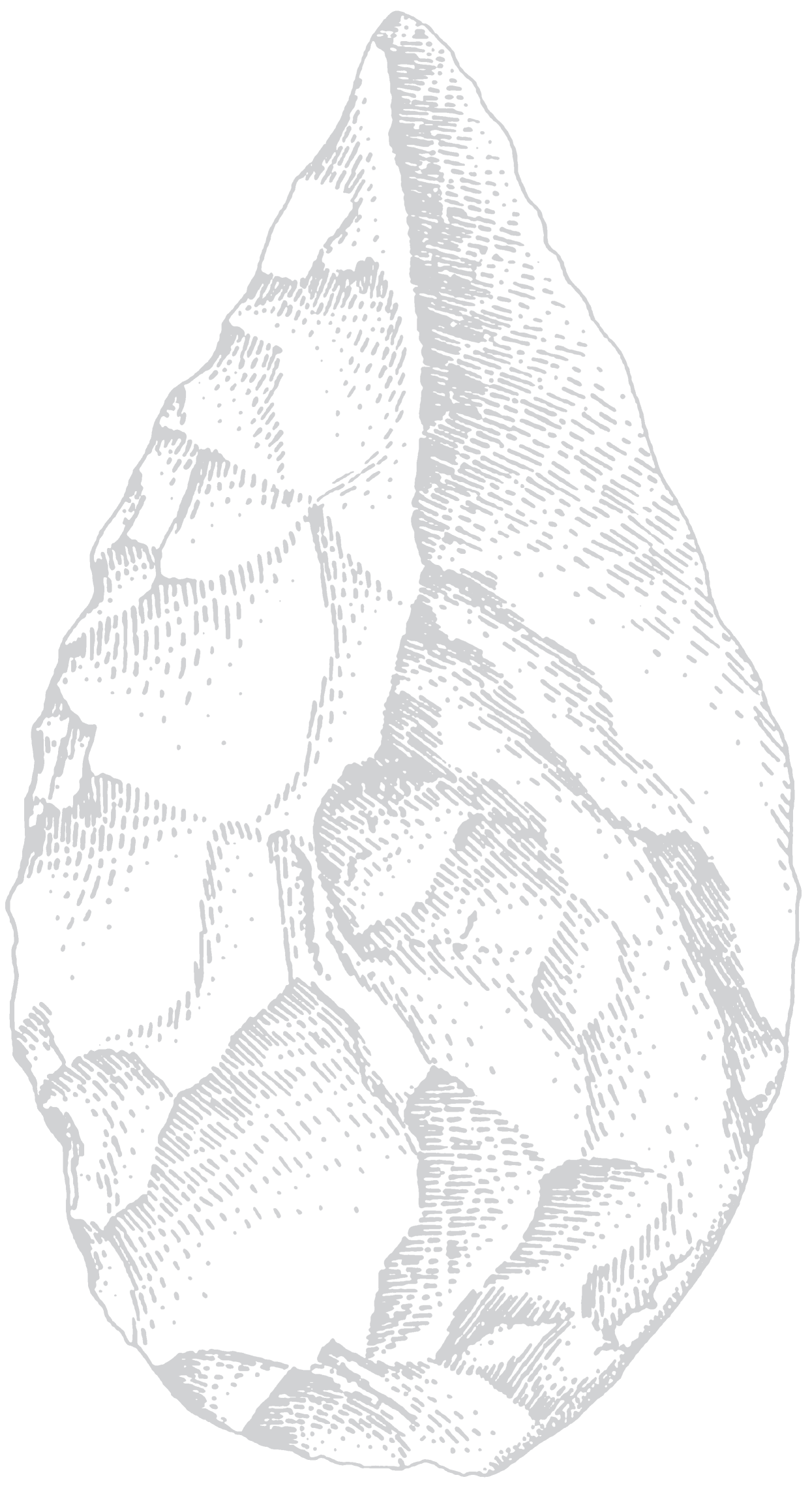




\section{U IISBOA \\ UNIVERSIDADE

\section{OPHIUSSA REVISTA DO CENTRO DE ARQUEOLOGIA DA UNIVERSIDADE DE LISBOA}

PUBLICAÇÃO ANUAL · ISSN 1645-653X · E-ISSN 2184-173X

Volume 5 - 2021

DIRECÇÃO E COORDENAÇÃO EDITORIAL

Ana Catarina Sousa

Elisa Sousa

\section{CONSELHO CIENTÍFICO}

André Teixeira

UNIVERSIDADE NOVA DE LISBOA

\section{Carlos Fabião}

UNIVERSIDADE DE LISBOA

Catarina Viegas

UNIVERSIDADE DE LISBOA

\section{Gloria Mora}

UNIVERSIDAD AUTÓNOMA DE MADRID

\section{Grégor Marchand}

CENTRE NATIONAL DE LA RECHERCHE SCIENTIFIQUE

\section{João Pedro Bernardes}

UNIVERSIDADE DO ALGARVE

José Remesal

UNIVERSIDADE DE BARCELONA

Leonor Rocha

UNIVERSIDADE DE ÉVORA

Manuela Martins

UNIVERSIDADE DO MINHO

Maria Barroso Gonçalves

INSTITUTO SUPERIOR DE CIÊNCIAS DO TRABALHO E DA EMPRESA

\section{Mariana Diniz}

UNIVERSIDADE DE LISBOA

Raquel Vilaça

UNIVERSIDADE DE COIMBRA

Victor S. Gonçalves

UNIVERSIDADE DE LISBOA

Xavier Terradas Battle

CONSEJO SUPERIOR DE INVESTIGACIONES CIENTÍFICAS

\section{SECRETARIADO}

André Pereira

\section{CAPA}

Biface proveniente de Casal do Azemél (Leiria).

Desenho de Amélia Marques. Museu D. Diogo de Sousa

(MDDS). (Cunha-Ribeiro, 1999)
REVISOR DE ESTILO

Francisco B. Gomes

PAGINAÇÃO

TVM Designers

IMPRESSÃO

AGIR - Produções Gráficas

DATA DE IMPRESSÃO

Dezembro de 2021

EDIÇÃO IMPRESSA (PRETO E BRANCO)

300 exemplares

EDIÇÃO DIGITAL (A CORES)

www.ophiussa.letras.ulisboa.pt

ISSN 1645-653X / E-ISSN 2184-173X

DEPÓSITO LEGAL 190404/03

Copyright ( $) 2021$, os autores

EDIÇÃO

UNIARQ - Centro de Arqueologia

da Universidade de Lisboa,

Faculdade de Letras de Lisboa

1600-214 Lisboa.

www.uniarq.net

www.ophiussa.letras.ulisboa.pt

uniarq@letras.ulisboa.pt

Revista fundada por Victor S. Gonçalves (1996). O cumprimento do acordo ortográfico de 1990 foi opção de cada autor.

Esta publicação é financiada por fundos nacionais através da FCT - Fundação para a Ciência e a Tecnologia, I.P., no âmbito dos projectos UIDB/00698/2020 e UIDP/00698/2020. 
ÍNDICE

O tecno-complexo Acheulense em Portugal:

contribuição para um balanço dos conhecimentos

CARLOS FERREIRA, JOÃO PEDRO CUNHA-RIBEIRO, EDUARDO MÉNDEZ-QUINTAS

Brief overview of zooarchaeological research within the framework

of Middle Palaeolithic subsistence theories

MARIANA NABAIS

A distribuição espacial dos materiais líticos da UE003 do Rodo:

testemunho de reocupações do sítio ao longo do Tardiglaciar?

CRISTINA GAMEIRO, THIERRY AUBRY, BÁRBARA COSTA, SÉRGIO GOMES,

YANN LE JEUNE, CARMEN MANZANO, MAURIZIO ZAMBALDI

O sítio do Neolítico Antigo de Montum de Baixo (Melides - Alentejo Litoral)

JOAQUINA SOARES, CARLOS TAVARES DA SILVA, SUSANA DUARTE

A economia alimentar em Chibanes (Setúbal) - horizonte campaniforme

JOÃO LUÍS CARDOSO, CARLOS TAVARES DA SILVA, JOAQUINA SOARES, FILIPE MARTINS

Luto en la cara: ablaciones de duelo en el Mediterráneo Ancestral

ÁLVARO GÓMEZ PEÑA, JOSÉ LUIS ESCACENA CARRASCO

Dois conjuntos anfóricos do Castelo de São Jorge (Lisboa):

Largo de Santa Cruz do Castelo e Pátio José Pedreira

VICTOR FILIPE

A face romana de Santa Olaia (Figueira da Foz, Portugal) -

uma leitura possível a partir da cultura material

RICARDO COSTEIRA DA SILVA, SARA OLIVEIRA ALMEIDA, ISABEL PEREIRA

Cerâmica estampada britânica em Portugal (1780-1920).

Identidade, domesticidade e relações

TÂNIA CASIMIRO, INÊS CASTRO, TIAGO SILVA

Recensões bibliográficas

(TEXTOS: JOÃO LUÍS CARDOSO, ANA CATARINA SOUSA, VICTOR S. GONÇALVES,

FRANCISCO B. GOMES, PEDRO ALBUQUERQUE, LEYRE MORGADO-RONCAL)

Política editorial 


\title{
0 sítio do Neolítico antigo de Montum de Baixo (Melides - Alentejo Litoral)
}

\section{The early Neolithic site of Montum de Baixo (Melides - Alentejo Coast)}

\author{
JOAQUINA SOARES \\ Museu de Arqueologia e Etnografia do Distrito de Setúbal - MAEDS/AMRS \\ UNIARQ - Centro de Arqueologia da Universidade de Lisboa \\ joaquinasoares1@gmail.com \\ ORCID iD: https://orcid.org/0000-0001-5957-3354
}

\section{CARLOS TAVARES DA SILVA}

Centro de Estudos Arqueológicos do MAEDS/AMRS

UNIARQ - Centro de Arqueologia da Universidade de Lisboa

ctavaressilva@gmail.com

ORCID iD: https://orcid.org/0000-0002-0447-9237

SUSANA DUARTE

Centro de Estudos Arqueológicos do MAEDS/AMRS

cea.maeds@amrs.pt

ORCID iD: https://orcid.org/0000-0001-6071-9680

RESUMO: Divulgam-se os resultados das escavações arqueológicas realizadas no povoado do Neolítico antigo evolucionado de Montum de Baixo na década de 80 do século passado, por dois dos signatários (C.T.S. e J.S.), no âmbito da investigação sobre a neolitização da Costa Sudoeste, que os mesmos têm vindo a desenvolver. Situado nas proximidades de fontes de matérias-primas siliciosas adequadas ao talhe lítico (sílex, calcedónia, cherte e jaspe), é provável que a economia de Montum de Baixo tenha aliado à actividade agrícola (provas indirectas), praticada, por hipótese, em estadas temporárias e recorrentes, a componente artesanal de produção excedentária de núcleos e suportes lamelares de sílex para as redes de troca regionais.

PALAVRAS-CHAVE: Neolítico antigo evolucionado, Costa Sudoeste Portuguesa, suportes lamelares de sílex, redes de troca regionais.

ABSTRACT: The results of the archaeological excavations carried out at the evolved early Neolithic settlement of Montum de Baixo, in the 80s of the last century, by two of the authors (C. T. S. and J. S.), are presented in the scope of the research on the Neolithization of the Southwest Portuguese Coast developed by the same authors. Located in the vicinity of siliceous raw materials suitable for lithic flaking (flint and chert), it is likely that the economy of Montum de Baixo has allied to farming (indirect evidence) practiced in temporary and recurrent occupations, the artisanal component of surplus production of flint cores and bladelets for the regional exchange networks.

KEYWORDS: evolved early Neolithic, Southwest Portuguese Coast, flint bladelets, regional exchange networks. 


\section{INTRODUÇÃO. O PROJECTO SOBRE A NEOLITIZAÇÃO DA COSTA SUDOESTE}

Desde a segunda metade dos anos 70 do século passado que temos vindo a estudar (J.S. e C.T.S.) o Neolítico antigo da Costa Sudoeste portuguesa, através de prospecções e escavações arqueológicas promovidas pelo Grupo de Trabalhos de Arqueologia do Gabinete da Área de Sines, Unidade de Arqueologia do Parque Natural do Sudoeste Alentejano e Costa Vicentina e Centro de Estudos Arqueológicos do Museu de Arqueologia e Etnografia do Distrito de Setúbal (Soares - Tavares da Silva 1979; 1993; 2003; 2004; 2018; Tavares da Silva - Soares 1981; 1982; 1983; 1987; 1997; 2007; 2015; 2020a; Tavares da Silva - Soares - Penalva 1985; Soares 1992; 1995; 1996a; 1996b; 1997; Soares - Mazzuco - Clemente Conte 2016; Soares - Tavares da Silva - Canilho 2005-2007; Tavares da Silva - Soares - Coelho-Soares 2010). Foi assim possível contribuir para o conhecimento do Neolítico antigo desta região, cronologicamente situado entre o segundo quartel/meados do $6 .^{\circ}$ milénio cal BC e meados do milénio seguinte, a partir da escavação de povoados de ar livre, localizados quer na linha de costa, nas proximidades de antigas praias, quer no interior, nas margens de cursos de água, em áreas baixas e planas de terrenos arenosos; possuem indústria lítica na tradição da do Mesolítico final, tradição com expressão em outros domínios: padrões de assentamento e estratégias de mobilidade e de gestão de recursos naturais (Soares 2020).

A decoração cerâmica tem sido utilizada como indicador cronológico face à relativa escassez de matéria orgânica datável (Tavares da Silva - Soares 1981); compreende dois estilos com relevância cronológica: durante o segundo e terceiro quartéis do $6 .^{\circ}$ milénio cal BC (Vale Pincel I, em Sines e Samouqueira II, em Porto Covo) predomina largamente a técnica da impressão, com recurso a reduzido número de matrizes e associada a motivos plásticos (cordões lisos ou decorados, mamilos) (Tavares da Silva - Soares 2015); no último quartel do mesmo milénio e na primeira metade do 5..$^{\circ}$ milénio cal $\mathrm{BC}$, período que designámos por Neolítico antigo evolucionado (Salema, Vale Marim II, Praia da Oliveirinha, Vale Vistoso, Medo Tojeiro), a decoração incisa é agora muito frequente a par de impressões obtidas a partir de considerável número de matrizes, e de elementos plásticos (Tavares da Silva - Soares - Coelho-Soares 2010).

A economia destas populações, embora já de produção de alimentos (testemunhos indirectos como mós manuais e lamelas com lustre de cereal), baseia-se em grande parte na recolecção, designadamente de marisco e na pesca; ocorrem mesmo, como no Mesolítico regional, estabelecimentos especializados na recolecção de invertebrados marinhos (concheiro do Medo Tojeiro, Almograve), dependentes certamente de estabelecimentos de base, onde a economia seria de largo espectro.

É, pois, no âmbito deste projecto de investigação que apresentamos o sítio do Neolítico antigo evolucionado de Montum de Baixo (Figs. 1 e 2).

\section{IDENTIFICAÇÃO}

Identificámos o povoado de Montum de Baixo (3807'09"N; 843'38'W; C.M.P. 1:25.000; folha 505), pertencente à freguesia de Melides, concelho de Grândola, distrito de Setúbal, no dia 5 de Agosto de 1975, através de prospecção de superfície (Fig. 1). Trata-se de um interflúvio, com 94 m de altitude na área de ocupação humana, aplanado e arenoso. É delimitado pela confluência de dois cursos de água, tributários da Ribeira de Melides, nos quais ainda hoje existem duas represas que se mantêm operacionais durante o estio, e alimentam corredor de vegetação natural, dominada pelo sobreiro. A jazida arqueológica localiza-se, pois, entre os contrafortes da Serra de Grândola e o Atlântico, do qual dista, em linha recta, cerca de $6 \mathrm{~km}$ (1,15 horas de marcha).

A descoberta de Montum de Baixo integrou um ciclo de trabalhos de campo desenvolvido na sub-região norte da Costa Sudoeste definida pelas bacias das ribeiras de Melides e Cascalheira, em troço litoral caracterizado pelas lagoas de Melides e Santo André (Fig. 2). Eram aí, desde há muito, conhecidas as grutas funerárias neolíticas de Melides (Nogueira 1927-1930) e, de descoberta mais recente, o dólmen da Pedra Branca (Ferreira et al. 1975). Identificámos e escavámos nesse território o acampamento mesolítico de Santa Marinha (Soares - Mazzucco - Tavares da Silva 2017: Fig. 1; 2021), o povoado do Neolítico antigo evolucionado da Salema (Soares - Tavares da Silva 1979; Tavares da Silva - Soares 1981; 1982), a sepultura proto-megalítica do 


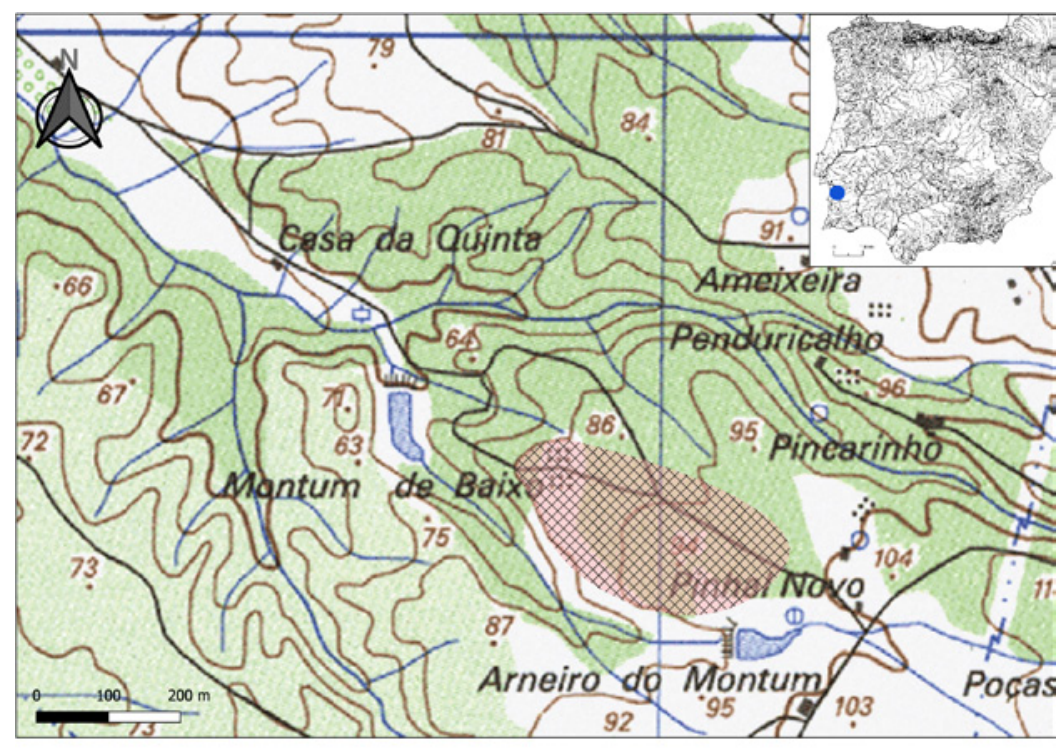

Area de dispersão de materiais atribuiveis ao Neolítico.
FIG. 1 Localização do sítio de Montum de Baixo na Península Ibérica e em extracto da Carta Militar Portuguesa (levantada na escala 1:25 000, folha 505), com indicação da área de dispersão de materiais atribuíveis ao Neolítico antigo evolucionado.

FIG. 2 Localização dos arqueossítios das bacias das ribeiras de Melides e Cascalheira referidos no texto. CMP, levantada na escala 1:25 000, folha 505. 1 - Sítio do Mesolítico final de Santa Marinha, 2 - gruta funerária neolítica do Lagar, 3 - gruta funerária neolítica do Zambujal, 4 - povoado do Neolítico antigo evolucionado de Montum de Baixo, 5 - necrópole do Bronze médio de Casas Velhas, 6 - dólmen da Pedra Branca, 7 - sítio do Bronze médio do sudoeste de Casa Nova da Eira, 8 - dólmen da Palhota, 9 - tholos (?) da Pedreira da Salema, 10 - povoado do Neolítico antigo evolucionado da Salema, 11 - sepultura proto-megalítica do Marco Branco, 12 - povoado da Idade do Bronze final da Cerradinha, 13 - sítio da Idade do Bronze final e Período Islâmico da Casa Nova.

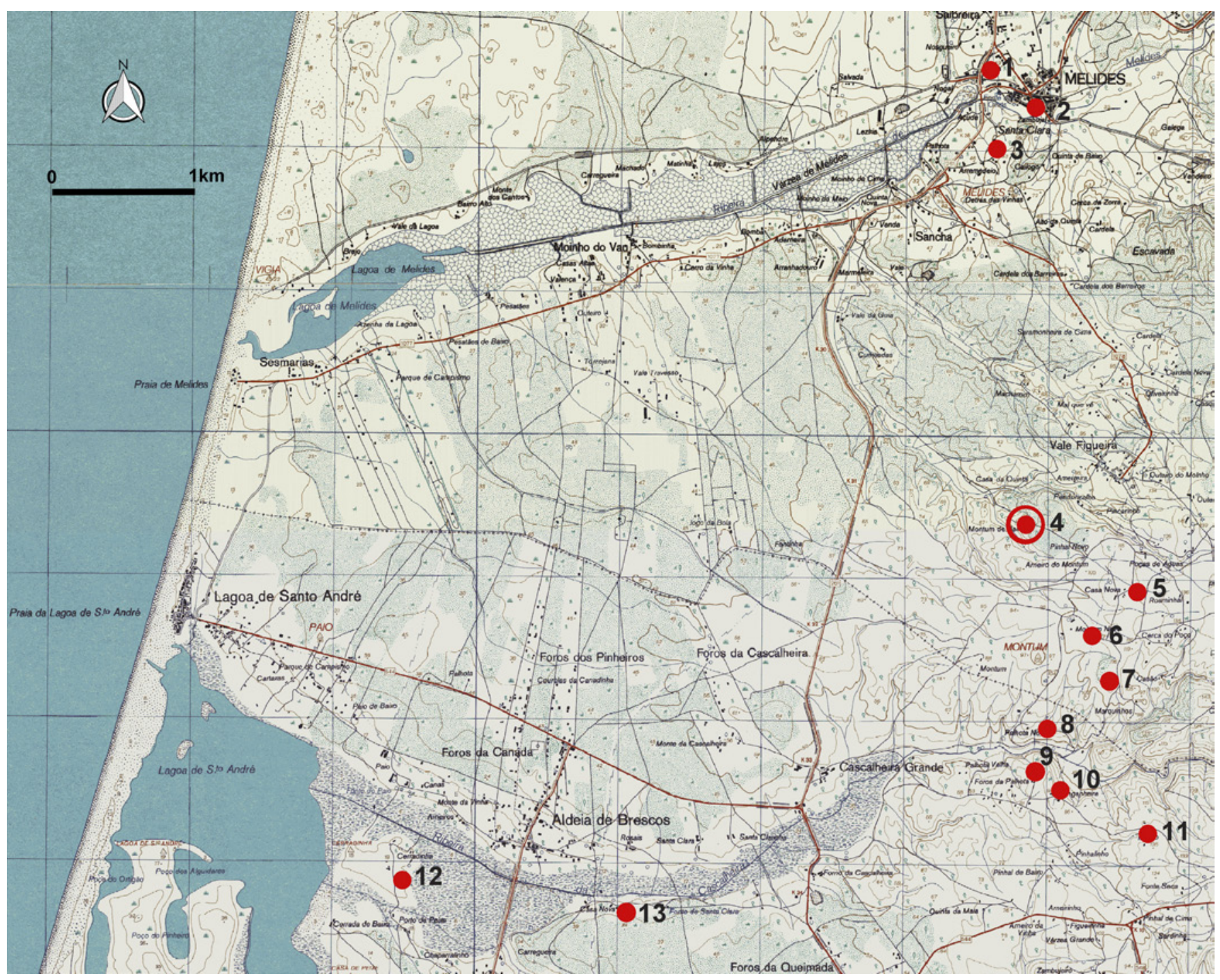



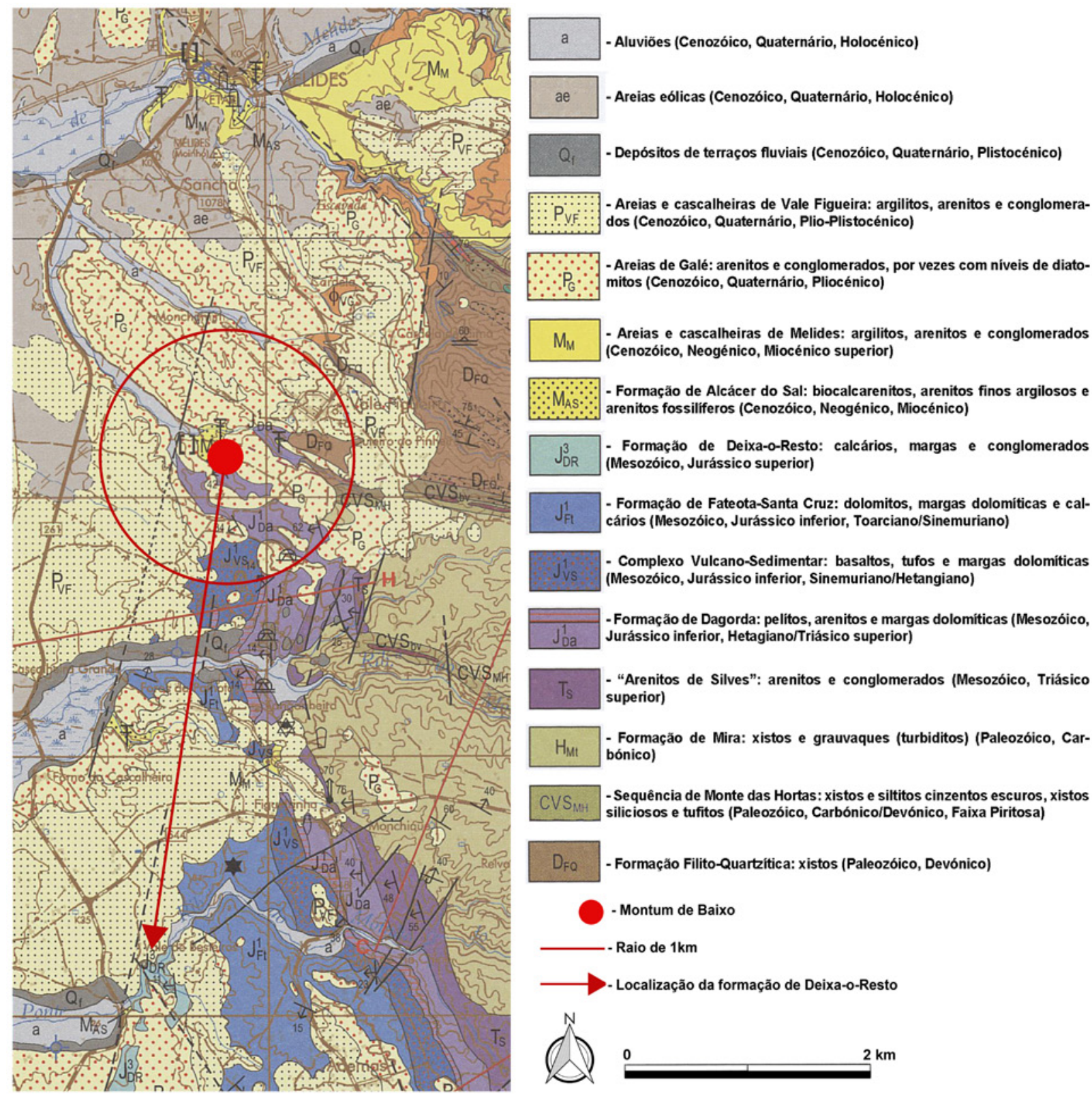

$M_{M} \quad$ - Areias e cascalheiras de Melides: argilitos, arenitos e conglomerados (Cenozóico, Neogénico, Miocénico superior)

$\because \because \because \because$ - Formaçăo de Alcácer do Sal: biocalcarenitos, arenitos finos argilosos e $\because$ arenitos fossiliferos (Cenozóico, Neogénico, Miocénico)

$J_{D R}^{3}$ - Formaçăo de Deixa-o-Resto: calcários, margas e conglomerados (Mesozóico, Jurássico superior)

1 - Formação de Fateota-Santa Cruz: dolomitos, margas dolomiticas e calcários (Mesozóico, Jurássico inferior, Toarciano/Sinemuriano)

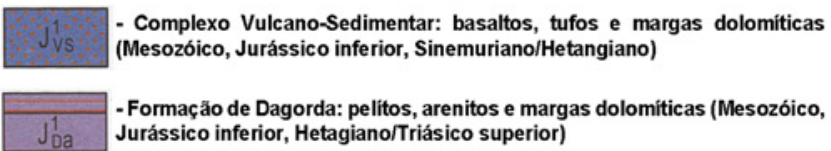
riásico superior)

- "Arenitos de Silves": arenitos e conglomerados (Mesozóico, Triásico superior) $H_{M t}$
bónico)

CVS -Sequência de Monte das Hortas: xistos e siltitos cinzentos escuros, xistos siliciosos e tufitos (Paleozóico, Carbónico/Devónico, Faixa Piritosa)

$D_{F Q}$ - Formaçăo Filito-Quartzítica: xistos (Paleozóico, Devónico)

\section{- Montum de Baixo}

- Raio de $1 \mathrm{~km}$

$\longrightarrow$ - Localização da formação de Deixa-o-Resto

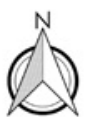

km

FIG. 3 Localização de Montum de Baixo na carta geológica de Portugal levantada à escala de 1:50.000, folha 42A-Grândola. Na área envolvente de $1 \mathrm{~km}$ de raio, estão presentes fontes de aprovisionamento de quase toda a diversidade de matérias abióticas utilizadas no talhe lítico; a cerca de 3 km, foram cartografados afloramentos da formação de Deixa-o-Resto, principal fonte do sílex regional (informação de Paulo Fonseca, que muito agradecemos).

Marco Branco (Tavares da Silva - Soares 1983; Soares - Tavares da Silva 2000; Soares 1996b), o dólmen da Palhota (Soares - Tavares da Silva 1976-1977), a necrópole de cistas da Idade do Bronze médio de Casas Velhas (Silva et al. 2016; Valério et al. 2019), os povoados do Bronze final da Cerradinha (Tavares da Silva Soares 1978) e de Casa Nova; registámos, mais recentemente, o povoado da Casa Nova da Eira, quiçá correlacionado com a necrópole das Casas Velhas (Soares - Tavares da Silva 2016).

O povoado neolítico de Montum de Baixo assentou sobre a formação de Areias de Galé, do Pliocénico, a qual contacta a nascente com a designada formação de Alcácer do Sal, do Miocénico. O sítio integra-se em área de grande diversidade geológica (Dias et al. 2011) de que destacamos, num raio de cerca de $3 \mathrm{~km}$, além das formações anteriormente referidas, as margas dolomíticas da formação de Dagorda, do Jurássico inferior, os xistos e grauvaques da formação filito-quartzítica do Devónico, os complexos vulcano-sedimentares do Carbónico e do Jurássico inferior e ainda a formação calcária de Deixa-o-Resto, também do Jurássico, contendo sílex (informação de Paulo Fonseca). 


\section{ESCAVAÇÃO}

A escavação viria a ocorrer cerca de 5 anos após a descoberta do sítio. Iniciaram-se os trabalhos a 11 de Março de 1980, pelo Grupo de Trabalhos de Arqueologia do Gabinete da Área de Sines, em colaboração com o Museu de Arqueologia e Etnografia do Distrito de Setúbal, sob a direcção de dois dos signatários (C.T.S. e J.S.).

Implantou-se um sistema de eixos ortogonais de orientação N-S e E-O, os quais permitiram subdividir a área potencialmente arqueológica em sectores (S.) de $20 \times 20 \mathrm{~m}$, numerados de oeste para este e de sul para norte. Cada sector foi subdividido em quadrados (Q.) de $1 \mathrm{~m}$ de lado, designados por letra maiúscula (W-E) e por número árabe (S-N). Foi estabelecida a cota convencional de $10 \mathrm{~m}$ no vértice NW do S.16. Todos os sedimentos foram crivados através de malha de $4 \mathrm{~mm}$. Escavaram-se cerca de $1500 \mathrm{~m}^{2}$, nos S. 16, 17, 26, 27, 35, 36, 44 e 54 (Fig. 4). Observou-se a seguinte estratigrafia:

C.1 - Areias cinzento-acastanhadas claras, revolvidas por trabalhos agrícolas e plantio de pinhal, com escasso espólio arqueológico, de espessura

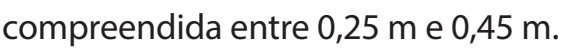

C. 2 - Areias castanho-amareladas, com estruturas de habitat aflorando na base, e cultura material neolítica (espessura de ca. 0,2m). A C.2 foi registada sobretudo nos sectores 16 e 17; na maior parte dos restantes sectores, esta camada foi muito afectada pelos trabalhos agrícolas. Mesmo no $\mathrm{S} .16$ verificou-se que a área mais oriental foi profundamente perturbada por valas de plantio de pinhal, tendo a C.1 atingido em numerosos quadrados o topo do substrato. Apesar da acentuada homogeneidade da cultura material, a recoIhida nas áreas de destruição da C.2 não foi considerada neste estudo. Não se conservou matéria orgânica. Este é um factor limitante comum a muitos sítios arqueológicos pré-históricos sobre areias da Costa Sudoeste.

C.3 - Areias amareladas claras do Plio-Pistocénico, correspondentes ao substrato geológico, nas quais foram abertas as fossas de combustão registadas nos sectores 16 e 17 .

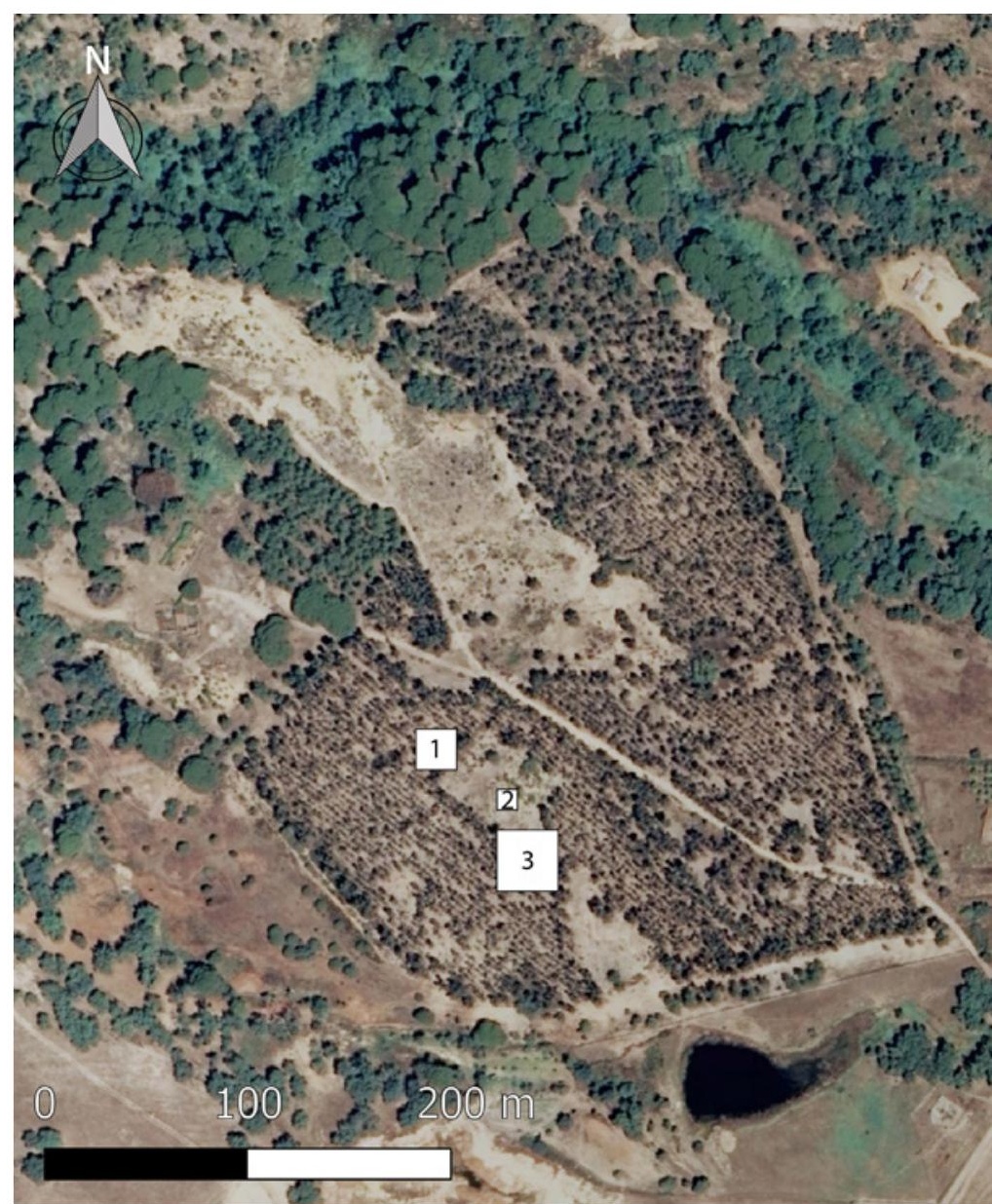

FIG. 4 Montum de Baixo. Vista aérea, com a localização da área escavada. Foto aérea gentilmente disponibilizada pelo arqueólogo Nuno Inácio, do Serviço de Património Histórico e Cultural e Museus-Arqueologia da Câmara Municipal de Grândola, a quem muito agradecemos.1- Sectores 44 e 54; 2- Sectores 35 e 36; 3- Sectores 16,17, 26 e 27.

\section{ESTRUTURAS}

A escavação revelou estruturas de habitat somente nos sectores 16 e 17 (Figs. 5-7), as quais afloravam na base da C.2, podendo, em alguns casos de destruição da camada arqueológica pela lavoura, terem sido cobertas directamente pela C.1. Nos restantes sectores, onde a camada arqueológica se encontrava revolvida em extensas áreas, até ao topo da C.3, não é possível afirmar que tenham ou não existido.

As estruturas postas a descoberto são em número de 16 e compreendem a seguinte tipologia (Figs. 6 e 7):

Tipo A - Estrs. V, IX, XIA, XIB e XVI. Depressão em "cuvette" dissimétrica contendo, em geral, numerosos termoclastos (exceptua-se a Estr. IX, com baixa densidade de termoclastos, que ocorriam 


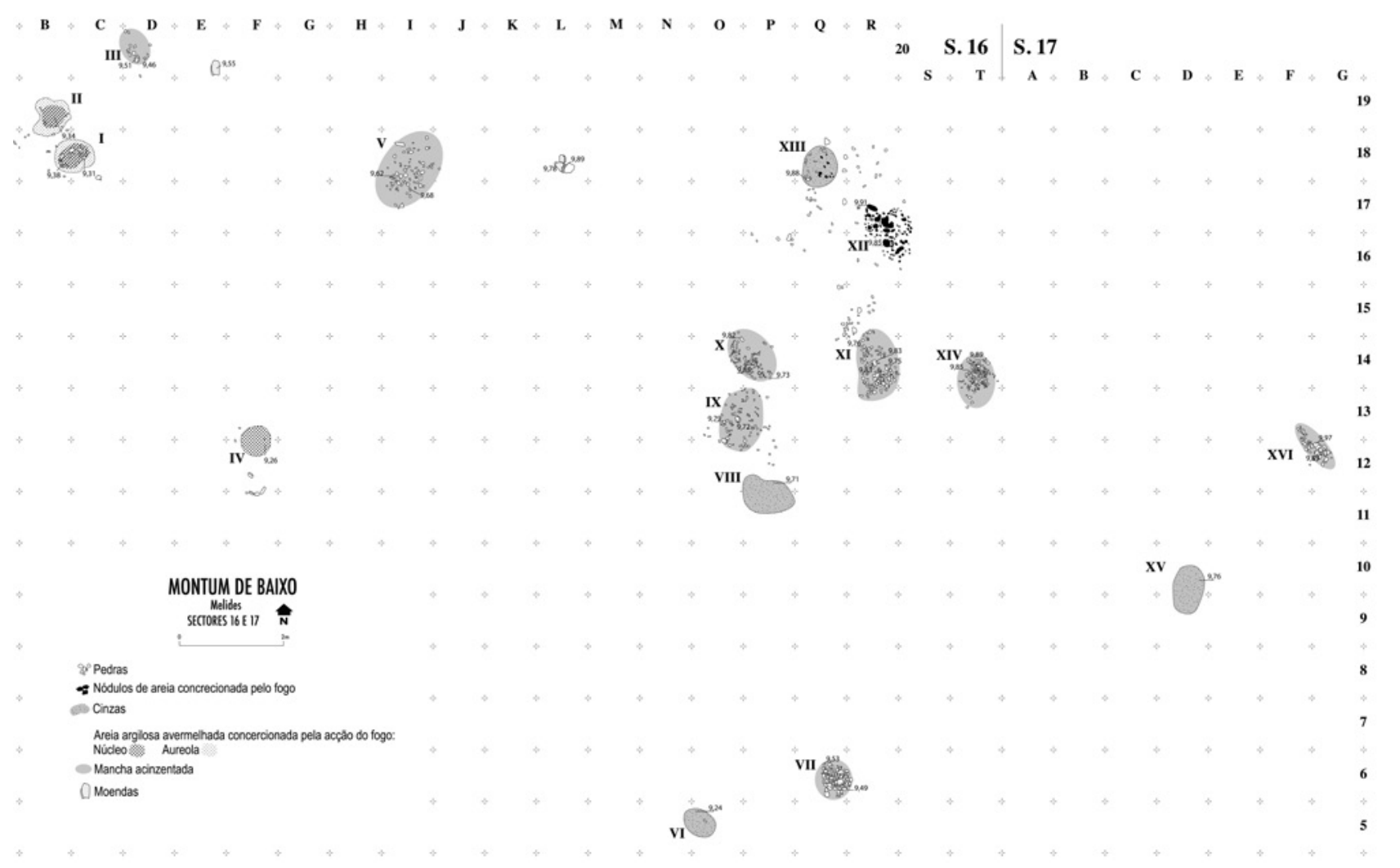

FIG. 5 Montum de Baixo. Planta dos Sectores 16 e 17.

de forma dispersa), embalados por areia castanho-acinzentada. Planta ovalada (Estrs. IX, XIA, XIB e XVI) com $0,45 \times 0,3 \mathrm{~m}$ a $1,2 \times 0,8 \mathrm{~m}$. Este tipo de estrutura de combustão, o mais comum no Neolítico antigo da Costa Sudoeste, dispersa-se regularmente pelos sectores 16 e 17 . Verifica-se grande proximidade entre as Estrs. XIA e XIB (distavam ca. 0,1 m) e ambas eram cobertas por um único nível de termoclastos semelhante a empedrado, que poderá ter correspondido a reconfiguração das anteriores fossas de combustão (Fig. 7).

Tipo B - Estrs. I, II e IV. Depressão em "cuvette" repleta de argila avermelhada e concrecionada por acção do calor, contendo escassos termoclastos. Planta subcircular (diâmetro ca. 0,45 m a 0,6 m); ou ovalada $(0,8 \times 0,6 \mathrm{~m})$; profundidade ca. 0,2 m. As depressões das Estrs. I e II possuíam auréola castanho-avermelhada concrecionada pelo fogo, com ca. 0,1 m de largura.

Sublinhamos, pela novidade, este aparelho térmico, que até agora não tínhamos identificado no Neolítico da Costa Sudoeste, onde a acumulação e conservação do calor são, regra geral, asseguradas por elementos pétreos, enquanto neste tipo de lareira aquelas funções são garantidas pela acumulação de material argiloso. $O$ tipo $B$ tende a localizar-se no quadrante NW do S.16, associado a indústria lítica (Fig. 8) e dissociado de recipientes cerâmicos.

Tipo C - Estr. XII. Concentração de nódulos de barro cozido, formando uma única camada e ocupando área de contorno irregular com ca. 1,3 ×0,9 m, nos Qs. R-S/16-17 do S.16 (Figs. 5 e 6). Parece tratar-se de estrutura de rejeição associada à limpeza de estruturas de tipo $B$.

Tipo D - Estrs. VII, X, XIV. Empedrado. Densa concentração de termoclastos, formando uma única camada, cuja espessura varia entre 0,05 e 0,1 m. Planta muito frequentemente de contorno irregular, a tender para circular (Estr. VII, diâmetro ca. $0,7 \mathrm{~m}$ ), ou para oval (Estrs. X e XIV, respectivamente

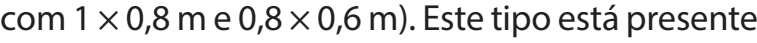
na Costa Sudoeste em sítios de Neolítico antigo evolucionado (Salema, Vale Marim II, Vale Vistoso e Gaspeia). Na zona oriental do S. 16, o tipo D (Fig. 5) surge aparentemente associado a estruturas dos tipos A e F. 

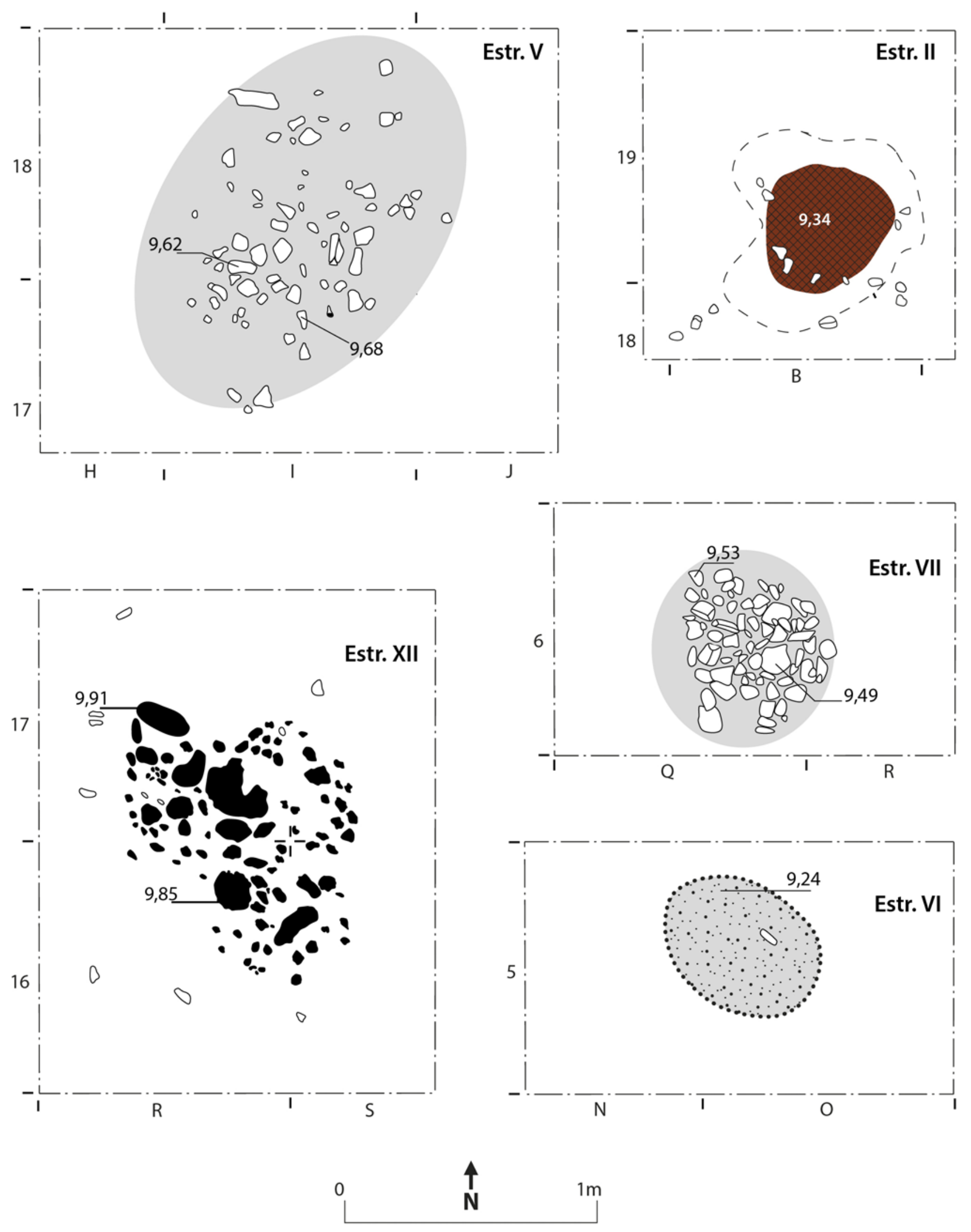

FIG. 6 Montum de Baixo. Plantas das estruturas domésticas pertencentes aos tipos: A (Estr.V); B (Estr.II); C (Estr.XII); D (Estr.VII); F (Estr.VI). 


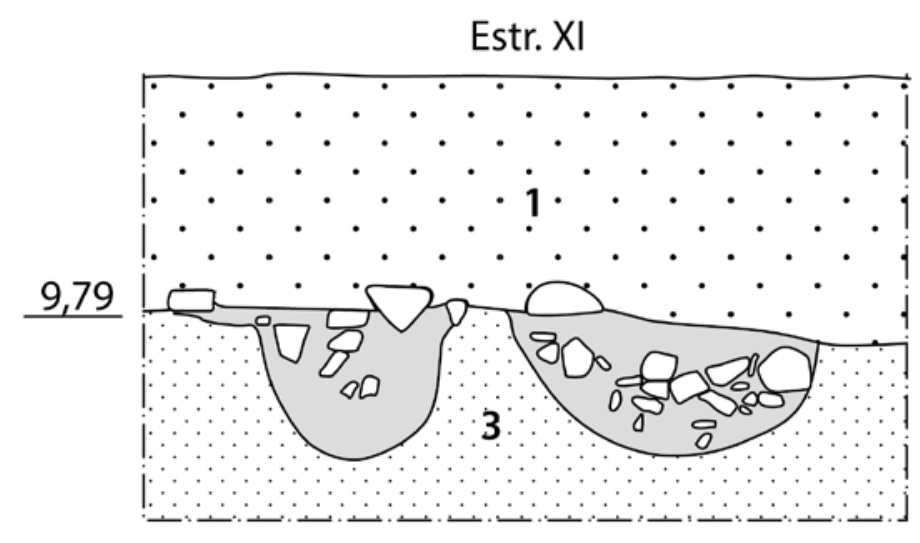

Estr. IV
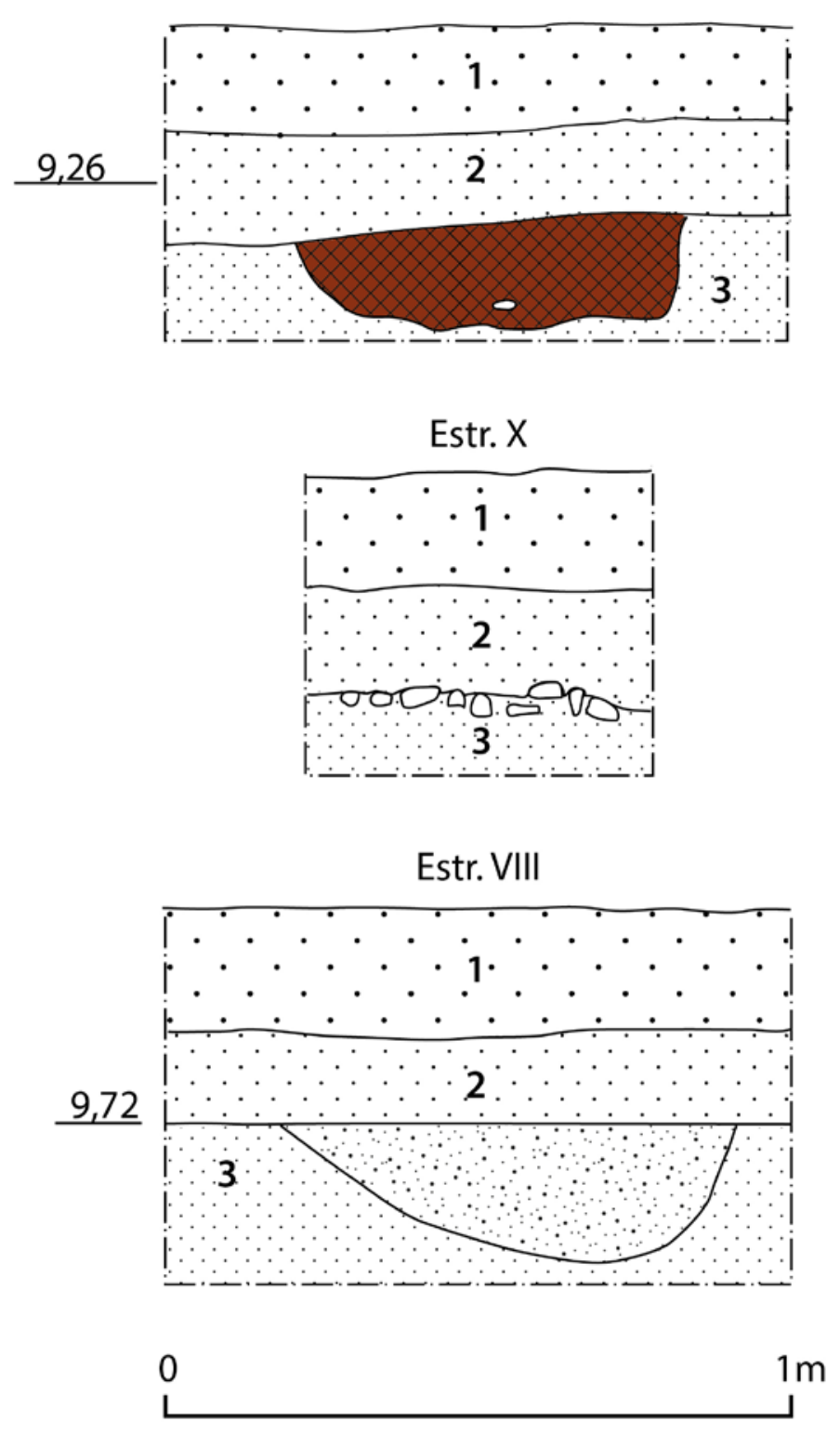

FIG. 7 Montum de Baixo. Perfis das estruturas domésticas pertencentes aos tipos A (Estr. XI), B (Estr. IV), D (Estr. X) e F (Estr. VIII).
Tipo E - Estr. III. Lareira plana. Bloco pétreo fracturado in situ por acção térmica; os respectivos termoclastos, remontáveis, em número de 11, dispersavam-se por superfície rubefacta, de areia concrecionada, de contorno irregular $(0,8 \times 0,5 \mathrm{~m})$. Tipo F-Estrs. VI, VIII, XIII eXV. Cinzeiro. Depressão em "cuvette" repleta de areia rica em cinzas e contendo raros termoclastos. Planta geralmente ovalada $(0,7 \times 0,48 \mathrm{~m} ; 0,9 \times 0,6 \mathrm{~m} ; 1 \times 0,6 \mathrm{~m})$ a subcircular (Estr. XIII, com ca. 0,8 m de diâmetro). Profundidade variando entre 0,1 m (Estr. XIII) e 0,2 m (Estrs. VI, VIII, $X V)$. Este tipo de estrutura, de rejeição, encontra-se em geral associado aos tipos A e D. É comum no Neolítico antigo da Costa Sudoeste.

As estruturas domésticas identificadas oferecem tipologia variada, mas sempre associada ao fogo. Organizam-se em dois núcleos principais. No quadrante NW do S.16, domina o tipo B, e, pelo menos aparentemente, associa-se ao talhe lítico (Fig. 8). Na zona oriental do mesmo sector, existe maior diversidade tipológica, com destaque para as lareiras em fossa com termoclastos, de tipo A, e grelhadores ou empedrados, de tipo $D$, sendo defensável uma associação à cerâmica e a actividades culinárias (Fig. 17).

$\mathrm{O}$ registo de estruturas de rejeição do tipo $\mathrm{F}$ documenta preocupações higiénicas, que mesmo em estadas pouco prolongadas, como defendemos para Montum de Baixo, faziam parte dos comportamentos sociais deste grupo.

\section{INDÚSTRIA LÍTICA}

Localizado em uma área de grande variedade petrográfica, a indústria lítica reflecte claramente esse posicionamento geográfico. Na manufactura dos artefactos utilizou-se uma acentuada diversidade de litotipos (Quadro 3): quartzo, cristal de rocha, sílex, calcedónia, cherte, lidito, quartzito, jaspe, xisto silicioso. Alguns entalhes e denticulados, buris de ângulo e flechas transversais foram, quiçá, deliberadamente manufacturados sobre quartzo leitoso de muito boa qualidade. O cristal de rocha era sem dúvida muito apreciado e mesmo pequenos cristais foram transformados pelo retoque e uso. O subsistema expedito, realizado sobre rochas de maior granulometria, como 
o quartzito e o grauvaque, tem uma pequena representação (2,2\%) (Quadro 1).

\subsection{Dimensão da amostra}

Foram inventariados 2223 artefactos líticos (Quadro 1), número que ainda não inclui a totalidade dos materiais recolhidos; daqueles, 99,1\% correspondem ao sistema tecnológico de lascagem, cabendo ao subsistema uso-intensivo 96,9\% dos efectivos. Os instrumentos polidos e bujardados detêm apenas 0,9\%.

QUADRO 1 MONTUM DE BAIXO. INDÚSTRIA LÍTICA.

CATEGORIASTECNOLÓGICAS

\begin{tabular}{|lcc|}
\hline CATEGORIAS TECNOLÓGICAS & N & $\%$ \\
\hline Indústria de pedra lascada & $\mathbf{2 2 0 4}$ & $\mathbf{9 9 . 1}$ \\
\hline Subsistema uso-intensivo & 2153 & 96.9 \\
\hline Subsistema indeterminado & 2 & 0.1 \\
\hline Subsistema expedito & 49 & 2.2 \\
\hline Instrumentos de pedra polida e bujardada & 19 & $\mathbf{0 . 9}$ \\
\hline Polidos & 12 & 0.5 \\
\hline Bujardados & 7 & 0.3 \\
\hline Total & 2223 & 100 \\
\hline
\end{tabular}

QUADRO 2 MONTUM DE BAIXO. SUBSISTEMA

USO-INTENSIVO. CATEGORIAS TECNOLÓGICAS DA TOTALIDADE DOS ARTEFACTOS LÍTICOS INVENTARIADOS

\begin{tabular}{lcc|} 
CATEGORIA TECNOLÓGICA & N & $\%$ \\
\hline Manuportes & 2 & 0.09 \\
\hline Subprodutos de talhe & 1547 & 71.9 \\
\hline Núcleos & 80 & 3.7 \\
\hline Produtos de debitagem & 192 & 8.9 \\
\hline Instrumentos retocados & 228 & 10.6 \\
\hline Peças com macro-vestígios de uso & 104 & 4.8 \\
\hline Total & $\mathbf{2 1 5 3}$ & $\mathbf{1 0 0}$ \\
\hline
\end{tabular}

Comparando estes resultados com os da ocupação neolítica da Gaspeia, constata-se que em Montum de Baixo o subsistema expedito é francamente menos representativo, em consonância com a elevada disponibilidade local de matérias-primas siliciosas micro e cripto-cristalinas (Fig. 3, Quadro 3). Dominam as cores de sílex acastanhadas, cerca de metade dos efectivos, particularmente as de tonalidades médias, seguidas pelas acinzentadas, branco incluído, em cerca de $1 / 3$ da amostra, predominando neste grupo cromático as tonalidades claras. Os instrumentos polidos e bujardados, já escassos em Gaspeia, têm em Montum de Baixo uma expressão ainda mais residual.

QUADRO 3 MONTUM DE BAIXO. INDÚSTRIA LÍTICA.

SUBSISTEMA USO-INTENSIVO. MATÉRIAS-PRIMAS

\begin{tabular}{lcccc} 
MATÉRIA-PRIMA & N & $\%$ & PESO (g) & $\%$ \\
\hline Quartzo leitoso & 126 & 5.9 & 419.8 & 7.2 \\
\hline Cristal de rocha & 86 & 4.0 & 94.6 & 1.6 \\
\hline Sílex/Cherte* & 454 & 21.1 & 599 & 10.2 \\
\hline Calcedónia & 18 & 0.8 & 98.4 & 1.7 \\
\hline $\begin{array}{l}\text { Cherte e rochas siliciosas } \\
\text { microcristalinas afins }\end{array}$ & 1333 & 61.9 & 3710.9 & 63.5 \\
\hline Jaspe & 50 & 2.3 & 254.3 & 4.3 \\
\hline Xisto silicioso & 61 & 2.8 & 445.1 & 7.6 \\
\hline Outras & 25 & 1.2 & 224.2 & 3.8 \\
\hline Total & 2153 & 100 & 5846.3 & 100 \\
\hline
\end{tabular}

* Não é possível descartar a possibilidade de algum cherte ter sido contabilizado como sílex, em análise macroscópica.

Analisaram-se 1378 artefactos do subsistema uso-intensivo (Quadro 11), a quase totalidade dos provenientes do $S .16$ e uma representação aleatória de todos os sectores intervencionados: S.17; S.26; S. 27; S.35; S.36; S.44; S.54. No quadrante NW do S.16 registou-se a maior densidade de artefactos líticos. Porém, não foi possível encontrar áreas funcionalmente diferenciadas. Esta concentração artefactual coincide com estruturas de habitat associadas ao fogo. No lado oriental do mesmo sector (fiadas O-S), muito embora tenham sido recuperadas algumas lareiras, a camada arqueológica encontrava-se muito desmantelada (Fig. 8). Como antes referimos, a jazida possuía uma única camada arqueológica, que em alguns dos sectores foi atingida por trabalhos silvícolas (plantio de pinhal) até ao substrato, com dispersão dos materiais. Não se observaram vestígios materiais de ocupação posterior à neolítica. A homogeneidade da indústria lítica documenta bem esta afirmação. 


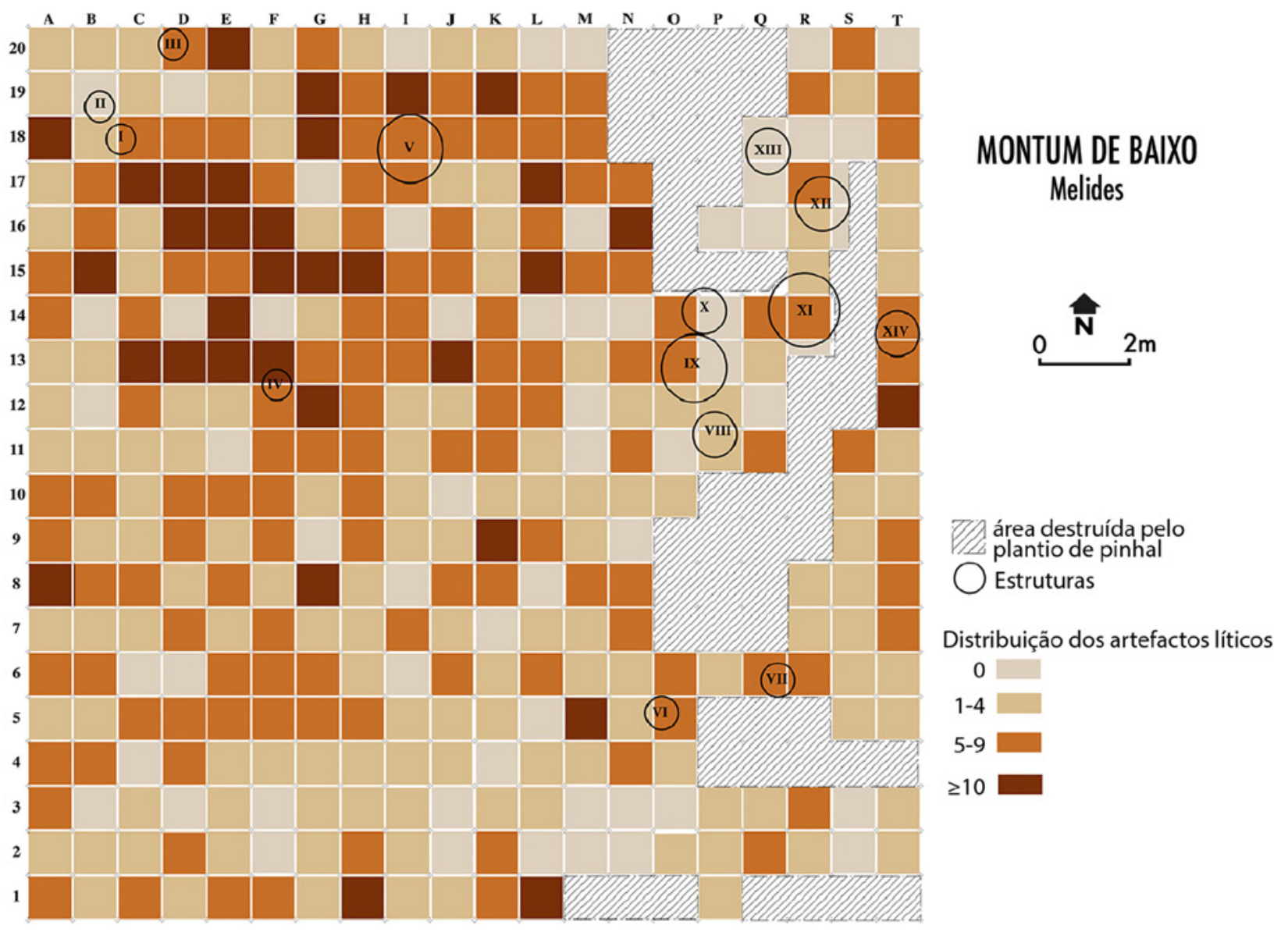

FIG. 8 Montum de Baixo. Sector 16. Distribuição da indústria lítica.

\subsection{Subsistema uso-intensivo}

\subsubsection{Tecnologia e Tipologia}

A actividade de talhe lítico do subsistema uso-intensivo foi intensa, estando presentes todas as etapas das cadeias operatórias. A elevada frequência de subprodutos dessa actividade é muito expressiva (c. $72 \%$, Quadro 2). Não é improvável que o grupo humano que se estabeleceu em Montum de Baixo assentasse a sua economia em duas componentes económicas principais: agricultura e actividade artesanal: manufactura de artefactos de pedra lascada (núcleos e suportes lamelares), destinada à rede de trocas regionais, pois amplas áreas do Alentejo são deficitárias em rochas siliciosas (sílex e cherte), de fractura concoidal, adequadas às técnicas de lascagem.

No povoado faltam, porém, núcleos em início de exploração e produtos de debitagem (c. 9\%, Quadro 2). Registámos numerosos subprodutos, onde se incluem nódulos de matéria-prima testados, resíduos amorfos diversos, lascas residuais, cuja dimensão máxima pode ficar aquém de $1 \mathrm{~cm}$, lascas de acon- dicionamento e/ou de reavivamento de núcleos. O córtex do sílex, cherte, calcedónia não possui rolamento, parecendo indicar aprovisionamento em fontes primárias de matéria-prima ou nas suas proximidades. É possível que a primeira selecção e desbaste de ganga ocorresse junto dos afloramentos. Não identificámos no povoado indícios de armazenagem de matérias-primas.

Os núcleos formatados e explorados no sítio, poliédricos irregulares na sua maioria, revelam estados avançados de exploração (em média: 25,8 $8 \pm 10,4 \times 25$, $6 \pm 10,6 \times 17,4 \pm 6,4 \mathrm{~mm}$ ) (Quadro 10A). A redução de carácter subprismático, dirigida para a extracção de lamelas, encontra-se também presente quer em fragmentos/flancos de núcleos, quer em exemplares de reduzidas dimensões, reveladoras de esgotamento (Fig. 9, n. 1). Estes possuem módulos volumétricos que recordam ainda os do Mesolítico regional pela sua reduzida largura (Marchand 2001; Soares - Mazzucco - Tavares da Silva 2021). No entanto, a maior parte da produção lamelar $(72,2 \%)$ apresenta larguras entre 
os 8 e os $12 \mathrm{~mm}$ (Quadro 9), distanciando-se quer da Gaspeia neolítica quer do sítio do Gaio, ambos atribuíveis ao Neolítico antigo evolucionado; Vale Pincel I, de cronologia mais alta, mas onde a economia agrícola estaria bem melhor implantada que nos povoados de Gaspeia e Gaio (Soares - Tavares da Silva - Gonzalez 2004), oferece um padrão qualitativo mais próximo. Desta forma, a interpretação dos dados tem de atender prioritariamente à funcionalidade da jazida. Podemos supor que a imagem da produção lamelar obtida para Montum de Baixo está de acordo com uma economia agrícola, complementada por actividade artesanal excedentária de talhe lítico lamelar, destinada à rede de trocas do grupo. Os produtos longos com largura superior a $12 \mathrm{~mm}$ são raros, o que se coaduna com a cronologia do Neolítico antigo proposta.

Nos produtos de debitagem dominam as lamelas (c. $60 \%$ ), seguidas pelas lascas, com $36,5 \%$; as lâminas detêm somente $3,6 \%$. Nos instrumentos retocados e com macro-vestígios de uso, as lascas possuem c. $58 \%$, as lamelas, 35\% e as lâminas, 3,6\%; os restantes suportes (núcleos e resíduos) perfazem 3,9\%. Esta inversão de frequências relativas observada nas lamelas é em parte explicada pela preferência atribuída às lascas como suportes dos instrumentos do fundo comum (Fig. 10), como raspadores, furadores, pontas atípicas, mas leva-nos também a reforçar a hipótese de ter havido produção artesanal excedentária, para consumo não local, ou seja, destinada à esfera do intercâmbio, com especialização na manufactura de suportes lamelares. Na Gaspeia, a diferença de frequências relativas entre lamelas brutas e lamelas transformadas é menor, não deixando de ser significativa, o que poderia dever-se à necessidade que o grupo teria de conservar stock de suportes lamelares, em contexto geográfico desprovido de sílex/cherte (Tavares da Silva - Soares 2020b: 128).

A produção de lamelas, que nestes povoados parece ser o principal objectivo do talhe lítico, obedece a uma padronização relativamente estandardizada. No caso vertente, o somatório dos tipos de talões facetado e reduzido atinge 77,5\% (Quadro 4), o somatório dos bolbos médios e difusos atinge 92,3\% (Quadro 5). A debitagem de lamelas por percussão indirecta $(43,8 \%)$ e pressão $(17,8 \%)$ adicionou a estas técnicas tradicionais o aquecimento prévio da matéria-prima em 36\% da amostra, restando para a percussão directa (a mais utilizada na debitagem de lascas), somente o valor residual de 1,8\% (Quadro 6). O recurso frequente ao aquecimento prévio da matéria-prima elege desde logo as lareiras como polos de actividade artesanal (Fig. 8). Algumas peças residuais foram abandonadas dentro do fogo e/ou na sua beira, mostrando indícios de profundas alterações de origem térmica como cúpulas, fissuração, fragmentação. O propósito de obtenção de suportes regulares, ainda longe do que será atingido na produção de produtos longos a partir do Neolítico médio, mostra já $45,5 \%$ de exemplares com secção transversal trapezoidal/subtrapezoidal (Quadro 7) e perfil longitudinal direito ou ligeiramente arqueado, em 54,6\% (Quadro 8).

QUADRO 4 MONTUM DE BAIXO. INDÚSTRIA LITTICA. SUBSISTEMA USO-INTENSIVO. TALÃO

\begin{tabular}{lcc|cc|cc|cc} 
& \multicolumn{2}{c}{ LASCA } & \multicolumn{2}{c}{ LÂMINA } & \multicolumn{2}{c}{ LAMELA } & \multicolumn{2}{c}{ TOTAL } \\
\cline { 2 - 9 } TALÄO & $\mathbf{N}$ & $\%$ & $\mathbf{N}$ & $\%$ & $\mathbf{N}$ & $\%$ & $\mathbf{N}$ & $\%$ \\
\hline Cortical & 32 & 11.8 & & & 3 & 2.1 & 35 & 8.3 \\
\hline Liso & 88 & 32.4 & 1 & 14.3 & 10 & 7.0 & 99 & 23.5 \\
\hline Diedro & 15 & 5.5 & & & 5 & 3.5 & 20 & 4.8 \\
\hline Côncavo & 9 & 3.3 & 1 & 14.3 & 11 & 7.7 & 21 & 5.0 \\
\hline Facetado & 51 & 18.8 & 1 & 14.3 & 61 & 43.0 & 113 & 26.8 \\
\hline Reduzido & 54 & 19.9 & 2 & 28.6 & 49 & 34.5 & 105 & 24.9 \\
\hline Massacrado & 18 & 6.6 & 1 & 14.3 & 1 & 0.7 & 20 & 4.8 \\
\hline Modificado* & 5 & 1.8 & 1 & 14.3 & 2 & 1.4 & 8 & 1.9 \\
\hline Total & $\mathbf{2 7 2}$ & 100 & $\mathbf{7}$ & $\mathbf{1 0 0}$ & $\mathbf{1 4 2}$ & $\mathbf{1 0 0}$ & $\mathbf{4 2 1}$ & 100 \\
\hline
\end{tabular}

* Alterado posteriormente à debitagem da peça.

QUADRO 5 MONTUM DE BAIXO. INDÚSTRIA LÍTICA. SUBSISTEMA USO-INTENSIVO. BOLBO

\begin{tabular}{lccc|cc|cc|ccc|} 
& \multicolumn{2}{c}{ LASCA } & \multicolumn{2}{c}{ LÂMINA } & \multicolumn{2}{c}{ LAMELA } & \multicolumn{2}{c}{ TOTAL } \\
\cline { 2 - 10 } BOLBO & $\mathbf{N}$ & $\%$ & $\mathbf{N}$ & $\%$ & $\mathbf{N}$ & $\%$ & $\mathbf{N}$ & $\%$ \\
\hline Proeminente & 117 & 43.5 & & & 5 & 3.5 & 122 & 29.2 \\
\hline Médio & 96 & 35.7 & 4 & 57.1 & 90 & 63.4 & 190 & 45.5 \\
\hline $\begin{array}{l}\text { Parcial/ } \\
\text { eliminado }\end{array}$ & 19 & 7.1 & 1 & 14.3 & 5 & 3.5 & 25 & 6.0 \\
\hline Difuso & 35 & 13.0 & 2 & 28.6 & 41 & 28.9 & 78 & 18.7 \\
\hline Modificado* & 2 & 0.7 & & & 1 & 0.7 & 3 & 0.7 \\
\hline Total & 269 & 100 & 7 & 100 & 142 & 100 & 418 & 100 \\
\hline
\end{tabular}

* Alterado posteriormente à debitagem da peça. 
QUADRO 6 MONTUM DE BAIXO. INDÚSTRIA LÍTICA. SUBSISTEMA USO-INTENSIVO. TÉCNICA DE DEBITAGEM

\begin{tabular}{|c|c|c|c|c|c|c|c|c|}
\hline \multirow{2}{*}{ TÉCNICA DE DEBITAGEM } & \multicolumn{2}{|c|}{ LASCA } & \multicolumn{2}{|c|}{ LÂMINA } & \multicolumn{2}{|c|}{ LAMELA } & \multicolumn{2}{|c|}{ TOTAL } \\
\hline & $\mathbf{N}$ & $\%$ & $\mathbf{N}$ & $\%$ & $\mathbf{N}$ & $\%$ & $\mathbf{N}$ & $\%$ \\
\hline Percussão directa & 162 & 58.7 & & & 3 & 1.8 & 165 & 36.5 \\
\hline Percussão indirecta & 83 & 30.1 & 7 & 100 & 74 & 43.8 & 164 & 36.3 \\
\hline Pressão & 6 & 2.2 & & & 30 & 17.8 & 36 & 8.0 \\
\hline Aquecimento prévio / percussão directa & 1 & 0.4 & & & 1 & 0.6 & 2 & 0.4 \\
\hline Aquecimento prévio / percussão indirecta & 14 & 5.1 & & & 16 & 9.5 & 30 & 6.6 \\
\hline Aquecimento prévio / pressão & 4 & 1.4 & & & 21 & 12.4 & 25 & 5.5 \\
\hline Aquecimento da matéria-prima & 6 & 2.2 & & & 24 & 14.2 & 30 & 6.6 \\
\hline Total & 276 & 100 & 7 & 100 & 169 & 100 & 452 & 100 \\
\hline
\end{tabular}

QUADRO 7 MONTUM DE BAIXO. SUBSISTEMA TECNOLÓGICO USO-INTENSIVO. SECÇÃO TRANSVERSAL.

\begin{tabular}{|c|c|c|c|c|c|c|c|c|}
\hline \multirow{2}{*}{ SECÇÃO TRANSVERSAL } & \multicolumn{2}{|c|}{ LASCA } & \multicolumn{2}{|c|}{ LÂMINA } & \multicolumn{2}{|c|}{ LAMELA } & \multicolumn{2}{|c|}{ TOTAL } \\
\hline & $\mathbf{N}$ & $\%$ & $\mathbf{N}$ & $\%$ & $\mathbf{N}$ & $\%$ & $\mathbf{N}$ & $\%$ \\
\hline Biconvexa & 2 & 1.4 & & & & & 2 & 0.6 \\
\hline Plano-convexa & 5 & 3.4 & & & & & 5 & 1.5 \\
\hline Convexo-côncava & & & & & 1 & 0.6 & 1 & 0.3 \\
\hline Ovalada & 1 & 0.7 & & & & & 1 & 0.3 \\
\hline Trapezoidal/subtrapezoidal & 24 & 16.6 & 6 & 37.5 & 80 & 45.5 & 110 & 32.6 \\
\hline Triangular/subtriangular & 57 & 39.3 & 10 & 62.5 & 92 & 52.3 & 159 & 47.2 \\
\hline Irregular & 56 & 38.6 & & & 3 & 1.7 & 59 & 17.5 \\
\hline Total & 145 & 100 & 16 & 100 & 176 & 100 & 337 & 100 \\
\hline
\end{tabular}

QUADRO 8 MONTUM DE BAIXO. SUBSISTEMA TECNOLÓGICO USO-INTENSIVO. PERFIL LONGITUDINAL

\begin{tabular}{|c|c|c|c|c|c|c|c|c|}
\hline \multirow{2}{*}{ PERFIL LONGITUDINAL } & \multicolumn{2}{|c|}{ LASCA } & \multicolumn{2}{|c|}{ LÂMINA } & \multicolumn{2}{|c|}{ LAMELA } & \multicolumn{2}{|c|}{ TOTAL } \\
\hline & $\mathbf{N}$ & $\%$ & $\mathbf{N}$ & $\%$ & $\mathbf{N}$ & $\%$ & $\mathbf{N}$ & $\%$ \\
\hline Direito & 44 & 31.4 & 8 & 61.5 & 50 & 33.3 & 102 & 33.7 \\
\hline Ligeiramente arqueado & 3 & 2.1 & 2 & 15.4 & 32 & 21.3 & 37 & 12.2 \\
\hline Arqueado & 19 & 13.6 & 2 & 15.4 & 43 & 28.7 & 64 & 21.1 \\
\hline Muito arqueado & 3 & 2.1 & & & 4 & 2.7 & 7 & 2.3 \\
\hline Torso & 7 & 5.0 & 1 & 7.7 & 8 & 5.3 & 16 & 5.3 \\
\hline Irregular & 58 & 41.4 & & & 3 & 2.0 & 61 & 20.1 \\
\hline Ultrapassado & 6 & 4.3 & & & 10 & 6.7 & 16 & 5.3 \\
\hline Total & 140 & 100 & 13 & 100 & 150 & 100 & 303 & 100 \\
\hline
\end{tabular}


Obteve-se o seguinte padrão tipométrico para as lamelas brutas de Montum de Baixo: 23,2 $\pm 5,3 \times 9,3$ $\pm 1,6 \times 2,6 \pm 1,0 \mathrm{~mm}$, sendo o quociente esp./larg. de $0,3 \pm 0,3$ (Quadro 10A); as lamelas transformadas pelo retoque apresentam dimensões muito próximas das anteriores e as transformadas pelo uso possuem um comprimento ligeiramente superior: $24,5 \pm 6,9 \times 9,3 \pm$

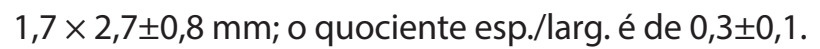

A análise tipológica dos utensílios retocados, com $16,5 \%$ da amostra estudada (Quadro 11), mostrou, como expectável, uma melhor representação do grupo tipológico dos entalhes e denticulados (5\%, Fig. 12), seguido pelo grupo das peças de bordo abatido (2\%,
Fig. 11) e pelo dos raspadores (1,8\%). Os geométricos têm em Montum de Baixo uma baixa frequência relativa $(0,9 \%)$ e a técnica do microburil parece ter caído em desuso (5 exs). Este é um dos aspectos em que a utensilagem de pedra lascada de Montum mais difere da de Gaspeia, revelando a diversidade de modos de vida durante o Neolítico antigo e a necessidade de questionar mais sistematicamente a funcionalidade dos contextos.

Dos 13 geométricos registados (Quadro 11, Fig. 12), 10 são segmentos; observaram-se as seguintes dimensões médias destes últimos: 18,8 $83,4 \times 7,6 \pm 1,5 \times 2,6 \pm 0,4 \mathrm{~mm}$ (Quadro 10B).

QUADRO 9 MONTUM DE BAIXO. ANÁLISE COMPARATIVA DA LARGURA DOS PRODUTOS LONGOS (MM).

\begin{tabular}{|c|c|c|c|c|c|}
\hline LARGURA (mm) & $\begin{array}{c}\text { GASPEIA } \\
\text { MESOLITICA }\end{array}$ & GASPEIA NEOLÍTICA & VALE PINCEL I & GAIO & MONTUM DE BAIXO \\
\hline $3-3,9$ & 0 & 1 & 0 & 0 & 0 \\
\hline $4-4,9$ & 7 & 1 & 1 & 0 & 0 \\
\hline $5-5,9$ & 10 & 9 & 2 & 4 & 1 \\
\hline $6-6,9$ & 16 & 22 & 8 & 7 & 12 \\
\hline $7-7,9$ & 13 & 15 & 9 & 10 & 24 \\
\hline $8-8,9$ & 9 & 9 & 19 & 8 & 40 \\
\hline $9-9,9$ & 5 & 12 & 21 & 4 & 45 \\
\hline $10-10,9$ & 6 & 9 & 19 & 3 & 36 \\
\hline $11-11,9$ & 3 & 3 & 13 & 2 & 48 \\
\hline $12-12,9$ & 0 & 4 & 14 & 0 & 9 \\
\hline $13-13,9$ & 1 & 1 & 4 & 1 & 8 \\
\hline $14-14,9$ & 0 & 1 & 4 & 1 & 6 \\
\hline $15-15,9$ & 0 & 1 & 0 & 1 & 1 \\
\hline $16-16,9$ & 1 & 0 & 2 & 0 & 1 \\
\hline $17-17,9$ & 0 & 0 & 0 & 0 & 2 \\
\hline $18-18,9$ & 0 & 0 & 1 & 0 & 1 \\
\hline Total & 71 & 88 & 117 & 41 & 234 \\
\hline
\end{tabular}


QUADRO 10A MONTUM DE BAIXO. SUBSISTEMA TECNOLÓGICO USO-INTENSIVO. MÉDIAS DAS DIMENSÕES MÁXIMAS DAS PRINCIPAIS CATEGORIAS MORFOFUNCIONAIS E SUPORTES

\begin{tabular}{|c|c|c|c|c|c|c|c|c|c|c|c|c|c|c|}
\hline \multirow{2}{*}{$\begin{array}{l}\text { CATEGORIAS } \\
\text { MORFOFUNCIONAIS }\end{array}$} & \multicolumn{4}{|c|}{ L. MÁX. (mm) } & \multicolumn{2}{|c|}{ I. MÁX. (mm) } & \multicolumn{4}{|c|}{ ESP. MÁX. (mm) } & \multicolumn{4}{|c|}{ E./l. } \\
\hline & $\mathbf{N}$ & $\%$ & $\mathbf{N}^{\prime}$ & $\overline{\mathbf{X}}$ & $\mathbf{N}^{\prime}$ & $\overline{\mathbf{X}}$ & $\mathbf{N}^{\prime}$ & & $\overline{\mathbf{X}}$ & & $\mathbf{N}^{\prime}$ & & $\overline{\mathbf{X}}$ & \\
\hline Núcleos & 80 & 5.8 & 48 & $25.8 \pm 10.4$ & 47 & $25.6 \pm 10.6$ & 73 & 17.4 & \pm 6 & 6.4 & 47 & 0.7 & \pm & 0.1 \\
\hline Subprodutos de talhe & 772 & 56.1 & 377 & $19.0 \pm 7.0$ & 388 & $13.7 \pm 5.6$ & 389 & 6.4 & \pm 3 & 3.8 & 388 & 0.5 & \pm & 0.3 \\
\hline Produtos de debitagem & 192 & 14.0 & 88 & $23.1 \pm 4.9$ & 188 & $12.5 \pm 6.3$ & 191 & 3.7 & \pm 2 & 2.2 & 188 & 0.3 & \pm & 0.2 \\
\hline Lasca & 70 & 5.1 & 53 & $23.0 \pm 4.7$ & 68 & $17.6 \pm 7.9$ & 70 & 5.6 & \pm 2 & 2.5 & 68 & 0.3 & \pm & 0.1 \\
\hline Lâmina & 7 & 0.5 & 1 & $27.5 \pm$ & 7 & $13.1 \pm 0.9$ & 7 & 3.2 & \pm 1 & 1.2 & 7 & 0.3 & \pm & 0.1 \\
\hline Lamela & 115 & 8.4 & 34 & $23.2 \pm 5.3$ & 113 & $9.3 \pm 1.6$ & 114 & 2.6 & \pm 1 & 1.0 & 113 & 0.3 & \pm & 0.3 \\
\hline Instrumentos retocados & 228 & 16.6 & 139 & $23.3 \pm 8.0$ & 193 & $15.4 \pm 7.0$ & 227 & 5.8 & \pm 4 & 4.0 & 193 & 0.4 & \pm & 0.2 \\
\hline Núcleo & 7 & 0.5 & 7 & $26.6 \pm 10.8$ & 7 & $20.7 \pm 7.4$ & 7 & 15.4 & & 7.3 & 7 & 0.7 & \pm & 0.2 \\
\hline Resíduo & 6 & 0.4 & 6 & $31.3 \pm 15.7$ & 6 & $15.5 \pm 10.4$ & 6 & 14.2 & \pm 6 & 6.2 & 6 & 1.1 & \pm & 0.4 \\
\hline Lasca & 133 & 9.7 & 95 & $22.6 \pm 7.2$ & 113 & $18.4 \pm 6.6$ & 132 & 6.5 & \pm 3 & 3.1 & 113 & 0.4 & \pm & 0.2 \\
\hline Lâmina & 6 & 0.4 & 3 & $34.3 \pm 10.5$ & 6 & $14.2 \pm 1.6$ & 6 & 4.3 & & 1.2 & 6 & 0.3 & \pm & 0.1 \\
\hline Lamela & 76 & 5.5 & 28 & $22.0 \pm 5.6$ & 61 & $9.3 \pm 1.7$ & 76 & 3.1 & \pm 1 & 1.0 & 61 & 0.4 & \pm & 0.1 \\
\hline $\begin{array}{l}\text { Peças com macro } \\
\text { vestígios de uso }\end{array}$ & 104 & 7.6 & 70 & $24.1 \pm 7.6$ & 104 & $15.1 \pm 7.2$ & 104 & 4.9 & \pm 2 & 2.9 & 104 & 0.3 & & 0.1 \\
\hline Lasca & 57 & 4.1 & 53 & $23.8 \pm 7.8$ & 57 & $19.2 \pm 7.2$ & 57 & 6.6 & \pm 3 & 3.0 & 57 & 0.4 & \pm & 0.1 \\
\hline Lâmina & 6 & 0.4 & 1 & $35.0 \pm$ & 6 & $15.3 \pm 2.0$ & 6 & 4.0 & \pm 1 & 1.3 & 6 & 0.3 & \pm & 0.1 \\
\hline Lamela & 41 & 3.0 & 16 & $24.5 \pm 6.9$ & 41 & $9.3 \pm 1.7$ & 41 & 2.7 & \pm 0 & 0.8 & 41 & 0.3 & \pm & 0.1 \\
\hline
\end{tabular}

$\mathrm{N}$ - número total de registos; $\mathrm{N}^{\prime}$ - número de registos completos.

Os geométricos só foram incluídos na dimensão espessura, uma vez que o comprimento e a largura que ostentam podem ser diferentes dos do suporte original.

QUADRO 10B MONTUM DE BAIXO. DIMENSÕES MÉDIAS DOS GEOMÉTRICOS

\begin{tabular}{|c|c|c|c|c|c|c|c|c|c|c|c|c|c|c|c|}
\hline \multirow{2}{*}{ GEOMÉTRICOS } & \multicolumn{4}{|c|}{ L. MÁX. (mm) } & \multicolumn{4}{|c|}{ I. MÁX. (mm) } & \multicolumn{4}{|c|}{ ESP. MÁX. (mm) } & \multicolumn{3}{|c|}{ E./l. } \\
\hline & $\mathbf{N}$ & $\mathbf{N}^{\prime}$ & & $\overline{\mathbf{X}}$ & $\mathbf{N}^{\prime}$ & & $\overline{\mathbf{X}}$ & & $\mathbf{N}^{\prime}$ & & $\overline{\mathbf{X}}$ & & $\mathbf{N}^{\prime}$ & & $\overline{\mathbf{X}}$ \\
\hline Triângulo & 1 & & & & 1 & 10 & & & 1 & 2 & & & 1 & 0.2 & \\
\hline Trapézio & 2 & 1 & & 20 & 2 & 9.5 & \pm 0 & 0.7 & 2 & 2.8 & & 0.4 & 2 & 0.3 & \pm 0.02 \\
\hline Segmento & 10 & 8 & 18.8 & \pm 3.4 & 10 & 7.6 & \pm 1 & 1.5 & 10 & 2.6 & \pm & 0.4 & 10 & 0.4 & \pm 0.1 \\
\hline Flecha transversal & 4 & 4 & 16.0 & \pm 3.4 & 4 & 14.1 & \pm 2 & 2.8 & 4 & 4.8 & \pm & 2.3 & 4 & 0.3 & \pm 0.1 \\
\hline
\end{tabular}


QUADRO 11 MONTUM DE BAIXO. SUBSISTEMA

USO-INTENSIVO. TIPOLOGIA

\begin{tabular}{|c|c|c|}
\hline TIPOLOGIA & $\mathbf{N}$ & $\%$ \\
\hline Manuportes & 2 & 0.15 \\
\hline Núcleos & 80 & 5.8 \\
\hline Fragmento de núcleo indeterminado & 13 & \\
\hline Fragmento de núcleo subprismático & 3 & \\
\hline Flanco de núcleo subprismático & 2 & \\
\hline Flanco de núcleo irregular com um plano de percussão & 2 & \\
\hline Núcleo esboçado/testado & 6 & \\
\hline Núcleo de lamelas com um plano de percussão & 3 & \\
\hline Núcleo subprismático com dois planos de percussão & 3 & \\
\hline Núcleo poliédrico irregular & 40 & \\
\hline Núcleo esgotado prismático e subprismático & 8 & \\
\hline Subprodutos de talhe & 772 & 56.02 \\
\hline Resíduo & 619 & \\
\hline Lasca residual & 76 & \\
\hline Lasca de descorticagem & 11 & \\
\hline Lasca de acondicionamento de núcleo & 44 & \\
\hline Lasca de crista & 6 & \\
\hline Lâmina estreita de crista & 1 & \\
\hline Lamela residual & 1 & \\
\hline Lamela de acondicionamento de núcleo & 3 & \\
\hline Lamela de crista & 6 & \\
\hline Microburil & 3 & \\
\hline Piquant-trièdre & 2 & \\
\hline Produtos de debitagem & 192 & 13.93 \\
\hline Lasca não retocada & 70 & \\
\hline Lâmina não retocada & 7 & \\
\hline Lamela não retocada & 115 & \\
\hline Instrumentos retocados & 228 & 16.5 \\
\hline Raspadores & 25 & 1.8 \\
\hline Raspador sobre resíduo & 1 & \\
\hline Raspador sobre núcleo & 7 & \\
\hline Raspador subcircular sobre lasca & 2 & \\
\hline Raspador unguiforme sobre lasca & 1 & \\
\hline Micro-raspador subcircular & 1 & \\
\hline
\end{tabular}


TIPOLOGIA

Raspador simples sobre extremidade de lasca

Raspador denticulado sobre lasca

4

Raspador lateral sobre lasca

Raspador simple sobre extremidade de lamela

Micro-raspador sobre lamela

4

Furadores

Furador sobre resíduo

Furador sobre lasca

1

Furador espatuliforme sobre lasca

10

Furador sobre extremidade de lâmina estreita

1

Furador sobre extremidade de lamela

1

Furador espesso/raspador subcircular*

1

Buris

Buril de ângulo sobre fractura/bordo bruto

12

Buril múltiplo de ângulo sobre fractura/bordo bruto

1

Buril diedro

1

Buril de ângulo/raspador lateral*

1

Peças de bordo abatido

27

2.0

Lasca com bordo abatido parcial

2

Lasca de bordo abatido rectilíneo

Lasca de bordo abatido apontada

Lamela de bordo abatido parcial

Lamela de bordo abatido rectilíneo

Lamela de bordo abatido sinuoso

Lamela de bordo abatido arqueado

Lamela de bordo abatido apontada

Truncaturas

Truncatura sobre lasca residual

Truncatura sobre lamela

8

1

4

4

1

1

6

8

1

7

Geométricos

13

0.9

Triângulo

1

Trapézio

1

Trapézio com truncaturas côncavas

1

Esboço de segmento (?)

Segmento 


\begin{tabular}{|c|c|c|}
\hline TIPOLOGIA & $\mathbf{N}$ & $\%$ \\
\hline Flechas transversais & 4 & 0.3 \\
\hline Flecha transversal & 4 & \\
\hline Entalhes e denticulados & 69 & 5.0 \\
\hline Entalhe sobre resíduo & 1 & \\
\hline Entalhe sobre lasca & 18 & \\
\hline Entalhe sobre lamela & 2 & \\
\hline Denticulado sobre resíduo & 2 & \\
\hline Denticulado sobre núcleo & 1 & \\
\hline Denticulado sobre lasca & 32 & \\
\hline Denticulado sobre lâmina & 3 & \\
\hline Denticulado sobre lamela & 10 & \\
\hline Peças com retoque simples, marginal e parcial & 22 & 1.6 \\
\hline Lasca com retoque simples, marginal e parcial & 10 & \\
\hline Lâmina estreita com retoque simples e marginal & 1 & \\
\hline Lamela com retoque simples e marginal & 11 & \\
\hline Diversos & 24 & 1.7 \\
\hline Ponta atípica sobre resíduo & 1 & \\
\hline Ponta atípica sobre lasca & 18 & \\
\hline Ponta atípica sobre lâmina & 1 & \\
\hline Ponta atípica sobre lamela & 4 & \\
\hline Peças com macro vestígios de uso & 104 & 7.5 \\
\hline Lasca não retocada com vestígios de uso & 56 & \\
\hline Lasca com denticulado de uso (elemento de foice?) & 1 & \\
\hline Lâmina não retocada com vestígios de uso & 6 & \\
\hline Lamela não retocada com vestígios de uso & 38 & \\
\hline Lamela não retocada com lustre de cereal (elemento de foice) & 1 & \\
\hline Lamela de bordo abatido com lustre de cereal & 1 & \\
\hline Lamela com truncatura oblíqua e lustre de cereal & 1 & \\
\hline Total & 1378 & 100 \\
\hline
\end{tabular}

* Instrumento duplo

A análise do estado de conservação dos bordos dos artefactos permite, enquanto se aguarda pela traceologia, e com as necessárias reservas, classificar como utensílios (vestígios de uso) peças não retocadas. Um número relativamente elevado de efectivos foi classificado neste grupo tipológico (7,5\%, Quadro 11). Merecem destaque 3 lamelas com lustre de cereal, sendo nestes casos os vestígios de uso funcional e economicamente mais relevantes que o retoque (abrupto) presente em dois dos exemplares (Fig. 13). 

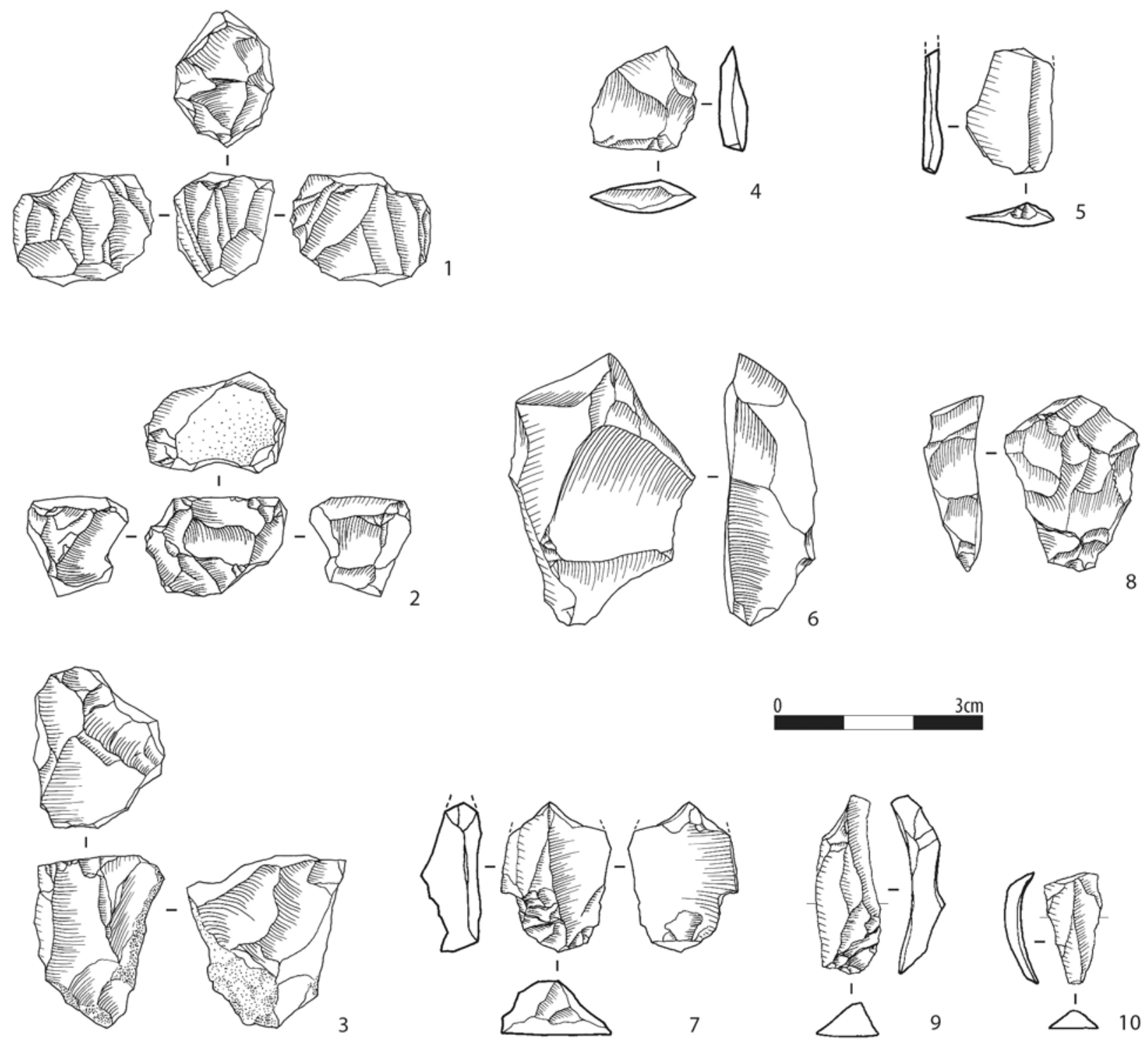

FIG. 9 Montum de Baixo. Indústria lítica do subsistema uso-intensivo. 1 - núcleo prismático esgotado (MBM.122); 2 e 3 - núcleos esgotados irregulares (MBM115 e MBM183); 4 e 5 - lascas residuais (MBM.190 e MBM.168); 6 e 7 - lascas de acondicionamento de núcleo (MBM.186 e MBM.1); 8 - lasca de crista (MBM.136); 9 - lamela de crista (MBM.117; 10 - lamela residual (MBM202). Desenhos de Fernanda de Sousa. 

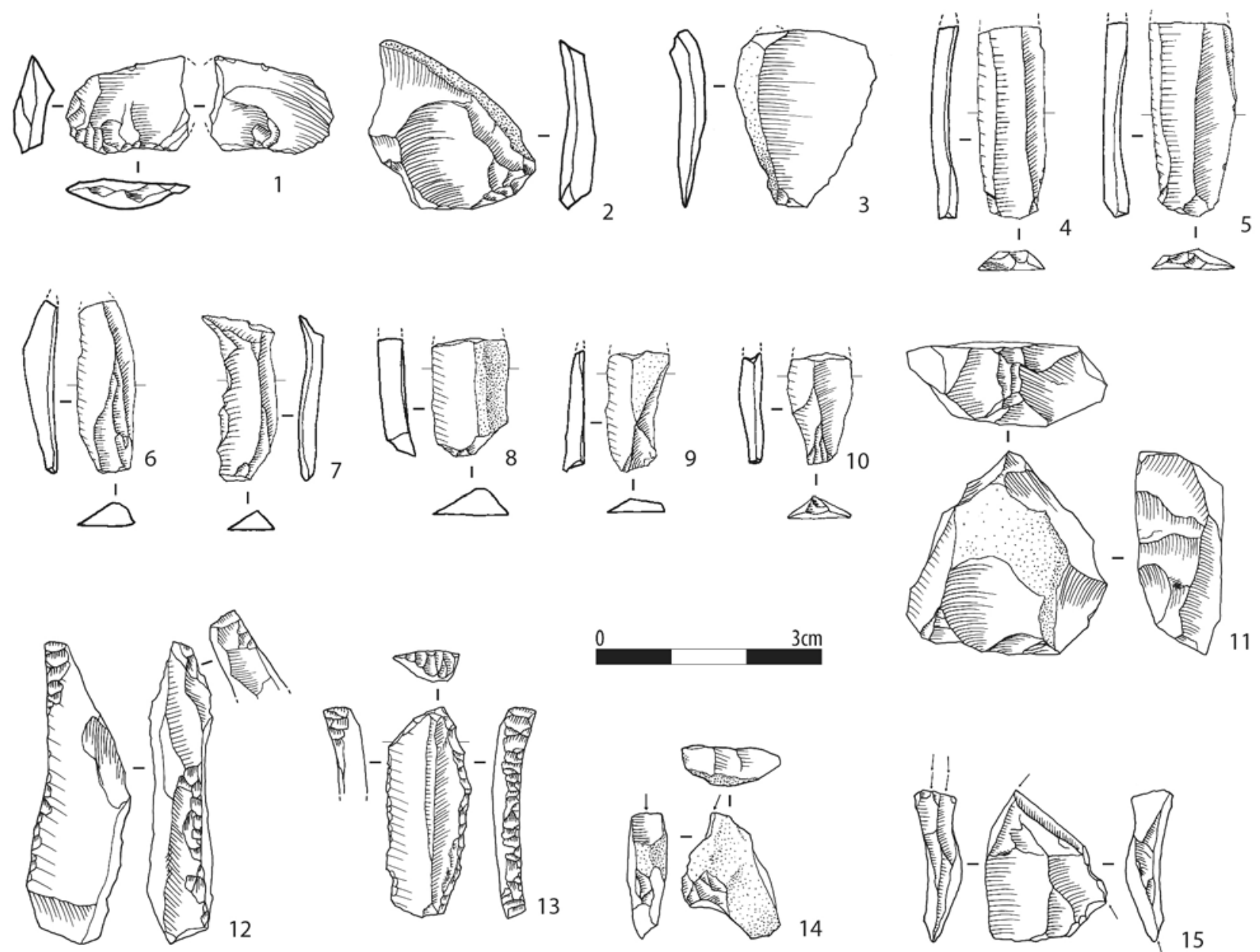

FIG. 10 Montum de Baixo. Indústria lítica do subsistema uso-intensivo. 1 a 3 - lascas não retocadas (MBM.21, MBM137 e MBM.12); 4 a 10 - lamelas não retocadas (MBM.174, MBM.70, MBM.178, MBM.32, MBM.7, MBM.23 e MBM.24); 11 - raspador ogival sobre núcleo (MBM.157); 12 - furador sobre resíduo (MBM. 270); 13 - furador sobre lamela (MBM.93); 14 - buril de ângulo sobre fractura (MBM.120); 15 - buril multiplo de ângulo sobre lasca (MBM.58). Desenhos de Fernanda de Sousa. 

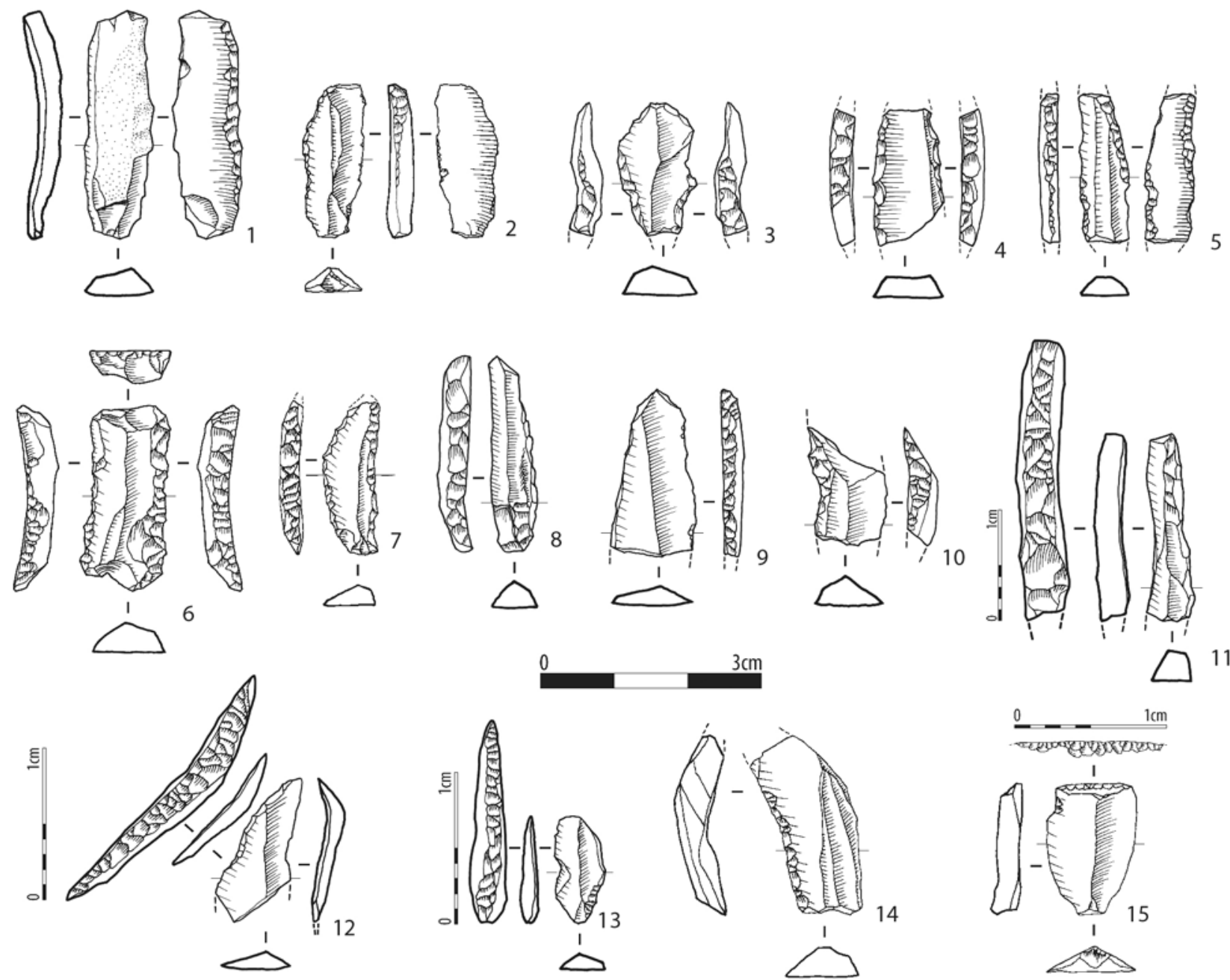

FIG. 11 Montum de Baixo. Indústria lítica do subsistema uso-intensivo. 1 a 14 - lamelas de bordo abatido (MBM.1182, MBM.108, MBM.460, MBM.595 e MBM.1321, MBM.179, MBM.30, MBM.882, MBM.2271, MBM.1936, MBM.814, MBM.1251, MBM.642 e MBM.14); 15 - lamela com truncatura (MBM.142). Desenhos de Fernanda de Sousa. 

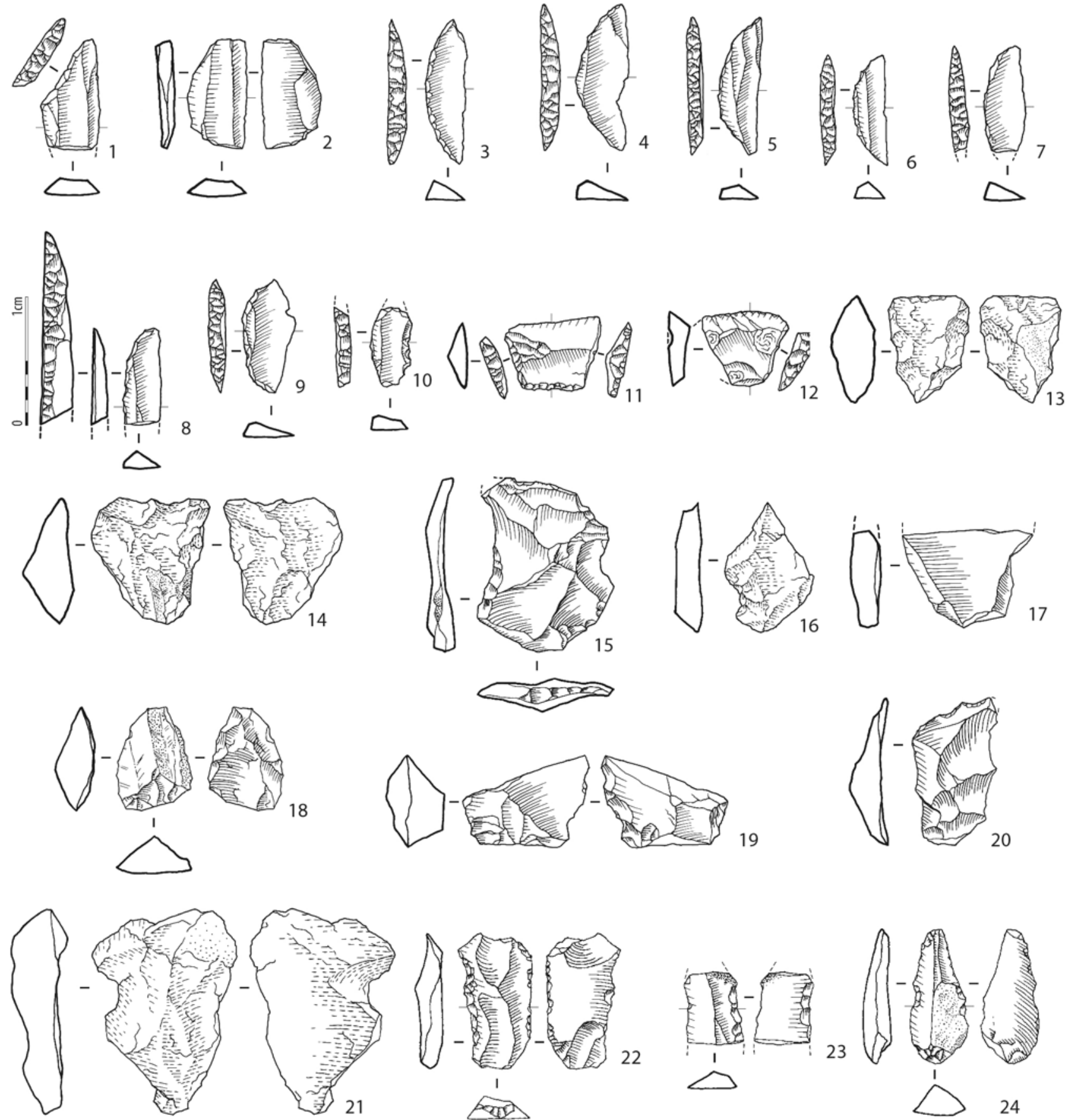

FIG. 12 Montum de Baixo. Indústria lítica do subsistema uso-intensivo. 1 - trapézio (MBM.1968); 2 - esboço de segmento (MBM.1148); 3 a 10 - segmentos (MBM.38, MBM.1042, MBM.1199, MBM.156, MBM.1107, MBM.488, MBM.1527 e MBM.389); 11 a 14 - flechas transversais (MBM.1138, MBM.1820, MBM.551 e MBM.841); 15 a 21 - entalhes e denticulados sobre lasca (MBM.212, MBM.34, MBM.56, MBM.11, MBM.65, MBM.155 e MBM.183); 22 a 24 - denticulados sobre lamela (MBM.213, MBM.9 e MBM.118). Desenhos de Fernanda de Sousa. 

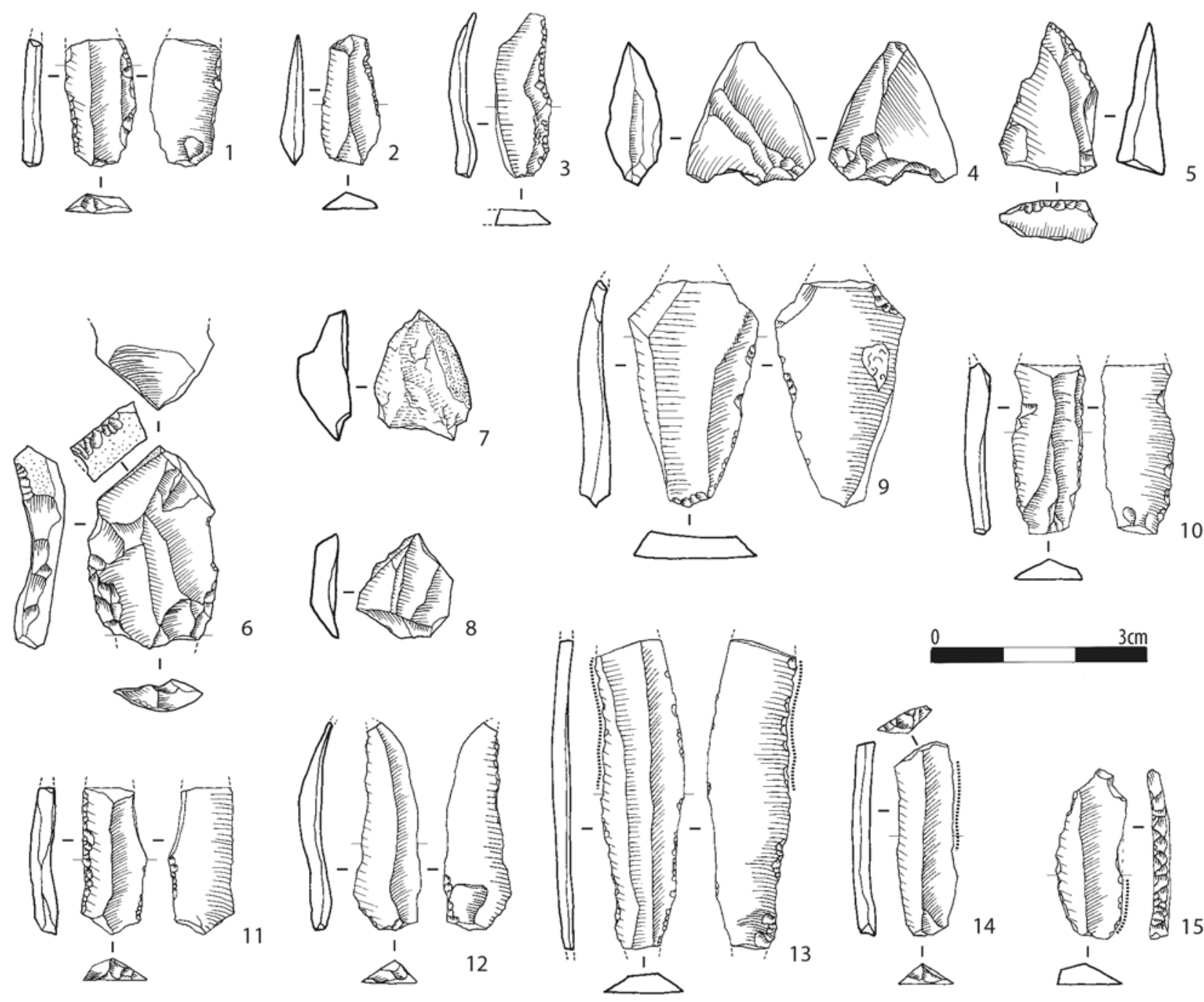

FIG. 13 Montum de Baixo. Indústria lítica do subsistema uso-intensivo. 1 a 3 - lamelas com retoque simples e marginal (MBM.220, MBM.10 e MBM.259); 4 a 8 - pontas atípicas sobre lasca (MBM.64, MBM.123, MBM.60, MBM.125 e MBM.57); 9 - lâmina não retocada com macro vestígios de uso (MBM.71); 10 a 12 - lamelas não retocadas com macro vestígios de uso (MBM.18, MBM.173 e MBM.77); 13 a 15 - lamelas com lustre de cereal (MBM.141, MBM.263 e MBM.262). Desenhos de Fernanda de Sousa. 


\subsection{Instrumentos polidos e bujardados}

Os instrumentos polidos e bujardados (Figs. 14-16) possuem uma baixa frequência relativa como anteriormente afirmámos (0,9\%). À excepção do grauvaque e quartzito recolhidos localmente, em meio fluvial, talvez na Ribeira de Melides, as restantes matérias-primas implicaram percursos mais extensos, de escala regional. Poderiam ter vindo de uma distância entre 30 e 40 km, possivelmente do Lousal/Canal Caveira. Uma pequena enxó votiva de fibrolite (Quadros 13 e 14, Fig. 15) terá chegado ao povoado muito provavelmente através da rede de trocas inter-regionais de longo curso, pois, por agora, a origem mais próxima daquela matéria-prima (seja a Zona Ofiolítica de Morais-Bragança ou a Zona Centro-lbérica) dista cerca de $600 \mathrm{~km}$ de Montum de Baixo (Soares - Fonseca - Duarte 2020). Esta peça é notável pelo seu grau de miniaturização $(20 \times 22 \times 6 \mathrm{~mm}$; peso de $4 \mathrm{~g})$; menor que o exemplar de Alvalade (Soares - Fonseca - Duarte 2020: 252), aproxima-se das enxós votivas dos povoados de Moita da Ladra (Cardoso - Caninas 2010) e da Encosta de Sant'Ana (Leitão - Cardoso - Martins 2021: Fig. 83). A informação mais interessante fornecida pela biografia da enxó votiva de fibrolite de Montum de Baixo é a da integração do sítio no contexto económico e superstrutural do Neolítico peninsular.

QUADRO 12 MONTUM DE BAIXO. MATÉRIA-PRIMA DOS INSTRUMENTOS POLIDOS E BUJARDADOS

\begin{tabular}{|lc|}
\hline MATÉRIA-PRIMA & N \\
\hline Instrumentos polidos & $\mathbf{1 2}$ \\
\hline Quartzovaque & 1 \\
\hline Anfibolito & 7 \\
\hline Talco-xisto & 2 \\
\hline Xisto silicioso & 1 \\
\hline Fibrolite & 1 \\
\hline Instrumentos bujardados & $\mathbf{7}$ \\
\hline Grauvaque & 5 \\
\hline Quartzito & 1 \\
\hline Anfibolito & 1 \\
\hline Total & 19 \\
\hline
\end{tabular}

QUADRO 13 MONTUM DE BAIXO. INSTRUMENTOS POLIDOS E BUJARDADOS. TIPOLOGIA

\begin{tabular}{|l|l|}
\hline TIPOLOGIA & N \\
\hline Instrumentos polidos & 12 \\
\hline Machado & 5 \\
\hline Machado pequeno & 1 \\
\hline Machado médio & 1 \\
\hline Machado ind. & 3 \\
\hline Enxó & 4 \\
\hline Enxó miniaturizada & 1 \\
\hline Enxó média (?) & 1 \\
\hline Fragmento de enxó & 2 \\
\hline Sacho & 3 \\
\hline Sacho pequeno & 2 \\
\hline Sacho médio & 19 \\
\hline Instrumentos bujardados & $\mathbf{1}$ \\
\hline Percutor & $\mathbf{7}$ \\
\hline Percutor duplo oblongo & 1 \\
\hline Polidor & 1 \\
\hline Polidor sobre seixo & 1 \\
\hline Mó manual & 1 \\
\hline Elemento dormente simples (frags.) & 1 \\
\hline Elemento movente simples & 1 \\
\hline Elemento movente duplo & 1 \\
\hline Total & 1 \\
\hline
\end{tabular}

O conjunto dos artefactos polidos biselados (Quadros 13 e 14, Figs. 14 e 15) dá-nos conta de instrumentos de trabalho, fragmentados pelo uso, com a excepção da enxó de carácter votivo, antes referida. Os machados possuem ligeira vantagem numérica, seguidos por enxós e sachos. À excepção de uma enxó que poderia ser de maior formato (média ou longa), os módulos pequeno e médio dominaram nos restantes artefactos polidos.

Nos artefactos bujardados (Quadros 13 e 14, Fig. 16), mau grado a pequenez da amostra, salienta-se a fraca representação da utensilagem moageira. Este facto aponta no sentido de um povoado que provavelmente não seria ocupado de forma permanente, estando o 
QUADRO 14 MONTUM DE BAIXO. CARACTERIZAÇÃO GERAL DOS INSTRUMENTOS DE PEDRA POLIDA E BUJARDADA

\begin{tabular}{|c|c|c|c|c|c|c|}
\hline INV. & CONTEXTO & TIPO $^{* *}$ & CONSERVAÇÃO & $\begin{array}{l}\text { DIMENSÕES } \\
\mathrm{L} \times \mathrm{I} \times \mathrm{e} \mathrm{mm}\end{array}$ & E./l. & $\begin{array}{c}\text { PESO } \\
\mathbf{g}\end{array}$ \\
\hline MBM.1098 & S.44; Q.H15; C.2 & machado pequeno - MP1 & C & $97 \times 49 \times 31$ & 0.63 & 197 \\
\hline MBM.302 & S.26; Q.T6; C.2 & machado pequeno - MP2 & $\mathrm{FL}$ & $110 \times 40 \times 33$ & 0.82 & 194 \\
\hline MBM.13 & S.54; Q.M10; C.2 & machado médio (?) - MM2 & FP & $8 \times 5 \times 3,4$ & 0.68 & 149 \\
\hline MBM.209 & S.44; Q.L19; C.2 & machado & FP & $53 \times 38 \times 30$ & 0.78 & 70 \\
\hline MBM.1091 & S.44; Q.G17; C.2 & machado & FP & $43 \times 33 \times 30$ & 0.9 & 42 \\
\hline MBM.1052 & S.16; Q.L13; C.2 & enxó miniaturizada - EP1 & C & $20 \times 22 \times 6$ & 0.3 & 4 \\
\hline MBM.1072 & S.16; Q.E16; C.2 & enxó média - EM1 & FD & $102 \times 65 \times 18$ & 0.27 & 235 \\
\hline MBM.274 & S.36; Q.C $8 ;$ C.2 & sacho pequeno - SP1 & C & $67 \times 44 \times 20$ & 0.5 & 67 \\
\hline MBM. $455^{* * *}$ & S.16; Q.D5; C.2 & sacho pequeno - SP2 & C & $79 \times 42 \times 17$ & 0.4 & 89 \\
\hline MBM.1083 & S.16; Q.J16; C.2 & sacho médio - SM1 & $\mathrm{FP}$ & $124 \times 53 \times 40$ & 0.75 & 355 \\
\hline MBM.1060 & S.16; Q.H18; C.2 & percutor duplo oblongo & C & $100 \times 59 \times 42$ & 0.7 & 387 \\
\hline MBM.1097 & S.16; Q.H12; C.2 & polidor sobre seixo rolado & C & $50 \times 50 \times 24$ & 0.48 & 90 \\
\hline MBM.1078 & S.36; Q.B5; C.2 & elemento movente discoidal & C & $130 \times 98 \times 43$ & 0.4 & 859 \\
\hline MBM.1067 & S.16; Q.A1;C.2 & elemento movente duplo discoidal & C & $102 \times 102 \times 25$ & 0.24 & 356 \\
\hline MBM.1139 & $\begin{array}{c}\text { S.16; Q.E20; C.2 } \\
\text { base; Estr.III }\end{array}$ & elemento movente duplo sobre seixo rolado & C & $152 \times 150 \times 58$ & 2.6 & 3043 \\
\hline
\end{tabular}

Conservação: C - completo; FP - fragmento proximal; FD - fragmento distal; FL - fragmento longitudinal. Gume: normal = largura máxima da peça; reduzido < largura máxima da peça; expandido > largura máxima da peça. Técnica: L - lascagem; P - polimento; B - bujardagem.

* Não foram considerados dois elementos dormentes de mó de grauvaque provenientes do S.16, C.2, Qs.D20 e L18 (Fig. 5) por dificuldade de acesso aos mesmos; ${ }^{* *}$ Segundo Soares, Fonseca, Duarte, 2020; ${ }^{* * *}$ Apresenta alterações térmicas; ${ }^{* * * *}$ Associado à estrutura de combustão Estr. III, de tipo E. 


\begin{tabular}{|c|c|c|c|c|c|c|}
\hline $\begin{array}{l}\text { CONTORNO } \\
\text { GERAL }\end{array}$ & $\begin{array}{c}\text { SECÇÃO } \\
\text { LONGITUDINAL }\end{array}$ & $\begin{array}{c}\text { SECÇÃO } \\
\text { TRANSVERSAL }\end{array}$ & TALÃO & GUME & TÉCNICA & MATÉRIA-PRIMA \\
\hline triangular & $\begin{array}{l}\text { biconvexa } \\
\text { simétrica }\end{array}$ & oval & pontiagudo & expandido & $\mathrm{P}+\mathrm{B}$ & anfibolito alterado \\
\hline fusiforme & $\begin{array}{l}\text { biconvexa } \\
\text { simétrica }\end{array}$ & subcircular & pontiagudo & reduzido & B & anfibolito \\
\hline fusiforme (?) & - & oval & pontiagudo & - & B & anfibolito \\
\hline fusiforme (?) & - & oval & pontiagudo & - & B & anfibolito (?) \\
\hline indeterminado & - & circular & pontiagudo & - & B & anfibolito \\
\hline trapezoidal & $\begin{array}{l}\text { biconvexa } \\
\text { assimétrica }\end{array}$ & oval & rectilíneo & expandido & $\mathrm{P}$ & fibrolite \\
\hline rectangular & plano-convexa & sub-rectangular & - & normal & $\mathrm{P}$ & talco-xisto \\
\hline subtriangular & $\begin{array}{l}\text { biconvexa } \\
\text { assimétrica }\end{array}$ & elíptica & oval & expandido & $\mathrm{P}+\mathrm{B}$ & quartzovaque \\
\hline subtrapezoidal & $\begin{array}{c}\text { aprox. plano- } \\
\text { convexa }\end{array}$ & subtrapezoidal & oval & expandido & $L+P$ & $\begin{array}{l}\text { anfibolito fino } \\
\text { muito alterado }\end{array}$ \\
\hline triangular & $\begin{array}{l}\text { convexo- } \\
\text { côncava }\end{array}$ & oval & pontiagudo & - & B & anfibolito \\
\hline subrectangular & ovalada & oval & oval+massacrado & - & $\mathrm{P}$ & $\begin{array}{c}\text { anfibolito muito } \\
\text { alterado originado } \\
\text { de basalto }\end{array}$ \\
\hline subtrapezoidal & irregular & irregular & - & - & $P$ & quartzito \\
\hline ovalado & sub-rectangular & sub-rectangular & - & - & B & grauvaque \\
\hline subcircular & sub-rectangular & sub-rectangular & - & - & B & grauvaque \\
\hline subquadrangular & sub-rectangular & sub-rectangular & - & - & B & grauvaque \\
\hline
\end{tabular}


1

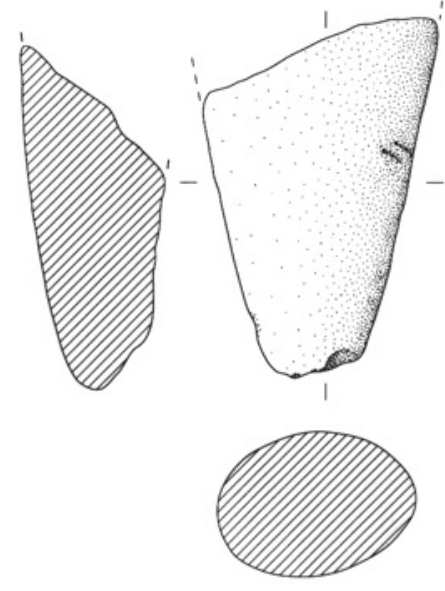

3

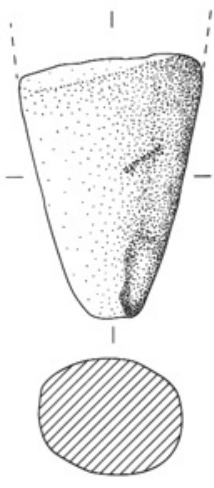

4

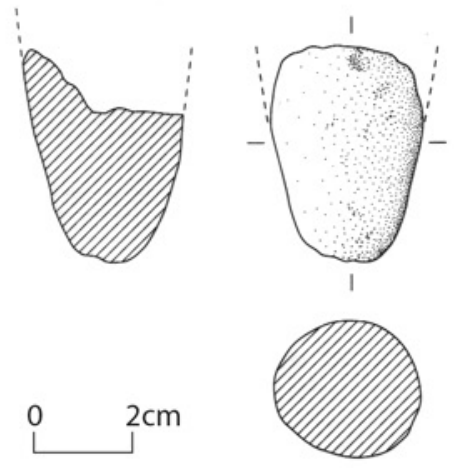

2
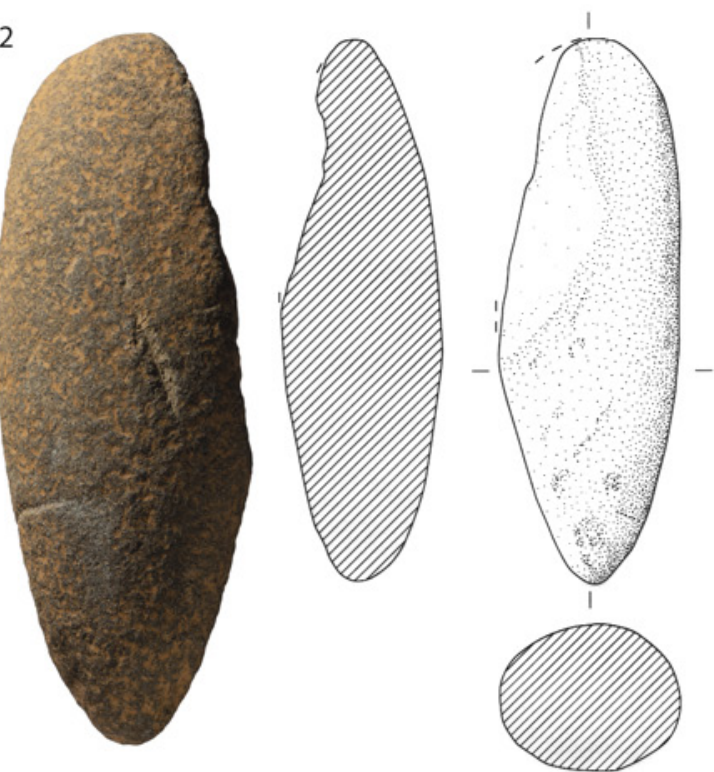

5
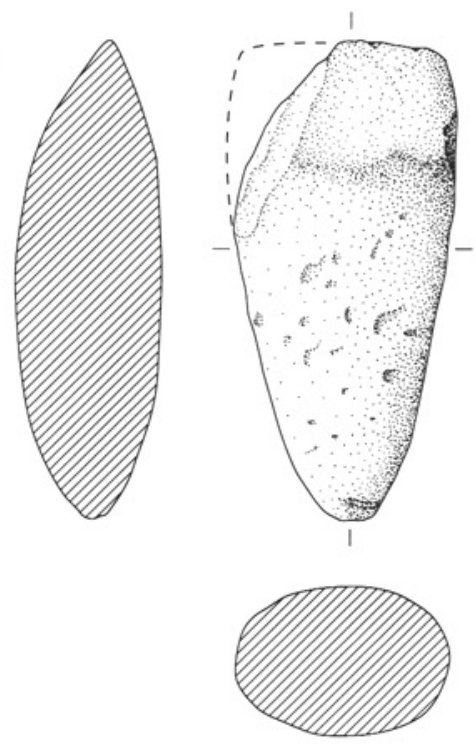

FIG. 14 Montum de Baixo. Instrumentos de pedra polida. Machados: 1 - MBM.13; 2 - MBM.302; 3 - MBM.209; 4 - MBM.1091; 5 - MBM.1098. Desenhos de Ana Castela. 
1
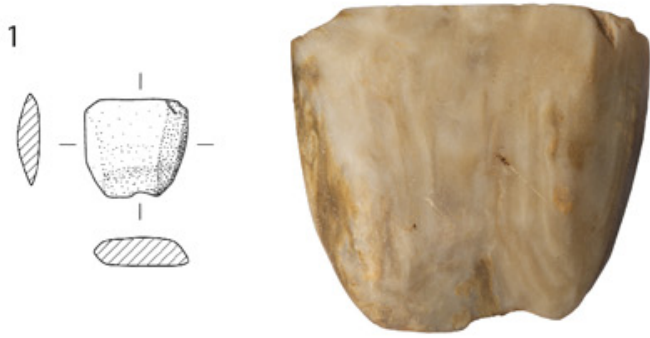

3
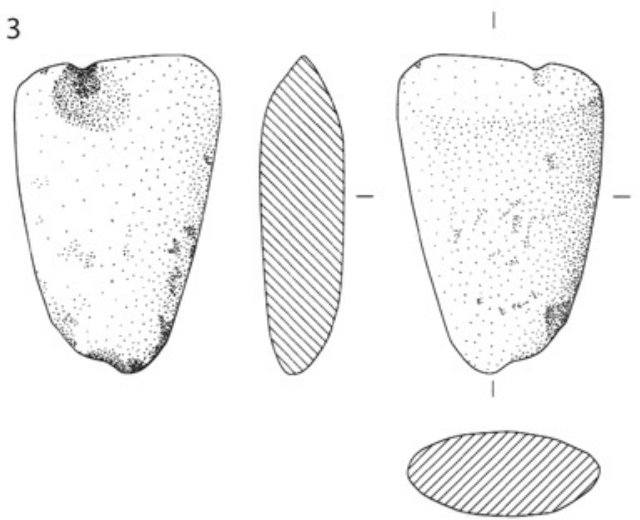

4

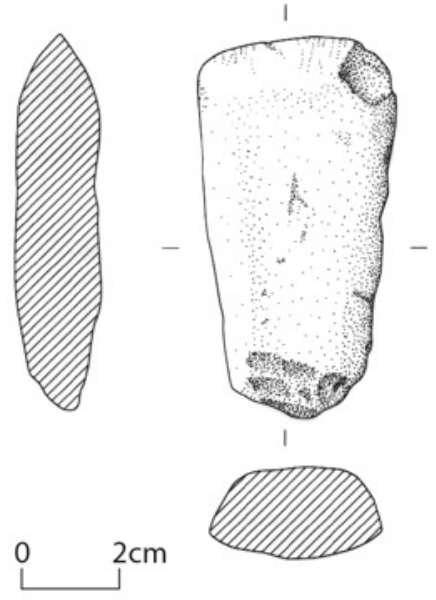

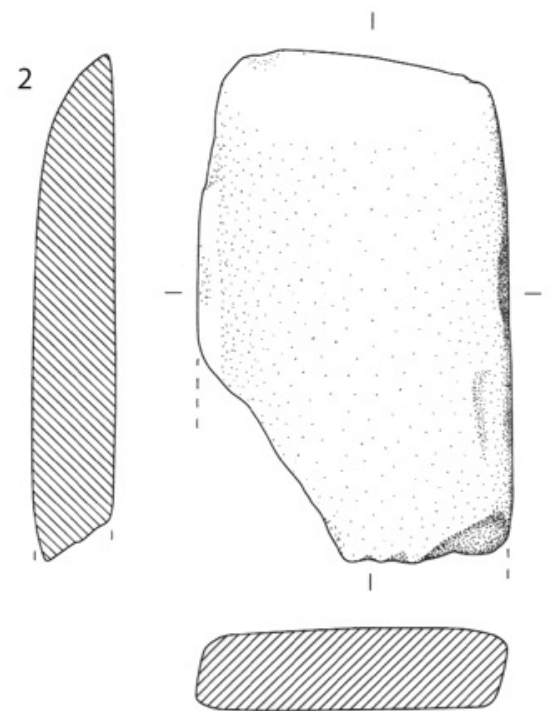

5
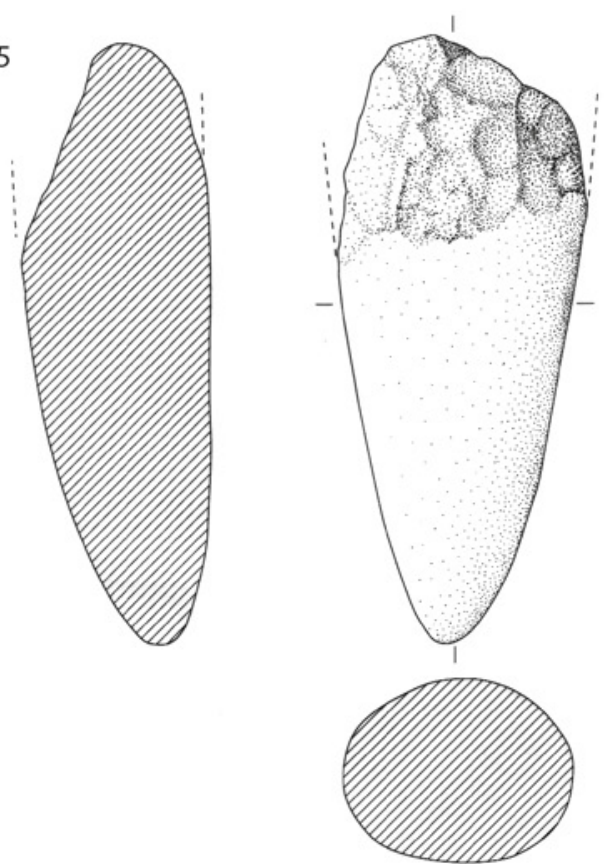

FIG. 15 Montum de Baixo. Instrumentos de pedra polida. Enxós: 1 - MBM.1052 (de fibrolite e miniaturizada); 2 - MBM.1072. Sachos: 3 - MBM.274; 4 - MBM.455; 5 - MBM.1083. Desenhos de Ana Castela. 

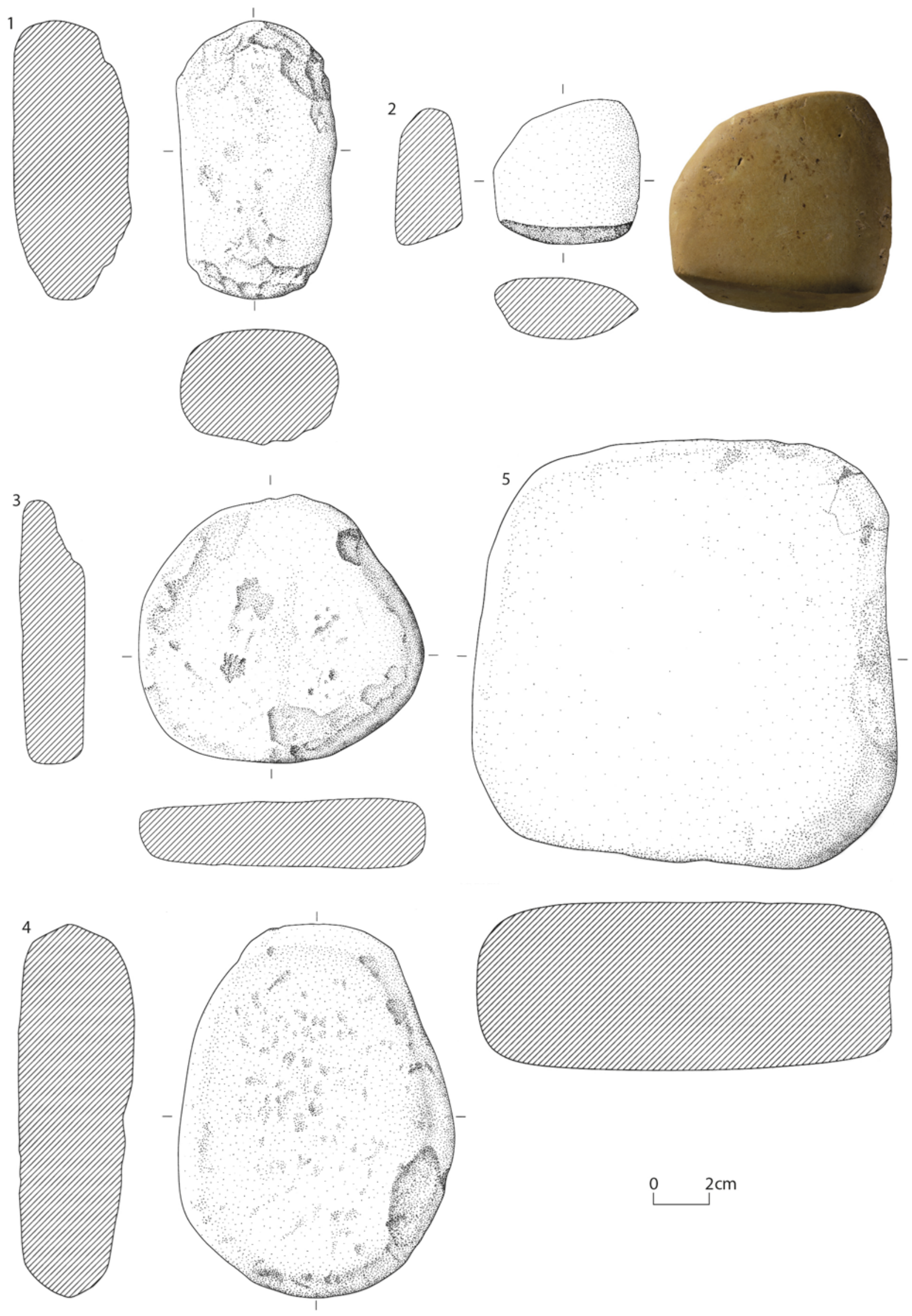

FIG. 16 Montum de Baixo. Instrumentos bujardados: 1 - percutor duplo (MBM.1060); 2 - polidor sobre seixo (MBM.1097); 3 - mó manual, elemento movente duplo discoidal (MBM.1067); 4 - mó manual, elemento movente (MBM.1078); 5 - mó manual, elemento movente duplo (MBM.1139). Desenhos de Ana Castela. 
"celeiro" do grupo e a importante função moageira em outro habitat de ocupação mais estável. No entanto, pode também colocar-se a hipótese desta função se encontrar em uma outra área não escavada de Montum de Baixo. Dos elementos de mó, todos de grauvaque, apenas os moventes se encontram completos, sobre seixos rolados; dois pertencem ao tipo discoidal, mais adelgaçado; o elemento de maior eficiência, de contorno subquadrangular (MBM.1078), possui peso ligeiramente superior a $3 \mathrm{~kg}$ e associava-se a estrutura de combustão; como sucede em outros povoados desta cronologia, o fogo doméstico constituía-se como polo organizador de muitas das actividades do grupo, quer na Costa do Sudoeste (p. ex. Gaspeia), quer na Estremadura (p. ex. Carrascal).

\section{CERÂMICA}

Procedemos ao exame de 58 fragmentos de recipientes cerâmicos providos de atributos diagnosticáveis (morfologia, decoração, elementos de preensão) que integravam um universo de 203 fragmentos $(\mathrm{NMI}=21)$ provenientes de 330 quadrados do S.16 (o menos afectado pelas lavouras) e 29 exumados dos Ss. 17 (Qs. C2, C8, C16, C18 e F14), 26 (Qs. B2, C2, S4), 35 (Q. Q20), 36 (Qs. A18, D19, F8, F10, F19 e G18), 44 (Qs, B14, H18 e N13) e 54 (Qs. C1, C18, D9, G7, 16, L3 e N10), os únicos quadrados desses sectores que conservavam a C.2.

No S.16, o número de fragmentos (203, NMI=21), exumado de $330 \mathrm{~m}^{2}$, ou seja $0,6 / \mathrm{m}^{2}, 3,5 / \mathrm{m}^{3}$, é francamente baixo; a sua dispersão é muito acentuada, notando-se somente uma ténue concentração nos Qs. J-N/5-10 (Fig. 17), e o seu estado de fragmentação, muito elevado: 193 fragmentos $>25</=50 \mathrm{~mm}$ e somente $30>50</=100 \mathrm{~mm}$. Isto sugere ocupação ou ocupações recorrentes de curta duração talvez dedicadas a actividade especializada.

Considerando apenas os fragmentos com elementos tipologicamente significativos, em número de 58, atenderemos, na sua análise, à pasta, morfologia, cor/cozedura, tratamento das superfícies, decoração e preensão.

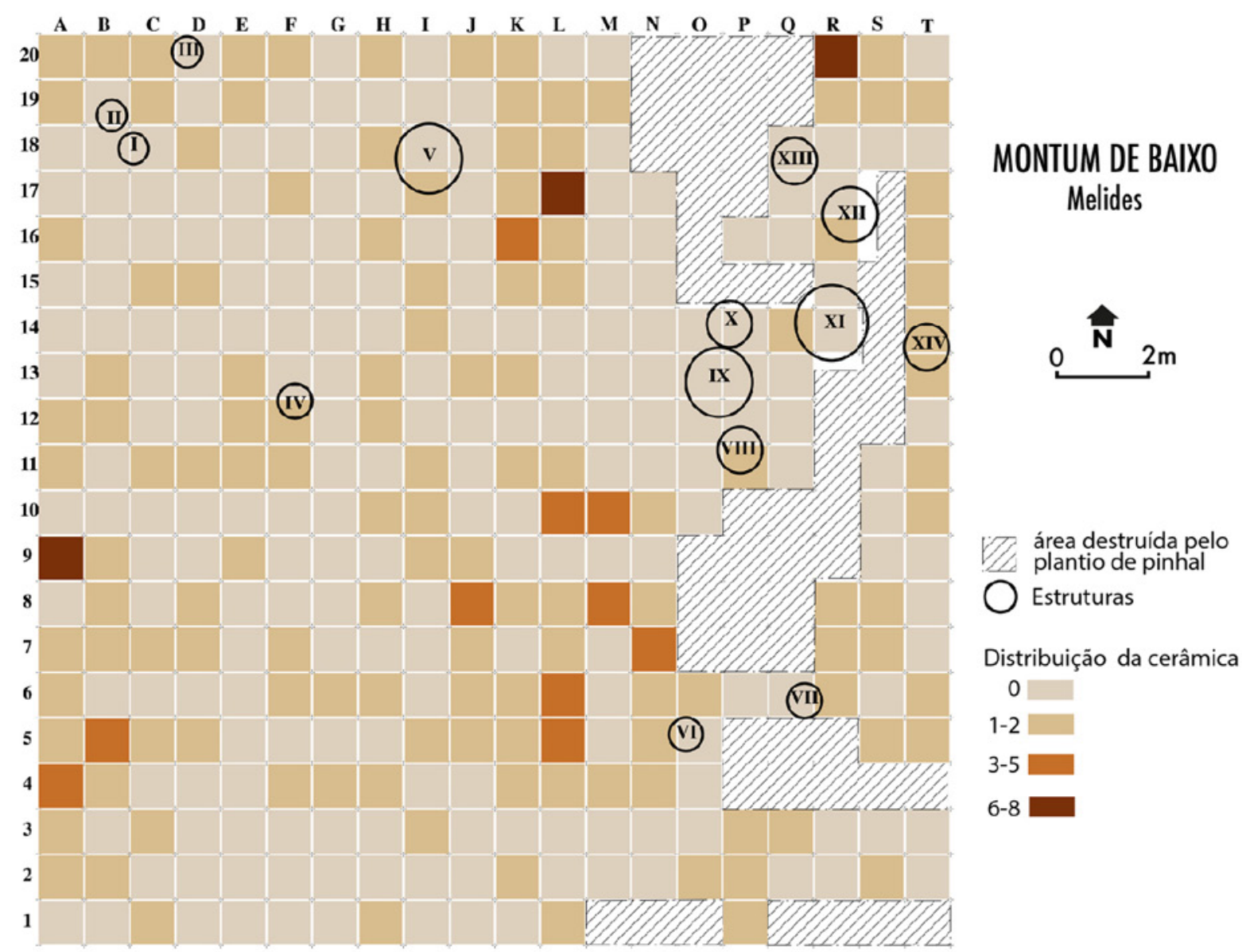

FIG. 17 Montum de Baixo. Sector 16. Distribuição da cerâmica. 
A pasta foi objecto de análise macroscópica, o que permitiu somente uma aproximação à textura (compacidade, frequência e dimensão dos e.n.p.: fina, com escassos e.n.p. $>0,5 \mathrm{~mm}$; média, com numerosos e.n.p. $>0,5 \mathrm{~mm}$ e $<1 \mathrm{~mm}$; grosseira, com abundantes e.n.p. $>$ $1 \mathrm{~mm}$. Estabelecemos os seguintes grupos: A1 - pasta fina e compacta; A2 - pasta fina e pouco compacta; B1 - pasta média e compacta; B2 - pasta média e pouco compacta; C1 - pasta grosseira e compacta; C2 - pasta grosseira e pouco compacta.

Verificou-se (Quadro 15) um relativo equilíbrio entre pastas compactas e pouco compactas, com ligeira dominância das primeiras. Nas taças em calote, as duas texturas possuem pesos semelhantes; nos esferoidais/ ovoides existe um ligeiro predomínio das pastas compactas. Por outro lado, as pastas finas e médias (e.n.p. raramente ultrapassando $1 \mathrm{~mm}$ ) são francamente maioritárias, com 44 exs., contra 14 de grosseiras (abundantes e.n.p. superiores a $1 \mathrm{~mm}$ ); estas últimas estão melhor representadas nos esferoidais/ovoides. Nota-se, de um modo geral, um fabrico cuidado e controlado.

QUADRO 15 MONTUM DE BAIXO. CERÂMICA.

FORMA/PASTA

\begin{tabular}{ccccc} 
& \multicolumn{3}{c}{ FORMA } & \\
\cline { 2 - 4 } PASTA & \multicolumn{3}{c}{ TOTAL } \\
\cline { 2 - 4 } A1 & 3 & 2 & 6 & 11 \\
\hline A2 & 3 & 4 & - & 7 \\
\hline B1 & 4 & 8 & 5 & 17 \\
\hline B2 & 3 & 1 & 5 & 9 \\
\hline C1 & 1 & 1 & 2 & 4 \\
\hline C2 & 1 & 4 & 5 & 10 \\
\hline Total & 15 & 20 & 23 & 58 \\
\hline
\end{tabular}

Pasta: A1 - fina e compacta; A2 - fina e friável; B1 - média e compacta; B2 - média e friável; C1 - grosseira e compacta; C2 - grosseira e friável. Forma: 1 - taça em calote; 2 - esferoidal/ovoide; 3 - indeterminada.

As formas distribuem-se por dois grandes grupos (Quadro 15), como é comum no Neolítico antigo regional: taças em calote e esferoidais/ovoides. A última destas formas é dominante. Em ambos os grupos o bordo é simples e desenvolve-se na continuação da parede do bojo, sem inflexões, com a excepção de um esferoidal/ovoide que possui o bordo ligeiramente extrovertido. Nas taças em calote, o bordo (e a parede do bojo) é inclinado para o exterior ou subvertical; nos esferoidais/ovoides o bordo é, em geral, subvertical ou inclinado, quase sempre ligeiramente, para o interior.

$\mathrm{O}$ diâmetro interno da boca varia nas taças entre $120 \mathrm{~mm}$ e $280 \mathrm{~mm}$ (média de $177 \mathrm{~mm}$ ) e nos esferoidais/ovoides, entre $90 \mathrm{~mm}$ e $290 \mathrm{~mm}$ (média de $146 \mathrm{~mm}$ ). A espessura está compreendida, nas taças, entre $7 \mathrm{~mm}$ e $15 \mathrm{~mm}$ (média de $9 \mathrm{~mm}$ ), e nos esferoidais/ovoides, entre $6 \mathrm{~mm}$ e $20 \mathrm{~mm}$ (média de $10 \mathrm{~mm}$ ).

Chamamos a atenção para o exemplar MBM.622 (Fig. 21, n. ${ }^{\circ}$ 25), um esferoidal/ovoide a tender para cilindroide, sem dúvida um grande contentor de armazenagem, com 290 mm de diâmetro interno na boca, e bojo com $20 \mathrm{~mm}$ de espessura. Era provido de pequena asa adjacente ao bordo e de asa vertical no bojo, que arrancava, superiormente, de cordão horizontal.

Os recipientes cerâmicos de Montum de Baixo foram cozidos (Quadro 16), predominantemente, em ambiente redutor com arrefecimento oxidante, pois são muito frequentes os exemplares com núcleo anegrado e superfícies avermelhadas (cor 3.3). A cor 2, anegrada (núcleo e superfícies), indicando cozedura totalmente redutora, foi registada, sobretudo, nas taças em calote. A cozedura totalmente oxidante (núcleo e superfícies avermelhadas, cor 1) é a menos frequente.

QUADRO 16 MONTUM DE BAIXO. CERÂMICA. COR/COZEDURA DA CERÂMICA

\begin{tabular}{ccccccccc} 
& \multicolumn{7}{c}{ COR / COZEDURA } & TOTAL \\
\cline { 2 - 6 } FORMA & 1 & 2 & 3.1 & 3.2 & 3.3 & 3.4 & \\
\hline 1 & 2 & 6 & 2 & - & 5 & - & 15 \\
\hline 2 & - & 4 & 4 & 2 & 10 & - & 20 \\
\hline 3 & 5 & 4 & 4 & 1 & 8 & 1 & 23 \\
\hline Total & 7 & 14 & 10 & 3 & 23 & 1 & 58 \\
\hline
\end{tabular}

Cor/cozedura: 1- totalmente avermelhada; 2 - totalmente anegrada; 3.1 - zona superficial externa avermelhada

e zona superficial interna anegrada; 3.2 - zona superficial externa anegrada e zona superficial interna avermelhada;

3.3 - núcleo anegrado e zonas superficiais avermelhadas; 3.4 - núcleo avermelhado e zonas superficiais anegradas. 

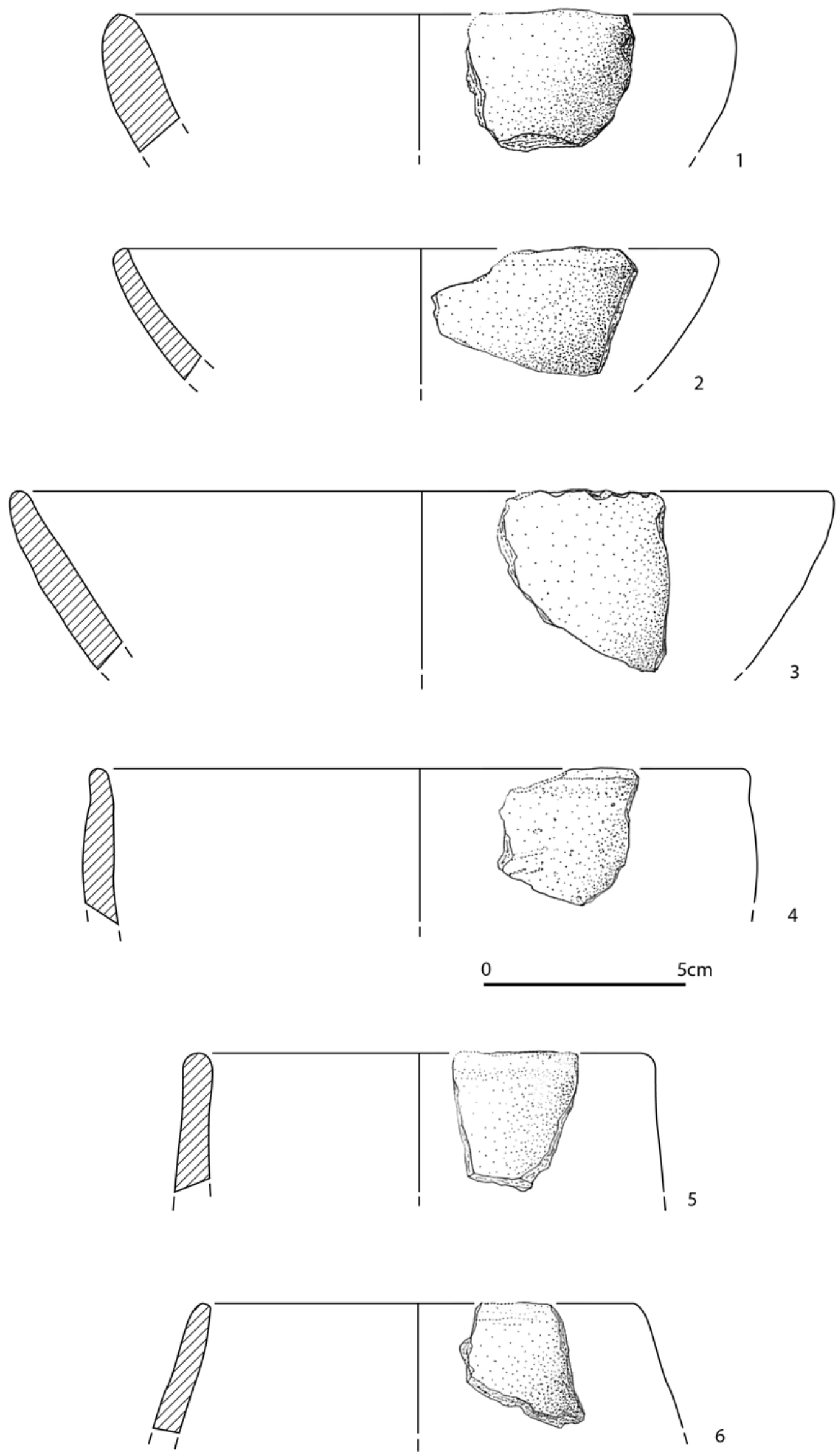

FIG. 18 Montum de Baixo. Cerâmica lisa. 1 - MBM.1633 (S.54, Q.D9, C.2); 2 - MBM.568 (S.17, Q.C8, C.2); 3 - MBM. 1614 (S.17, Q.F14, C.2); 4 - MBM.556 (S.16, Q.L17, C.2); 5 - MBM.2286 (S.16, Q.L5, C.2); 6 - MBM.2019 (S.16, Q.K2, C.2). Desenhos de Teresa Rita Pereira. 

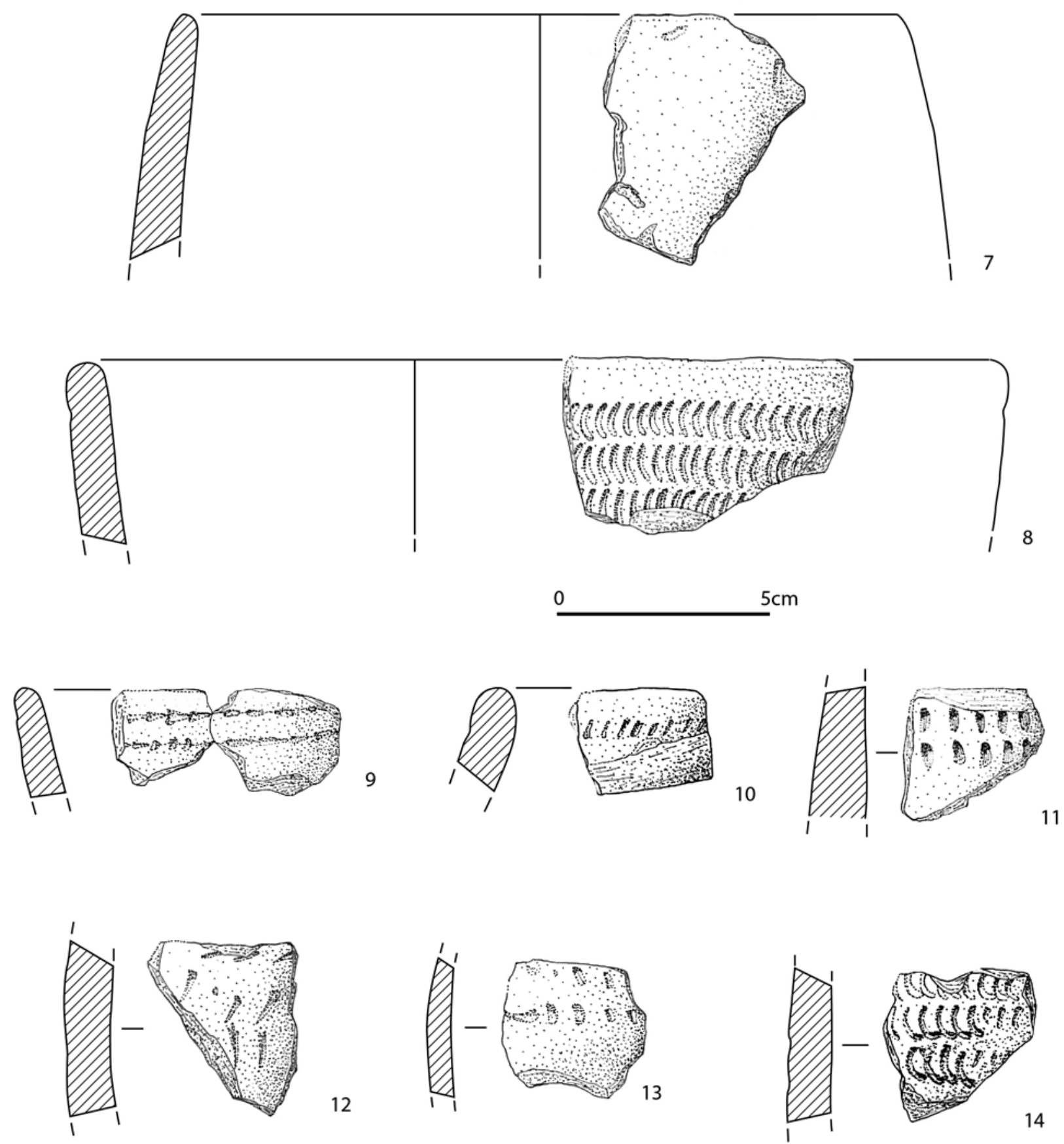

12
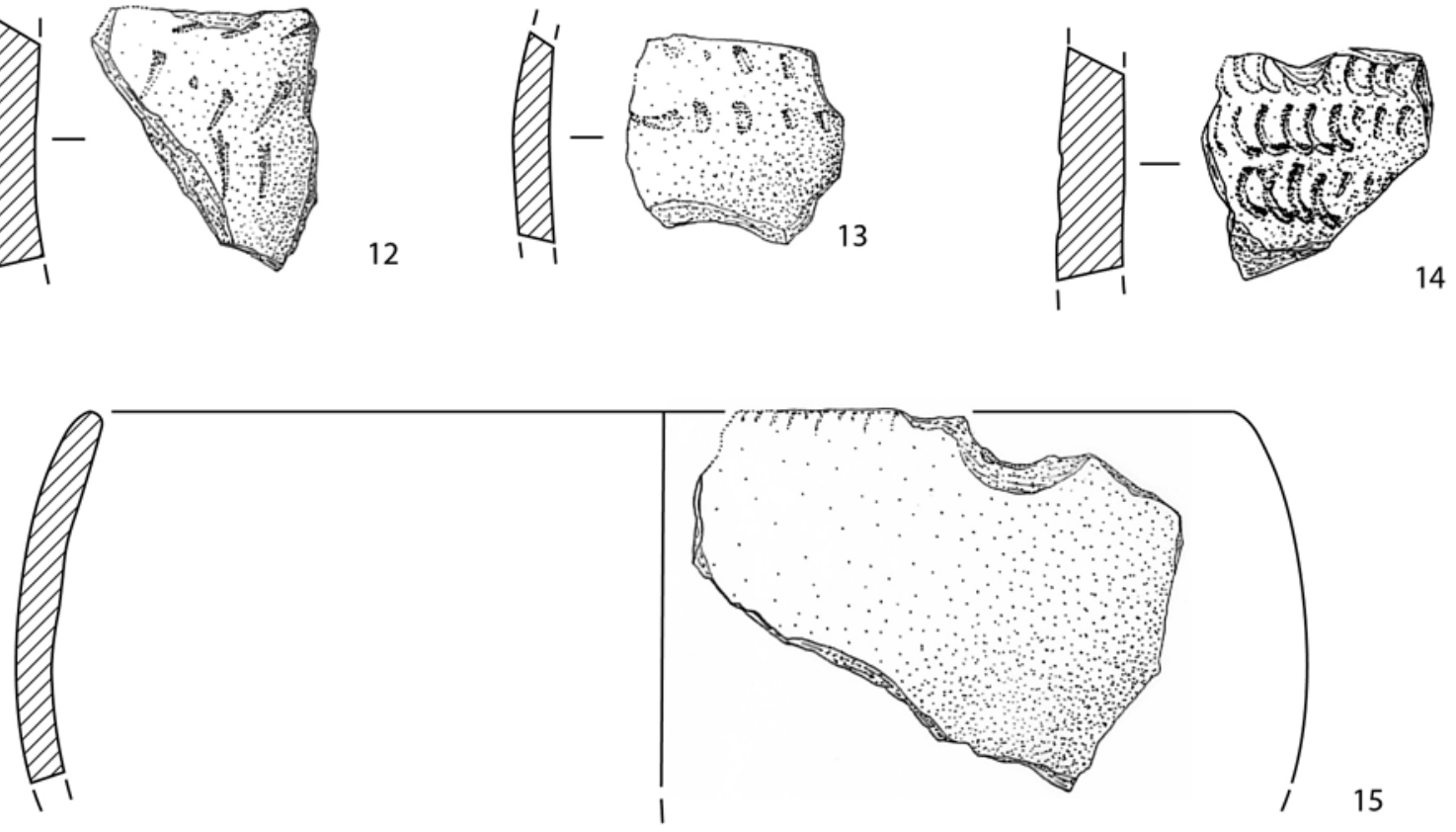

FIG. 19 Montum de Baixo. Cerâmica lisa (7), com decoração impressa (8-14) e incisa-bordo segmentado (15). 1 - MBM. 2288 (S.16, C.2); 8 - MBM.977 (S. 35, Q.Q20, C.2); 9 - MBM. 557 (S.16, Q.L7, C.2); 10 - MBM.68 (S. 54, Q.17, C.2); 11 - MBM.738 (S.16, Q.010, C.2); 12 - MBM.1729 (S.26, Q.B2, C.2); 13 - MBM.307 (S.17, Q.C10,C.2); 14 - MBM.1763 (S.54, Q.16, C.2); 15 - MBM.2138 (S.16, Q.13, C.2). Desenhos de Teresa Rita Pereira. 

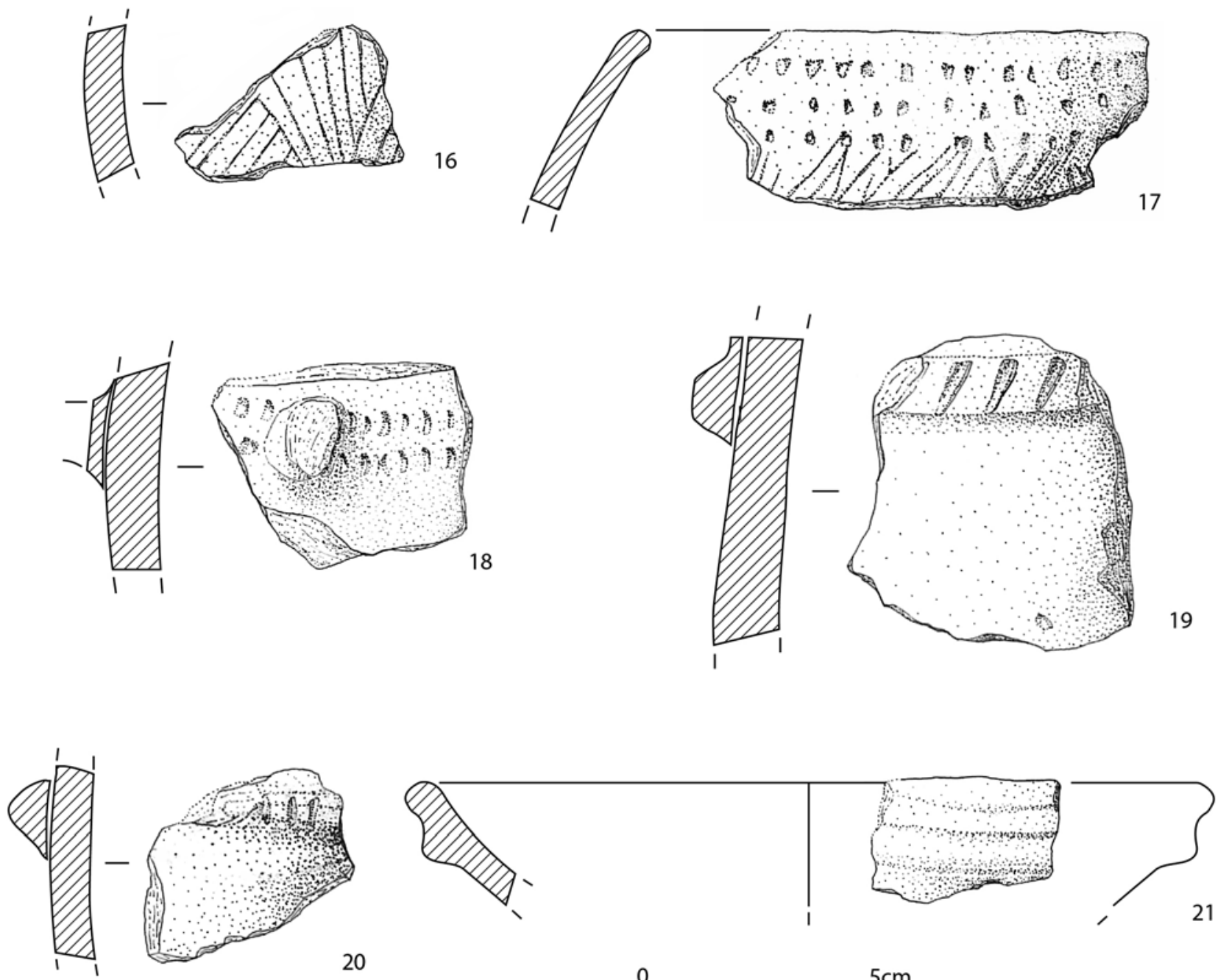

20
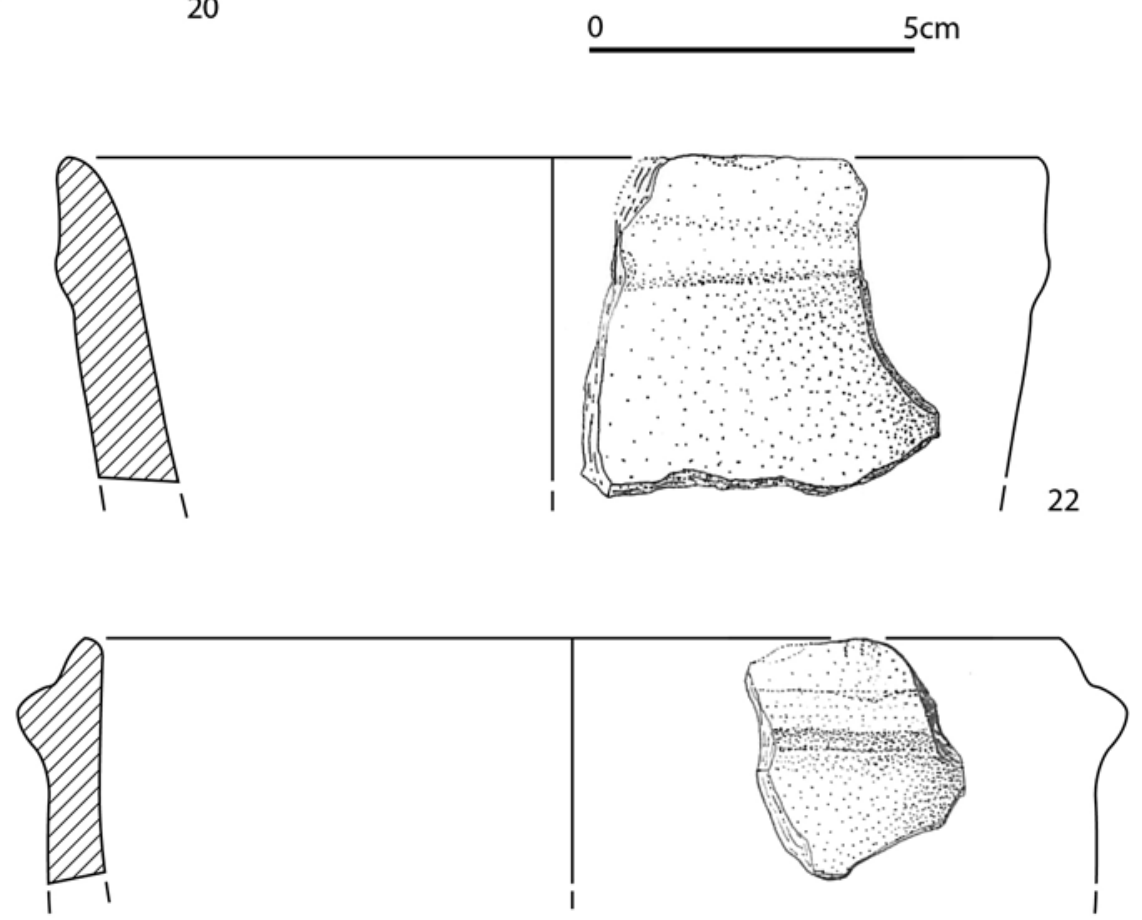

23

FIG. 20 Montum de Baixo. Cerâmica incisa (16), impressa+incisa (17), impressa+plástica (18-20) e plástica (21-23). 16 - MBM.1400 (S.16, Q.K17, C.2); 17 - MBM.624 (S.16, Q.L17, C.2); 18 - MBM.396 (S. 36, Q.D19, C.2); 19 - MBM. 101 (S.54, Q.F2, C.2); 20 - MBM.600 (S.54, Q.L3, C.2); 21 - MBM.298 (S.36, Q.F19, C.2); 22 - MBM.2283 (S.36, Q.A18, C.2); 23 - MBM.181 (S.16, Q.D9, C.2). Desenhos de Teresa Rita Pereira. 

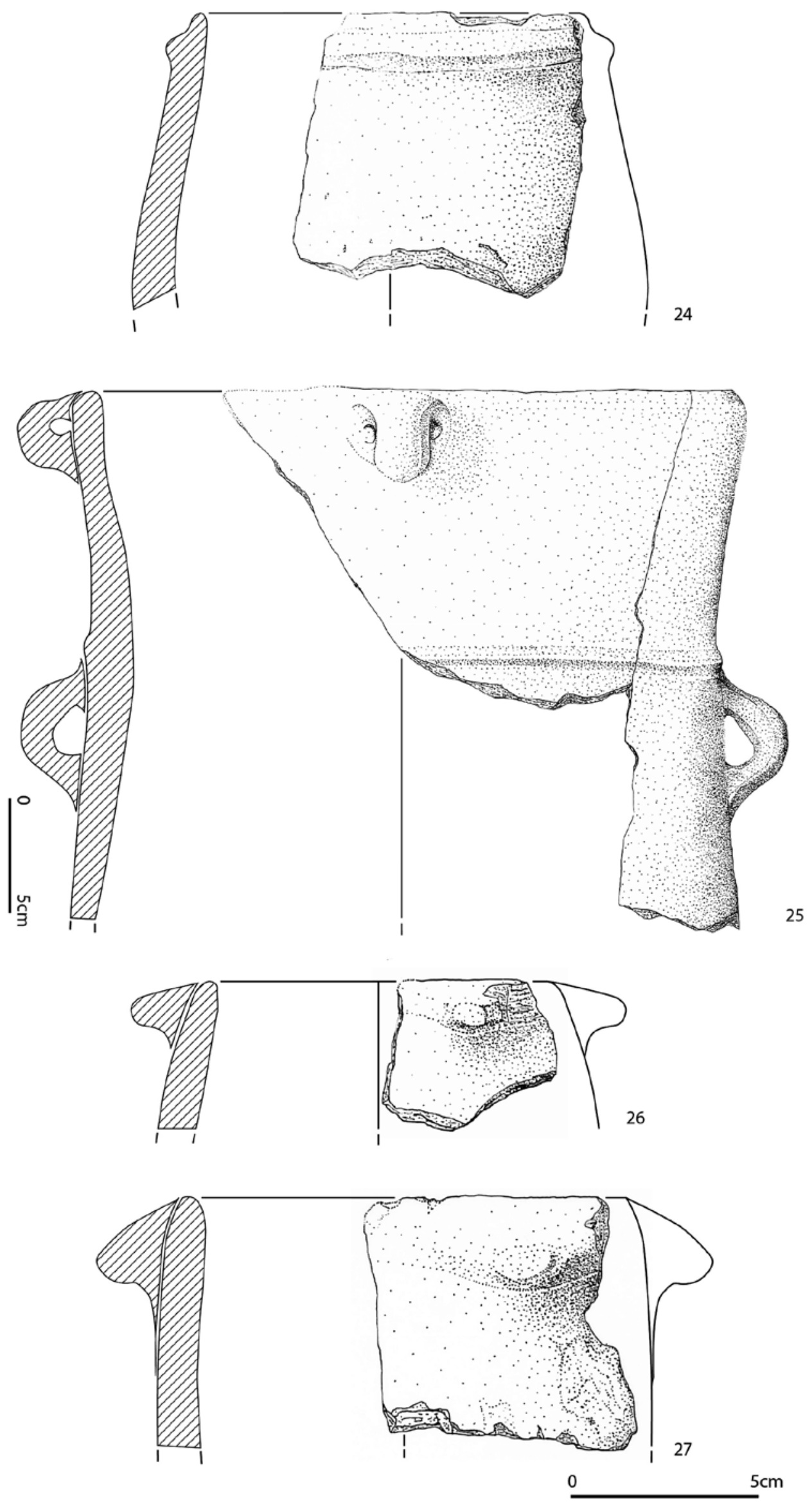

FIG. 21 Montum de Baixo. Cerâmica com decoração plástica. 24 - MBM.621 (S.16, Q.H8, C.2); 25 - MBM.622 (S.36, Q.F10, C.2); 26 - MBM.2287 (S.16, Q.N7, C.2); 27 - MBM.2295 (S. 16, Q.M8, C.2). Desenhos de Teresa Rita Pereira. 
Nas superfícies externas (Quadro 17) predominam as alisadas finas, quer nas taças em calote quer nos esferoidais/ovoides, principalmente nas primeiras, seguidas, a certa distância, pelas alisadas. As superfícies internas apresentam-se nas taças em calote, em geral, alisadas finas, enquanto nos esferoidais/ovoides dominam as alisadas.

QUADRO 17 MONTUM DE BAIXO. CERÂMICA.

TRATAMENTO DAS SUPERFÍCIES

\begin{tabular}{cccccccccccccc} 
& & \multicolumn{3}{c}{ SUPERFICIE EXTERNA } & \multicolumn{4}{c}{ SUPERFICIE INTERNA } \\
\cline { 2 - 9 } FORMA & $\mathbf{2}$ & $\mathbf{3}$ & $\mathbf{4}$ & $\mathbf{6}$ & TOTAL & $\mathbf{2}$ & $\mathbf{3}$ & $\mathbf{4}$ & $\mathbf{6}$ & TOTAL \\
\hline $\mathbf{1}$ & 9 & 4 & - & 2 & 15 & 9 & 4 & - & 2 & 15 \\
\hline $\mathbf{2}$ & 11 & 9 & - & - & 20 & 5 & 12 & 1 & 2 & 20 \\
\hline $\mathbf{3}$ & 13 & 3 & 2 & 5 & 23 & 9 & 9 & 2 & 3 & 23 \\
\hline Total & $\mathbf{3 3}$ & $\mathbf{1 6}$ & $\mathbf{2}$ & $\mathbf{7}$ & $\mathbf{5 8}$ & $\mathbf{2 3}$ & $\mathbf{2 5}$ & $\mathbf{3}$ & $\mathbf{7}$ & $\mathbf{5 8}$ \\
\hline
\end{tabular}

Superfícies: 2 - alisada fina; 3 - alisada; 4 - alisada tosca; 6 - erodida.

Dos 58 fragmentos cerâmicos analisados, 26 não apresentavam decoração (Fig. 18); 32 exemplares possuíam decoração (15 com bordo e 17 pertencentes ao bojo). Se considerarmos somente o material cerâmico proveniente do S.16, ficaremos em presença de apenas 15 fragmentos decorados que, para a totalidade da cerâmica proveniente desse sector (203 fragmentos), representam uma frequência relativa de $7,3 \%$; tomando como referência o $\mathrm{NMI}(=21)$ obtido para o mesmo sector essa relação é de $47,6 \%$.

A análise seguinte atenderá à totalidade dos fragmentos decorados (32 exemplares) provenientes, pois, quer do S.16 quer dos restantes sectores intervencionados (Figs. 19-21).
A decoração ocorre principalmente nos esferoidais/ovoides. A técnica da incisão é a pior representada, sendo suplantada pela plástica (inclui mamilos) e pela impressa (Quadro 18).

A decoração plástica é constituída por cordões horizontais lisos (6 exs.: 5 em esferoidais/ovoides e 1 em taça em calote) ou decorados por impressões (4 exs. em esferoidais/ovoides, sendo 3 segmentados e 1 decorado por espiga). Os cordões ocorrem sobretudo em esferoidais/ovoides de grande capacidade.

Tal como procedemos em relação à cerâmica da Gaspeia (Tavares da Silva - Soares 2020a; 2020b), incluímos os mamilos na decoração plástica, ainda que estes possam ter funcionado também como elementos de preensão. Foram registados 5 exemplares (piramidais, cónicos, hemisféricos): 4 em esferoidais/ovoides (quer fazendo corpo com o bordo quer inseridos no bojo), e 1 em recipiente de forma indeterminada.

A forma das impressões revela diversidade pouco acentuada: dominam as fusiformes (9 registos) seguidas pelos crescentes ( 6 registos). Relativamente mal representadas, surgem as triangulares (2 registos) e a pontuação ovalada (1 registo). A técnica boquique está presente em uma taça em calote e em um recipiente de forma indeterminada.

A organização em composições decorativas (Quadro 19) segue e completa o inventário que iniciámos ao estudar a cerâmica do Casal da Cerca (Tavares da Silva - Soares 2014) e prosseguido com o estudo da Gaspeia (Tavares da Silva - Soares 2020a; 2020b).

Relativamente a Montum de Baixo obtivemos 14 composições decorativas ( 6 elementares e 8 duplas); considerámos a totalidade dos fragmentos decorados (com e sem bordo):

QUADRO 18 MONTUM DE BAIXO. CERÂMICA. TÉCNICAS DECORATIVAS

\begin{tabular}{ccccccc} 
& \multicolumn{7}{c}{ TÉCNICAS DECORATIVAS } \\
FORMA & IMPRESSA & INCISA & PLÁSTICA & IMPRESSA + INCISA & IMPRESSA + PLÁSTICA \\
\cline { 2 - 7 } & 3 & - & 1 & - & - & 4 \\
\hline $\mathbf{1}$ & 1 & 2 & 7 & 1 & - & 11 \\
\hline $\mathbf{3}$ & 6 & 2 & 3 & 1 & 5 & 17 \\
\hline Total & 10 & 4 & 11 & 2 & 5 & 32 \\
\hline
\end{tabular}


QUADRO 19 MONTUM DE BAIXO. CERÂMICA. COMPOSIÇÕES DECORATIVAS

\begin{tabular}{|c|c|c|c|c|c|c|c|c|c|c|c|c|c|c|c|}
\hline \multirow{2}{*}{ FORMA } & \multicolumn{14}{|c|}{ COMPOSIÇÕES DECORATIVAS } & \multirow{2}{*}{ TOTAL } \\
\hline & A1 & A3 & A7 & B20 & B21 & B22 & B23 & C1 & C3 & D2 & D11 & E2 & E4 & E5 & \\
\hline 1 & - & 2 & - & - & - & - & - & 1 & - & - & - & - & - & - & 3 \\
\hline 2 & 1 & - & - & 1 & - & 1 & - & 5 & 3 & - & 1 & - & - & - & 12 \\
\hline 3 & - & 5 & 2 & - & 1 & - & 1 & - & 2 & 1 & - & 3 & 1 & 1 & 17 \\
\hline Total & 1 & 7 & 2 & 1 & 1 & 1 & 1 & 6 & 5 & 1 & 1 & 3 & 1 & 1 & 32 \\
\hline
\end{tabular}

\section{A-Decoração impressa}

A1 - Fiada rectilínea e horizontal (1 esferoidal/ovoide).

A3 - Série de fiadas rectilíneas horizontais, por vezes descontínuas e delimitando métopas (7 exs.: 2 taças em calote, uma delas com decoração boquique; 5 exs. de forma indeterminada).

A7 - Fiada horizontal de impressões em espiga (2 exs. de forma indeterminada).

\section{$B$ - Decoração incisa}

$B 20$ - Série de traços verticais (1 esferoidal/ovoide de lábio denteado).

B21 - Série horizontal de traços verticais sobre traço horizontal (1 ex. de forma indeterminada).

B22 - Duas séries horizontais de traços verticais separados por traço horizontal (1 esferoidal/ovoide).

B23 - Encanastrado (1 ex. de forma indeterminada).

\section{C-Decoração plástica}

C1 - Cordão horizontal liso (6 exs.: 1 taça em calote e 5 esferoidais/ovoides).

C3 - Mamilos (5 exs.: 3 esferoidais/ovoides e 2 de forma indeterminada).

\section{D-Decoração impressa + incisa}

D2 - Banda limitada por linhas incisas e paralelas e preenchida por impressões (1 ex. de forma indeterminada)

D11 - Série de fiadas rectilíneas e horizontais de impressões sobre faixa de "encanastrado" inciso (1 esferoidal/ovoide)

E-Decoração impressa + plástica

E2 - Cordão horizontal segmentado por impressões (3 exs. de forma indeterminada).

E4 - Série de fiadas horizontais de impressões interrompidas por mamilo (1 ex. de forma indeterminada).
E5 - Cordão horizontal decorado por espiga impressa (1 ex. de forma indeterminada).

A cerâmica de Montum de Baixo apresenta o menor número de composições decorativas relativamente à das duas jazidas anteriormente referidas o que pode ser devido à reduzida dimensão da amostra.

As composições B20, B21, B22, B23 e D1 1 são exclusivas de Montum de Baixo; esta jazida partilha com o Casal da Cerca as composições A1, A3, A7, C1, C3, D2 e E2 e com a Gaspeia, as composições A1, A3, C3, D2, E2, E4 e E5. Os três arqueossítios que temos vindo a referir possuem, pois, em comum as composições $A 1, A 3, C 3$, D2 e E2.

Ao considerarmos os mamilos como elementos decorativos, os elementos de preensão ficaram limitados a asas. Só duas destas se conservavam completas, fazendo parte do grande contentor da Fig. 21: uma, globular e vertical $(34 \times 30 \mathrm{~mm})$ é adjacente ao bordo, com perfuração horizontal ( $5 \mathrm{~mm}$ de diâmetro); a outra insere-se no bojo, imediatamente abaixo de cordão horizontal, é também vertical $(50 \times 45 \mathrm{~mm})$ e possui perfuração ovalada $(13 \times 24 \mathrm{~mm})$.

Foram ainda exumados 7 fragmentos de asas pertencentes a recipientes de formas indeterminadas: 4 das extremidades de inserção, cuja largura máxima varia entre 30 e $70 \mathrm{~mm}$ e 3 fragmentos mesiais (largura entre 27 e $33 \mathrm{~mm}$ ).

\section{CONSIDERAÇÕES FINAIS}

Privilegiámos deliberadamente uma abordagem virada para o estudo arqueográfico da informação empírica de um sítio até agora quase inédito, deixando a discussão teórica para outras leituras. 
As más condições de jazida de Montum de Baixo devidas sobretudo a actividades agrícolas, mas também a intensa lixiviação, impediram a conservação de matéria orgânica e provocaram a dispersão de materiais arqueológicos e a afectação de estruturas. Apesar destas limitações foi possível identificar um conjunto de estruturas domésticas de tipologia variada (fossas de combustão, empedrados, cinzeiros) (Figs. 5-7), com destaque para as lareiras em fossa preenchidas por aparelho argiloso destinado à concentração e conservação calorífica (tipo B), que não havíamos ainda identificado no Neolítico regional. De um modo geral, é possível afirmar que as lareiras polarizaram diversas actividades, nomeadamente a produção de utensilagem lítica (Fig. 8) além das operações de culinária (Fig. 17). A presença de estruturas de rejeição (tipo $F$ ) é reveladora de preocupações e comportamentos sociais de curadoria sanitária do espaço habitado, como tem sido observado em outros sítios coevos da região.

O padrão locativo de Montum de Baixo obedece à estratégia mais comum de implantação do habitat durante o Neolítico antigo: áreas planas, abertas, arenosas, por conseguinte pouco insalubres e propícias à agricultura de sacho, e nas proximidades de aquíferos. Ao mesmo tempo, este sítio beneficia de um enquadramento geológico de extraordinária diversidade, com formações do Devónico, Carbónico, Jurássico, Miocénico e Plio-Plistocénico, de fácil acessibilidade a qualificados recursos abióticos como sílex, matéria-prima escassa na generalidade da Costa Sudoeste.

A indústria de pedra lascada possui apreciável homogeneidade em toda a área escavada; em conformidade com a abundância local de matérias-primas siliciosas micro e criptocristalinas, o subsistema expedito é vestigial. A tecnologia de debitagem, com elevado recurso a aquecimento prévio da matéria-prima (c. 19\%, Quadro 6), focou-se na produção lamelar, excedentária face às necessidades de consumo do grupo, de acordo com a apreciável diferença quantitativa entre lamelas brutas e lamelas transformadas, o que nos leva a considerar a hipótese de ter sido a actividade artesanal de talhe lítico uma componente significativa da economia de Montum de Baixo, alimentando redes de troca. Ao contrário da abundância de lamelas, as lâminas são sempre escassas, quer não transformadas $(3,6 \%)$, quer transformadas pelo retoque $(2,6 \%)$, ou pelo uso (5,8\%), o que confere ao conjunto carácter microlítico. A matriz tipológica vai-se distanciando da tradição mesolítica, mas está ainda aquém da do Neolítico médio; a técnica do microburil encontra-se em declínio e os elementos de projéctil, constituídos quase exclusivamente por segmentos, algumas pontas de dorso e flechas transversais, apontam também para cronologia do Neolítico antigo.

A indústria de pedra bujardada utilizou seixos rolados de grauvaque e de quartzito, recolhidos provavelmente na Ribeira de Melides, sendo a escassez de elementos de mó ( 3 moventes e 2 dormentes em c. $1500 \mathrm{~m}^{2}$ escavados) e de recipientes cerâmicos $\left(0,6 / \mathrm{m}^{2}\right)$ aspectos relevantes para caracterizar um modo de ocupação não permanente. $A$ ideia consensual de que a práctica agrícola obriga a permanência ao longo de todo o ano, também deve ser relativizada. Quando escavámos o dólmen da Palhota, observámos que o casal de agricultores proprietário do terreno vivia em Santiago do Cacém a maior parte do ano e apenas residia no pequeno monte da Palhota nos períodos de cultivo e de colheita. É claro que não podemos transpor a realidade subactual para um passado tão longínquo, mas o referido anacronismo ajuda-nos a incluir a diversidade de soluções nas interpretações propostas. A escassez de cerâmica aponta para estabelecimento temporário, mas não inibe a hipótese de práctica agrícola. $\mathrm{O}$ transporte de cereais para os sítios de consumo e/ou armazenamento poderia ser vantajosamente realizado em cestos.

A indústria de pedra polida revela intensa utilização e foi manufacturada maioritariamente em anfibolito, o que implica alargar a esfera de interação de Montum de Baixo a uma geografia de escala regional $30-50 \mathrm{~km}$ de distância), mas foi o achado de uma enxó miniaturizada de fibrolite, certamente votiva, que viria quebrar qualquer pressuposto de isolamento deste grupo nos contrafortes da Serra de Grândola. Com efeito, este artefacto permite integrar o sítio nas redes de troca de escala transregional e também confirmar que estas peças miniaturizadas de fibrolite, muitas vezes descontextualizadas (p. ex. a enxó de Alvalade, Soares Fonseca - Duarte 2020: 252) surgem em contextos do Neolítico antigo evolucionado, como p. ex. na Moita da Ladra (Cardoso - Caninas 2010) e no povoado da Encosta de Sant'Ana (Leitão - Cardoso - Martins 2021: Fig. 83), datado por radiocarbono a partir de ossos de Cervus elaphus e Ovis/Capra (AMS Beta-546876 e Beta-546877) entre cerca de 5100 e 4900 cal BC. 
A análise da cerâmica confirma e reforça a proposta cronológica indicada pela indústria lítica. Predominam as formas ovoides, e a decoração insere-se no rico e variado universo da olaria do Neolítico antigo evolucionado, quer da Costa Sudoeste (Soares 2020), quer da Estremadura (Sousa 2016/2017; Cardoso 2021), de que destacamos a decoração de tipo boquique, a impressão do motivo espiga, mais ou menos estilizado, padrões incisos e decoração plástica.

No que se refere à decoração plástica, Montum de Baixo oferece um conjunto variado de taças e recipientes ovoides decorados por cordões abaixo do bordo, com paralelos próximos no povoado do Carrascal (Cardoso - Tavares da Silva - Soares 2008; Cardoso 2021), datado de 5300 a 5000 cal BC, 2 sigma, ou em Valada do Mato (Diniz 2007), sítio datado de 5040-4990 cal BC, 2 sigma (a datação mais fiável, visto as restantes terem sido obtidas a partir de ossos carbonizados). O grande contentor de armazenagem, subcilíndrico, de Montum de Baixo (MBM. 622, Fig. 21, n.25), decorado por cordão liso no bojo e por asinhas quer no bordo quer junto do cordão, possui paralelos em S. Pedro de Canaferrim (Simões 1999: Figs. 13 e 19), mas também no sítio da Cabranosa (Carvalho 2008: Est. 56, n. 1), considerado da fase inicial do Neolítico antigo. Esta analogia estilística, associada ao predomínio da técnica de impressão e a limitado leque de matrizes usados em Montum de Baixo poderá interpretar-se como um posicionamento cronológico dos inícios do Neolítico antigo evolucionado. Por agora, propomos a sua datação entre o último quartel do $60^{\circ}$ milénio cal $B C$ e os primeiros séculos do milénio seguinte (Soares 2020: Quadro 2).

\section{Bibliografia}

CARDOSO, J. L. (2021) - A estação do neolítico antigo do Carrascal (Oeiras): resultados das escavações realizadas. Estudos Arqueológicos de Oeiras. 22, 9-96.

CARDOSO, J. L. - CANINAS, J. C. (2010) - Moita da Ladra (Vila Franca de Xira). Resultados preliminares da escavação integral de um povoado calcolítico muralhado. In GONÇALVES, V. S. - SOUSA, A. C. (eds.), Transformação e Mudança no centro e sul de Portugal: o 4. ${ }^{\circ}$ e o.$^{\circ}$ milénios a.n.e.. Colóquio Internacional (Cascais, 2005). Cascais, 65-95.

CARDOSO, J. L. - TAVARES DA SILVA, C. - SOARES, J. (2008) A ocupação do Neolítico antigo do povoado do Carrascal (Leceia, Oeiras). Estudos Arqueológicos de Oeiras (Homenagem a O. da Veiga Ferreira). 16, 247-267.

CARVALHO, A. F. (2008) - A neolitização do Portugal meridional. Os exemplos do Maciço Calcário estremenho e do Algarve occidental (Promontoria Monográfica 12). Faro.
DIAS, R. P. (coord.) - OLIVEIRA J. T. - LEAL, J. - ROMÃO, J. INVERNO, C. -MANUPPELLA, G. - MACHADO, S. - RODRIGUES, A. - BARTOLOMEU, A. - PAIS, J. -RESSURREIÇÃO, R. - MATOS, J. - MIDÕES, C. - MATIAS, J. - TERESO, S. - CARVALHO, C. - CHAINHO, F. - PEREIRA, P. - LAMBERTO, V. - LEGOINHA, P. - ALVES, P. (2011) - Carta Geológica de Portugal. Folha 42A-Grândola. LNEG Lisboa.

DINIZ, M. (2007) - O sítio da Valada do Mato (Évora). Aspectos da neolitização no interior Sul de Portugal (Trabalhos de Arqueologia, 48). Lisboa.

FERREIRA, O. da V. - ZBYSZEWSKI, G. - LEITÃO, M. - NORTH, C. T. - SOUSA, H. R. de (1975) - Le Monument mégalithique de Pedra Branca auprès de Montum (Melides). Comunicações dos Serviços Geológicos de Portugal. 59, 107-192.

LEITÃO, V. - CARDOSO, J. L. - MARTINS, F. (2021) - A estação do Neolítico antigo da Encosta de Sant'ana (Lisboa). Resultados das campanhas de escavação de 2004 a 2006. Estudos Arqueológicos de Oeiras. 28, 97-198.

MARCHAND, G. (2001) - Les traditions techniques du Mésolithique final dans le sud du Portugal: les industries lithiques des amas coquilliers de Várzea da Mó et de Cabeço do Rebolador (fouilles M. Heleno). Revista Portuguesa de Arqueologia. 4 (2), 47-110.

NOGUEIRA, A. M. (1927-1930) - Estação neolítica de Melides. Grutas sepulcrais. Comunicações dos Serviços Geológicos de Portugal. Tomo XVI, 41-54.

SILVA, A. M. - GIL, P. - SOARES, J. - TAVARES DA SILVA, C. (2016) - Short report: evidence of non-masticatory dental use in Bronze Age individuals exhumed from the Necropolis of Casas Velhas (Portugal). Bulletin of the International association for paleodontology. 10(1), 31-38.

SIMÕES, T. (1999) - O sítio neolítico de S. Pedro de Canaferrim, Sintra. Contribuições para o estudo da neolitização da Península de Lisboa (Trabalhos de Arqueologia 12). Lisboa.

SOARES, J. (1992) - Les territorialités produites sur le littoral Centre-Sud du Portugal au cours du processus de néolithisation. Setúbal Arqueológica. 9-10, 19-35.

SOARES, J. (1995) - Mesolítico-Neolítico na Costa Sudoeste: transformações e permanências. In JORGE, V. O. (coord.) - Actas do $1 .^{\circ}$ Congresso de Arqueologia Peninsular, VI (Trabalhos de Antropologia e Etnologia 35-2). Porto, 27-45.

SOARES, J. (1996a) - Para uma reconstrução do processo de neolitização em Portugal. Ophiussa. 0, 39-50.

SOARES, J. (1996b) - Na busca de um passado comum. O Neolítico e as origens do Megalitismo. Al-madan. 5 (II. ${ }^{\text {a S.) }}$, 37-45.

SOARES, J. (1997) - A transição para as formações sociais neolíticas na Costa Sudoeste portuguesa. In RODRÍGUEZ CASAL, A. (ed.) - O Neolítico Atlântico e as Orixes do Megalitismo (Actas do Colóquio Internacional). Santiago de Compostela, 587-608.

SOARES, J. (2020) - Neolitização do Sudoeste Português: preexistências e inovação. In TAVARES DA SILVA, C. - SOARES, J. (coords.) - O sítio arqueológico da Gaspeia e a neolitização do território de Alvalade - Sado (Setúbal Arqueológica 19). Setúbal, 299-324.

SOARES, J. - FONSECA, P. - DUARTE, S. (2020) - As primeiras sociedades camponesas e os instrumentos de pedra polida e bujardada do território de Alvalade. In TAVARES DA SILVA, C. - SOARES, J. (coord.) - O sítio arqueológico da Gaspeia e a neolitização do território de Alvalade - Sado (Setúbal Arqueológica 19). Setúbal, 177-297. 
SOARES, J. - MAZZUCCO, N. - CLEMENTE-CONTE, I. (2016) The first farming communities in the Southwest European Coast: A traceological approach to the lithic assemblage of Vale Pincel I. Journal of Antropological Archaeology. 41, 246-262.

SOARES, J. - MAZZUCCO, N. - TAVARES DA SILVA, C. (2017) - Marine adaptations in the Late Mesolithic of the Portuguese southwest coast: use-wear analysis of the lithic industry of Vale Marim I. Revista Portuguesa de Arqueologia. 20, 31-44.

SOARES, J. - MAZZUCCO, N. - TAVARES DA SILVA, C. (2021) The Late Mesolithic of the south-western coast of Portugal: the lithic industry of Vale Marim I in focus. In BORIĆ, D. - ANTONOVIĆ, D. - MIHAILOVIĆ, B. (eds.) - Foraging Assemblages, 1 (Proceedings of the Ninth International Conference on the Mesolithic in Europe, Belgrade, 2015). Belgrado, 301-307.

SOARES, J. - TAVARES DA SILVA, C. (1976-1977) - O monumento megalítico da Palhota (Santiago do Cacém). Setúbal Arqueológica. 2-3, 109-150.

SOARES, J. - TAVARES DA SILVA, C. (1979) - Alguns aspectos do Neolítico antigo do Alentejo Litoral. In Actas da I Mesa Redonda sobre o Neolítico e o Calcolítico em Portugal. Portugal (Trabalhos do Grupo de Estudos Arqueológicos do Porto 3). Porto, 9-52.

SOARES, J. - TAVARES DA SILVA, C. (1993) - Na transição Plistocénico-Holocénico: marisqueio na Pedra do Patacho. Al-madan. 2 (S.2), 21-29.

SOARES, J. - TAVARES DA SILVA, C. (2000) - Protomegalitismo no Sul de Portugal: inauguração das paisagens megalíticas, In GONÇALVES, V. S. (ed.) - Muitas antas, pouca gente? Actas do I Colóquio Internacional sobre Megalitismo (Trabalhos de Arqueologia 16). Lisboa, 117-134.

SOARES, J. - TAVARES DA SILVA, C. (2003) - A transição para o Neolítico na Costa Sudoeste portuguesa. In GONÇALVES, V. (ed.) - Muita gente, poucas antas? Origens, espaços e contextos do Megalitismo. Actas do II Colóquio Internacional sobre Megalitismo. Lisboa, 45-56.

SOARES, J. - TAVARES DA SILVA, C. (2004) - Alterações ambientais e povoamento na transição Mesolítico-Neolítico na Costa Sudoeste. In TAVARES, A. A. - TAVARES, M. J. F. - CARDOSO, J. L. (eds.) - Evolução geohistórica do litoral português e fenómenos correlativos. Lisboa, 397-423.

SOARES, J. - TAVARES DA SILVA, C. (eds.) (2016) - Atlas do Sudoeste Português. Património Cultural (CIMAL e MAEDS - programa comunitário PROVERE). Grândola: CIMAL. http://www.atlas. cimal.pt/drupal/?q=en/node/70

SOARES, J. - TAVARES DA SILVA, C. (2018) - Living in the southwest Portuguese coast during the Late Mesolithic: The case study of Vale Marim I. Journal of Archaeological Science: Reports. 18, 1011-1025.

SOARES, J. - TAVARES DA SILVA, C. - CANILHO, M. H. (2005-2007) - Matérias-primas minerais e mobilidade logística no Mesolítico da Costa Sudoeste. Os sítios de Samouqueira I e Armação Nova. Musa. Museus, Arqueologia e Outros Patrimónios. 2, 47-62.

SOARES, J. - TAVARES DA SILVA, C. - GONZALEZ, A. (2004) Gaio: um sítio do Neolítico antigo do estuário do Tejo. In / Jornadas de História e Património Local. Moita, 37-59.

SOUSA, A. C. (2016/2017) - Os tempos do Neolítico na Região de Lisboa: o povoamento. Estudos Arqueológicos de Oeiras. $23,459-518$.
TAVARES DA SILVA, C. - SOARES, J. (1978) - Uma jazida do Bronze Final na Cerradinha (Lagoa de Santo André, Santiago do Cacém). Setúbal Arqueológica. 4, 71-115.

TAVARES DA SILVA, C. - SOARES, J. (1981) - Pré-história da Área de Sines. Lisboa.

TAVARES DA SILVA, C. - SOARES, J. (1982) - Des structures d'habitat du Neolithique ancien au Portugal. In Le Neolithique ancien mediterraneen. Actes du Colloque Internacional de Prehistoire (Archeologie en Languedoc n. ${ }^{\circ}$ special). Montpellier, 17-28.

TAVARES DA SILVA, C. - SOARES, J. (1983) - Contribuição para o estudo do Megalitismo do Alentejo Litoral. A sepultura do Marco Branco (Santiago do Cacém). O Arqueólogo Português. 1 (S. IV), 63-88.

TAVARES DA SILVA, C. - SOARES, J. (1987) - Les communautés du Néolithique Ancien dans le Sud du Portugal. In Prémières Communautés Paysannes en Méditerranée Occidentale (Actes du Colloque International du C.N.R.S., Montpellier, 1983). Paris, 663-671.

TAVARES DA SILVA, C. - SOARES, J. (1997) - Economias costeiras na Pré-história do Sudoeste Português. O concheiro de Montes de Baixo. Setúbal Arqueológica. 11-12, 69-108.

TAVARES DA SILVA, C. - SOARES, J. (2007) - Osmose cultural e neolitização na Préhistória europeia. A propósito da transição Mesolítico-Neolítico no Sul de Portugal. Estudos Arqueológicos de Oeiras. 15, 37-46.

TAVARES DA SILVA, C. - SOARES, J. (2014) - O habitat do Neolítico antigo do Casal da Cerca (Palmela). In II Encontro de Arqueologia da Arrábida. Homenagem a A. I. Marques da Costa (Setúbal Arqueológica 15). Setúbal, 61-104.

TAVARES DA SILVA, C. - SOARES, J. (2015) - Neolitização da costa sudoeste portuguesa. A cronologia de Vale Pincel I. In GONÇALVES, V. - DINIZ, M. - SOUSA, A. C. (eds.) - Actas do 5. ${ }^{\circ}$ Congresso do Neolítico Peninsular (Estudos \& Memórias 8). Lisboa, 645-659.

TAVARES DA SILVA, C. - SOARES, J. (coord.) (2020a) - O sítio arqueológico da Gaspeia e a neolitização do território de Alvalade - Sado (Setúbal Arqueológica 19). Setúbal.

TAVARES DA SILVA, C. - SOARES, J. (2020b) - Ocupação neolítica da Gaspeia. In TAVARES DA SILVA, C. - SOARES, J. (coords.) O sítio arqueológico da Gaspeia e a neolitização do território de Alvalade - Sado (Setúbal Arqueológica 19). Setúbal, 115-162.

TAVARES DA SILVA, C. - SOARES, J. - COELHO-SOARES, A. (2010) - Arqueologia de Chãos de Sines. Novos elementos sobre o povoamento pré-histórico. In Actas do 20 Encontro de História do Alentejo Litoral. Sines, 10-33.

TAVARES DA SILVA, C. - SOARES, J. - PENALVA, C. (1985) Para o estudo das comunidades neolíticas do Alentejo litoral: o concheiro do Medo Tojeiro. Arqueologia. 11, 5-15.

VALÉRIO, P. - ARAÚJO, M. F. - SOARES, A. M. M. - SOARES, J. - TAVARES DA SILVA, C. (2019) - Os metais das necrópoles de cistas de Casas Velhas (Melides) e da Provença (Sines). $O$ encontro de antigas e novas tecnologias no Bronze Pleno do Sudoeste. In J. SOARES, J. - PINTO, I. V. - TAVARES DA SILVA, C. (coords.) - Do Paleolítico ao Período Romano Republicano. Actas do IX Encontro do Sudoeste Peninsular (Setúbal Arqueológica 18). Setúbal, 89-96. 


\section{POLÍTICA EDITORIAL}

A Ophiussa - Revista do Centro de Arqueologia da Universidade de Lisboa foi iniciada sob a direcção de Victor S. Gonçalves em 1996, tendo sido editado o volume 0. O volume 1 (2017) é uma edição impressa e digital da UNIARQ - Centro de Arqueologia da Universidade de Lisboa.

O principal objectivo desta revista é a publicação e divulgação de trabalhos com manifesto interesse, qualidade e rigor científico sobre temas de Pré-História e Arqueologia, sobretudo do território europeu e da bacia do Mediterrâneo.

A Ophiussa - Revista do Centro de Arqueologia da Universidade de Lisboa publicará um volume anual. A partir de 2018, os artigos submetidos serão sujeitos a um processo de avaliação por parte de revisores externos (peer review). O período de submissão de trabalhos decorrerá sempre no primeiro trimestre e a edição ocorrerá no último trimestre de cada ano.

A revista divide-se em duas secções: artigos científicos e recensões bibliográficas. Excepcionalmente poderão ser aceites textos de carácter introdutório, no âmbito de homenagens ou divulgações específicas, que não serão submetidos à avaliação por pares. Isentas desta avaliação estão também as recensões bibliográficas.

Todas as submissões serão avaliadas, em primeira instância, pela Coordenação Editorial, no que respeita ao seu conteúdo formal e à sua adequação face à política editorial e às normas de edição da revista. Os trabalhos que cumprirem estes requisitos serão posteriormente submetidos a um processo de avaliação por pares cega / blind peer review (mínimo de dois revisores). O Conselho Científico, constituído pela direcção da UNIARQ e por investigadores externos, acompanhará o processo de edição.

Esta etapa será concretizada por investigadores externos qualificados, sendo os respectivos pareceres entregues num período não superior a três meses. Os revisores procederão à avaliação de forma objectiva, tendo em vista a qualidade do conteúdo da revista; as suas críticas, sugestões e comentários serão, na medida do possível, construtivos, respeitando as capacidades intelectuais do(s) autor(es). Após a recepção dos pareceres, o(s) autor(es) tem um prazo máximo de um mês para proceder às alterações oportunas e reenviar o trabalho.

A aceitação ou recusa de artigos terá como únicos factores de ponderação a sua originalidade e qualidade científica. O processo de revisão é confidencial, estando assegurado o anonimato dos avaliadores e dos autores dos trabalhos, neste último caso até à data da sua publicação.

Os trabalhos só serão aceites para publicação a partir do momento em que se conclua o processo da revisão por pares. Os textos que não forem aceites serão devolvidos aos seus autores. O conteúdo dos trabalhos é da inteira respon- sabilidade do(s) autor(es) e não expressa a posição ou opinião do Conselho Científico ou da Coordenação Editorial. A Revista Ophiussa segue as orientações estabelecidas pelo Commitee on Publication Ethics (COPE, Comité de Ética em Publicações): https://publicationethics.org/.

O processo editorial decorrerá de forma objectiva, imparcial e anónima. Erros ou problemas detetados após a publicação serão investigados e, se comprovados, haverá lugar à publicação de correções, retratações e/ou respostas. As colaborações submetidas para publicação devem ser inéditas. As propostas de artigo não podem incluir qualquer problema de falsificação ou de plágio. Para efeito de detecção de plágio será utilizada a plataforma URKUNDU (https:// www.urkund.com/pt-br/).

As ilustrações que não sejam do(s) autor(es) devem indicar a sua procedência. O Conselho Científico e a Coordenação Editorial assumem que os autores solicitaram e receberam autorização para a reprodução dessas ilustrações, e, como tal, rejeitam a responsabilidade do uso não autorizado das ilustrações e das consequências legais por infracção de direitos de propriedade intelectual.

É assumido que todos os Autores fizeram uma contribuição relevante para a pesquisa reportada e concordam com o manuscrito submetido. Os Autores devem declarar de forma clara eventuais conflitos de interesse. As colaborações submetidas que, direta ou indiretamente, tiveram o apoio económico de terceiros, devem claramente declarar essas fontes de financiamento.

Os textos propostos para publicação devem ser inéditos e não deverão ter sido submetidos a qualquer outra revista ou edição electrónica. Aceitam-se trabalhos redigidos em português, inglês, espanhol, italiano e francês.

Esta edição disponibiliza de imediato e gratuitamente a totalidade dos seus conteúdos, em acesso aberto, de forma a promover, globalmente, a circulação e intercâmbio dos resultados da investigação científica e do conhecimento.

A publicação de textos na Ophiussa - Revista do Centro de Arqueologia da Universidade de Lisboa não implica o pagamento de qualquer taxa nem dá direito a qualquer remuneração económica.

Esta publicação dispõe de uma versão impressa, a preto e branco, com uma tiragem limitada, que será distribuída gratuitamente pelas bibliotecas e instituições mais relevantes internacionalmente, e intercambiada com publicações periódicas da mesma especialidade, que serão integradas na Biblioteca da Faculdade de Letras da Universidade de Lisboa. Conta, paralelamente, com uma versão digital, a cores, disponibilizada no endereço www.ophiussa.letras.ulisboa.pt, onde se pode consultar a totalidade da edição.

Para mais informações: ophiussa@letras.ulisboa.pt 


\section{EDITORIAL POLICY}

Ophiussa - Revista do Centro de Arqueologia da Universidade de Lisboa started in 1996, with the edition of volume 0 . From 2017, this journal is a printed and digital edition of UNIARQ - Centro de Arqueologia da Universidade de Lisboa.

The main objective of this journal is the publication and dissemination of papers of interest, quality and scientific rigor concerning Prehistory and Archeology, mostly from Europe and the Mediterranean basin.

Ophiussa - Revista do Centro de Arqueologia da Universidade de Lisboa will publish an annual volume. From 2018, submitted articles will be subject to a peer-review evaluation process. The submission period will always occur in the first quarter of each year and the edition will occur in the last quarter.

The journal is divided into two sections: scientific articles and bibliographic reviews. Exceptionally, texts of an introductory nature may be accepted, in the context of specific tributes or divulgations, which will not be submitted to peer-review evaluation. Exemptions from this evaluation are also the bibliographic reviews.

All submissions will be considered, in the first instance, by the Editorial Board, regarding its formal content and adequacy in face of the editorial policy and the journal's editing standards. Papers that meet these requirements will subsequently be submitted to a blind peerreview process (minimum of two reviewers). The Scientific Council, constituted by the directors of UNIARQ and external researchers, will follow the editing process.

This stage will be carried out by qualified external researchers, and their feedback will be delivered within a period of no more than two months. The reviewers will carry out the evaluation in an objective manner, in view of the quality and content of the journal; their criticisms, suggestions and comments will be, as far as possible, constructive, respecting the intellectual abilities of the author(s). After receiving the feedback, the author(s) has a maximum period of one month to make the necessary changes and resubmit the work.

Acceptance or refusal of articles will have as sole factors of consideration their originality and scientific quality. The review process is confidential, with the anonymity of the evaluators and authors of the works being ensured, in the latter case up to the date of its publication.

Papers will only be accepted for publication as soon as the peer review process is completed. Texts that are not accepted will be returned to their authors. The content of the works is entirely the responsibility of the author(s) and does not express the position or opinion of the Scientific Council or Editorial Board. The Journal Ophiussa follows the guidelines established by the Commitee on Publication Ethics (COPE, the Ethics Committee Publications): https:// publicationethics.org/
The editorial process will be conducted objectively, impartially and anonymously. Errors or problems detected after publication will be investigated and, if proven, corrections, retractions and / or responses will be published. Contributions submitted for publication must be unpublished. Article submissions can not include any problem of forgery or plagiarism. In order to detect plagiarism, the URKUNDU platform will be used.

Illustrations that are not from the author(s) must indicate their origin. The Scientific Council and Editorial Board assume that the authors have requested and received permission to reproduce these illustrations and, as such, reject the responsibility for the unauthorized use of the illustrations and legal consequences for infringement of intellectual property rights.

It is assumed that all Authors have made a relevant contribution to the reported research and agree with the manuscript submitted. Authors must clearly state any conflicts of interest. Collaborations submitted that directly or indirectly had the financial support of third parties must clearly state these sources of funding.

Texts proposed for publication must be unpublished and should not have been submitted to any other journal or electronic edition. Works written in Portuguese, English, Spanish, Italian and French are accepted.

The publication of texts in Ophiussa - Revista do Centro de Arqueologia da Universidade de Lisboa does not imply the payment of any fee nor does it entitle to any economic remuneration.

This edition immediately and freely provides all of its content, in open access, in order to promote global circulation and exchange of scientific research and knowledge. This publication has a limited printed edition in black and white, which will be distributed free of charge by the most relevant international libraries and institutions, and exchanged with periodicals of the same specialty, which will be integrated in the Library of Faculdade de Letras of Universidade de Lisboa. It also has a digital version, in color, available at address http://ophiussa.letras.ulisboa.pt, where one can consult the entire edition.

For more information contact: ophiussa@letras.ulisboa.pt 
REVISTA DO CENTRO DE ARQUEOLOGIA DA UNIVERSIDADE DE LISBOA

ÍNDICE

O tecno-complexo Acheulense em Portugal:

contribuição para um balanço dos conhecimentos

CARLOS FERREIRA, JOÃO PEDRO CUNHA-RIBEIRO, EDUARDO MÉNDEZ-QUINTAS

Brief overview of zooarchaeological research within the framework

of Middle Palaeolithic subsistence theories

MARIANA NABAIS

A distribuição espacial dos materiais líticos da UE003 do Rodo:

testemunho de reocupações do sítio ao longo do Tardiglaciar?

CRISTINA GAMEIRO, THIERRY AUBRY, BÁRBARA COSTA, SÉRGIO GOMES,

YANN LE JEUNE, CARMEN MANZANO, MAURIZIO ZAMBALDI

O sítio do Neolítico Antigo de Montum de Baixo (Melides - Alentejo Litoral)

63

JOAQUINA SOARES, CARLOS TAVARES DA SILVA, SUSANA DUARTE

A economia alimentar em Chibanes (Setúbal) - horizonte campaniforme

JOÃO LUÍS CARDOSO, CARLOS TAVARES DA SILVA, JOAQUINA SOARES, FILIPE MARTINS

Luto en la cara: ablaciones de duelo en el Mediterráneo Ancestral

ÁLVARO GÓMEZ PEÑA, JOSÉ LUIS ESCACENA CARRASCO

Dois conjuntos anfóricos do Castelo de São Jorge (Lisboa):

Largo de Santa Cruz do Castelo e Pátio José Pedreira

VICTOR FILIPE

A face romana de Santa Olaia (Figueira da Foz, Portugal) -

uma leitura possível a partir da cultura material

RICARDO COSTEIRA DA SILVA, SARA OLIVEIRA ALMEIDA, ISABEL PEREIRA

Cerâmica estampada britânica em Portugal (1780-1920).

Identidade, domesticidade e relações

TÂNIA CASIMIRO, INÊS CASTRO, TIAGO SILVA

Recensões bibliográficas

(TEXTOS: JOÃO LUÍS CARDOSO, ANA CATARINA SOUSA, VICTOR S. GONÇALVES,

FRANCISCO B. GOMES, PEDRO ALBUQUERQUE, LEYRE MORGADO-RONCAL)

Política editorial 